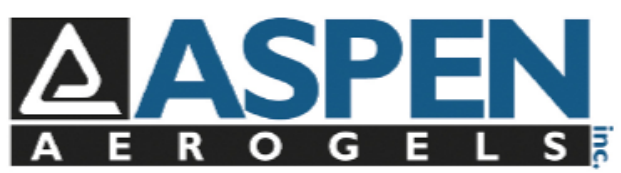

Final Report

9/29/00 through 10/15/04

\title{
Affordable Window Insulation with R-10/inch Rating
}

\section{Work Performed Under Contract:}

DE-FC26-00NT40998

\author{
Submitted By: \\ Aspen Aerogels, Inc. \\ 30 Forbes Road, Building B \\ Northborough, MA 01532 \\ Authors: Jenifer Marchesi Redouane Begag, Je Kyun Lee, Danny Ou, Jong Ho Sonn, \\ George Gould, Wendell Rhine \\ Submitted To: \\ U. S. Department of Energy \\ National Energy Technology Laboratory \\ COR: William Haslebacher \\ E-Mail: WILLIAM.HASLEBACHER@netl.doe.gov
}




\section{Disclaimer}

This report was prepared as an account of work sponsored by an agency of the United States Government. Neither the United States Government nor any agency thereof, nor any of their employees, makes any warranty, express or implied, or assumes any legal liability or responsibility for the accuracy, completeness, or usefulness of any information, apparatus, product, or process disclosed, or represents that its use would not infringe privately owned rights. Reference herein to any specific commercial product, process, or service by trade name, trademark, manufacturer, or otherwise does not necessarily constitute or imply its endorsement, recommendation, or favoring by the United States Government or any agency thereof. The views and opinions of authors expressed herein do not necessarily state or reflect those of the United States Government or any agency thereof. 


\begin{abstract}
During the performance of contract DE-FC26-00-NT40998, entitled "Affordable Window Insulation with R-10/inch Value", research was conducted at Aspen Aerogels, Inc. to develop new transparent aerogel materials suitable for window insulation applications. The project requirements were to develop a formulation or multiple formulations that have high transparency $(85-90 \%)$ in the visible region, are hydrophobic (will not opacify with exposure to water vapor or liquid), and have at least 2\% resiliency (interpreted as recoverable $2 \%$ strain and better than $5 \%$ strain to failure in compression). Results from an unrelated project showed that silica aerogels covalently bonded to organic polymers exhibit excellent mechanical properties. At the outset of this project, we believed that such a route is the best to improve mechanical properties. We have applied Design of Experiment (DOE) techniques to optimize formulations including both silica aerogels and organically modified silica aerogels ("Ormosils"). We used these DOE results to optimize formulations around the local/global optimization points.

This report documents that we succeeded in developing a number of formulations that meet all of the stated criteria. We successfully developed formulations utilizing a two-step approach where the first step involves acid catalyzed hydrolysis and the second step involves base catalyzed condensation to make the gels. The gels were dried using supercritical $\mathrm{CO}_{2}$ and we were able to make 1'x1'x 0.5 " panels that met the criteria established.
\end{abstract}




\section{Table of Contents}

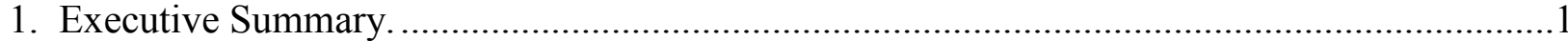

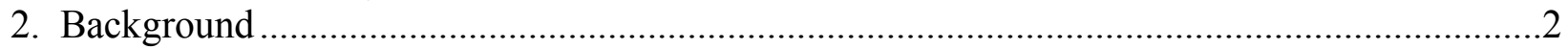

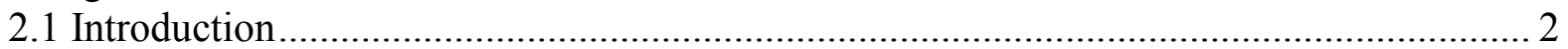

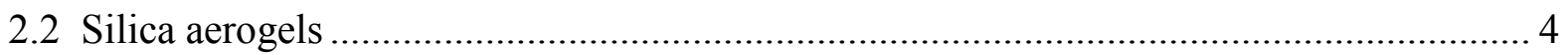

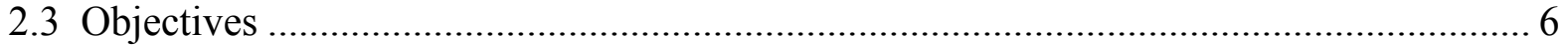

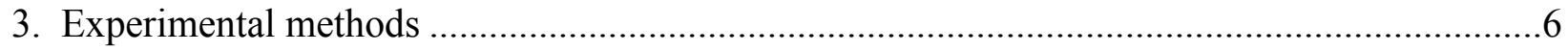

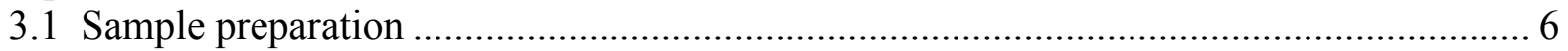

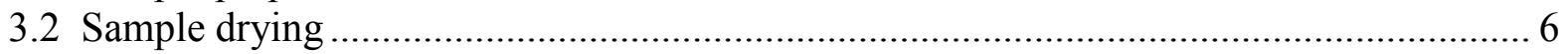

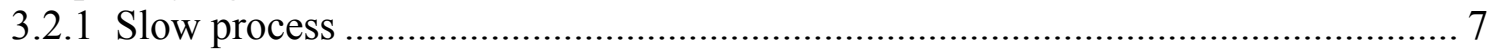

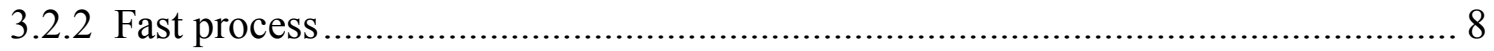

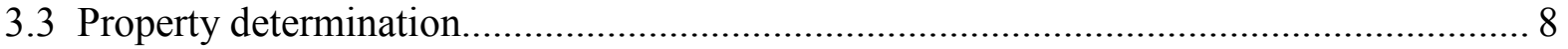

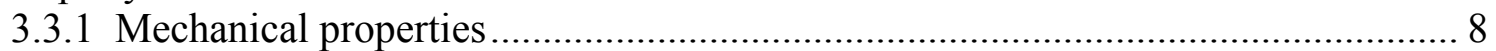

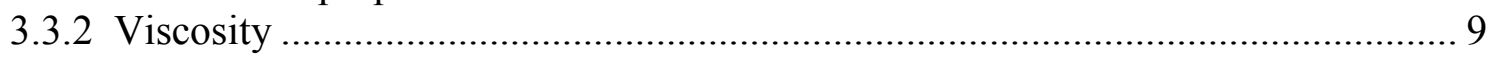

3.3.3 Surface area and pore size determination ......................................................... 9

4. Results 9

4.1 HF catalyzed, inherently hydrophobic silica aerogels prepared from hydrophobic

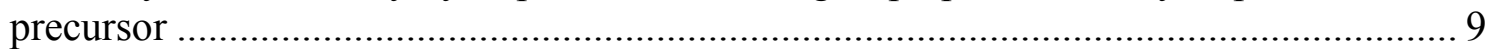

4.1.1 Influence of the concentration of HF on transparency.......................................... 9

4.1.2 Effect of Other catalysts..................................................................................... 11

4.2 Optimized formulation development for monolithic aerogels: Thermal conductivity and

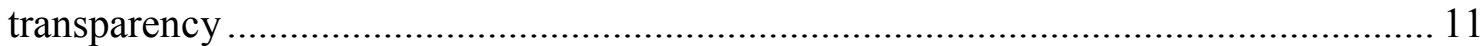

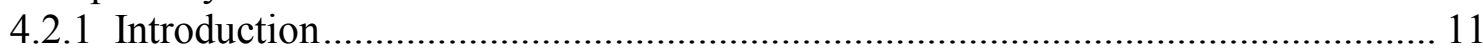

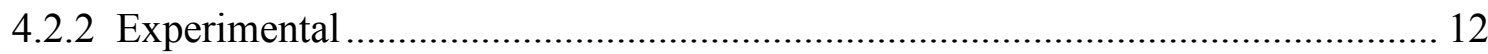

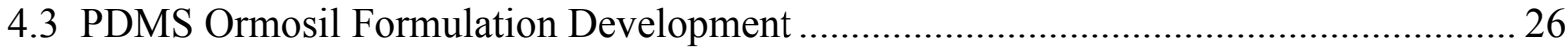

4.3.1 Transparent Ormosil aerogels (HF catalyzed) …………………..................... 26

4.4 Pure Silica Precursors For High Transparency Aerogels ................................................... 31

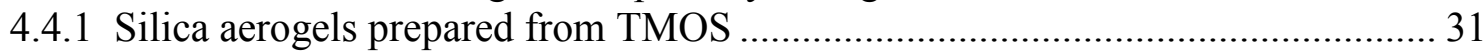

4.4.2 Cost Reduction: TMOS Derivatives and the Direct Process …………………..... 34

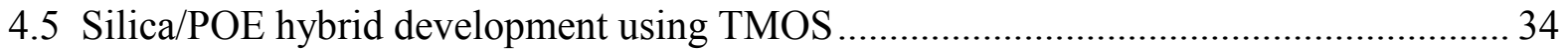

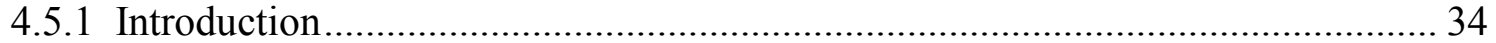

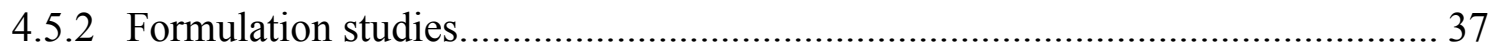

4.5.3 Optical characterization of silica/POE hybrid aerogels ....................................... 40

4.5.4 Selection of composition for scale-up............................................................ 43

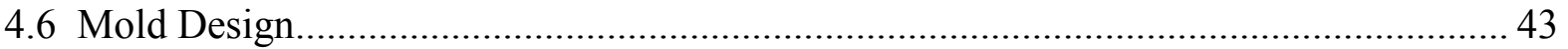

4.6.1 Design for 12" x 12" and 12" x 24" molds ........................................................ 43

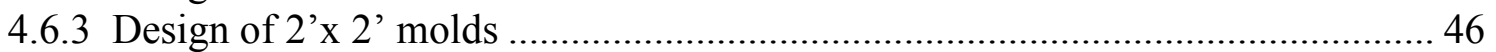

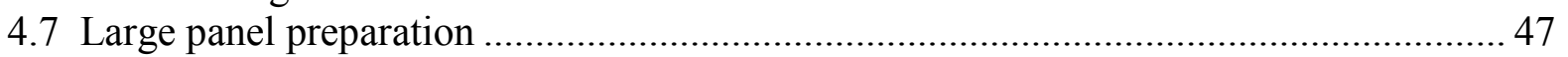

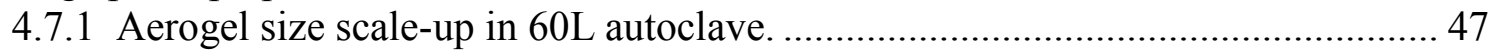

4.7.2 Aerogel size scale-up to 1'x1' panels in 120L autoclave .................................... 47

4.7.3 Large panel preparation in the 1000L autoclave................................................. 49

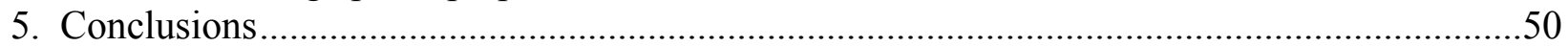

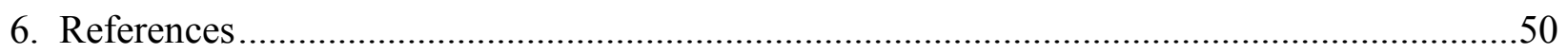




\section{List of Figures}

Figure 1. Silica aerogel structures have pore sizes between 2 and $50 \mathrm{~nm}$ (averaging about

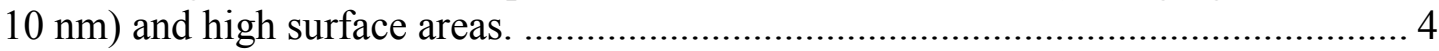

Figure 2. Preparation of Ormosils................................................................................. 5

Figure 3. Modification of the $\mathrm{SiO}_{2}$ surface for hydrophobicity........................................ 5

Figure 4. 4L-system for rapid aerogel production process optimization................................ 7

Figure 5. Three steps of supercritical $\mathrm{CO}_{2}$ drying. ......................................................... 7

Figure 6. Stability of silica aerogels function the concentration of HF............................... 10

Figure 7. State of a transparent aerogel catalyzed with $2 \% \mathrm{HF}$ after 3 months aging in a storage box (left) and a freshly made sample of the same composition (right). The sample was not thermally treated to drive off all remaining volatiles................ 10

Figure 8. The effect of aging temperature on the shrinkage factor as functions of target density and ratio of $\left[\mathrm{H}_{2} \mathrm{O}\right] /\left[\mathrm{SiO}_{2}\right]$ in the monolithic aerogels................................ 18

Figure 9. The effect of aging temperature on the thermal conductivity as functions of target density and ratio of $\left[\mathrm{H}_{2} \mathrm{O}\right] /\left[\mathrm{SiO}_{2}\right]$ in the monolithic aerogels........................ 18

Figure 10. Effects of (left) water and (right) catalyst on gel time at a fixed target density........ 20

Figure 11. The effects of temperature on the viscosity behavior as a function of time: (A) sample of target density of $0.04 \mathrm{~g} / \mathrm{cm}^{3},\left[\mathrm{H}_{2} \mathrm{O}\right] /\left[\mathrm{SiO}_{2}\right]=8$, and $\left[\mathrm{NH}_{4} \mathrm{OH}\right]$ of 0.001 mole, (B) samples of target density of $0.06 \mathrm{~g} / \mathrm{cm}^{3},\left[\mathrm{H}_{2} \mathrm{O}\right] /\left[\mathrm{SiO}_{2}\right]=8$, and $\left[\mathrm{NH}_{4} \mathrm{OH}\right]$ of 0.0001 mole

Figure 12. Arrhenius relation between temperature and viscosity where the slope of the fitted line indicates temperature dependence.

Figure 13. Effects of target density and water concentration on the transparency of aerogels.

Figure 14. Relationships between thermal conductivity and target and the final dried densities as a function of aging temperature and their fitting equations.... 22

Figure 15. Effects of target density, water content and aging temperature on important bulk, thermal, and optical properties of aerogel monoliths...

Figure 16. Dependence of pore volume (A), surface area (B), and pore size (C) on the target density and water content at a fixed aging temperature of $40^{\circ} \mathrm{C}$. 24

Figure 17. The effect of different aging solutions on the shrinkage factor and thermal conductivity values for aerogel monoliths as a function of aging temperature. ......... 24

Figure 18. The effect of aging condition on the mechanical properties of aerogels.................. 25

Figure 19. Density and thermal conductivity behavior of aerogels under compression............. 25

Figure 20. Comparison of pore volume, size, and surface area (left) and size distribution (right) for aerogel before and after compression at 4000 psi................................ 26

Figure 21. Synthesis of transparent/ hydrophobic/resilient aerogels ................................... 27

Figure 22. Relationship between shrinkage factor (A) and thermal conductivity (B) for 15

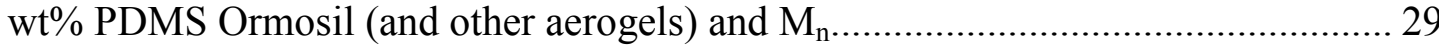

Figure 23. Relationship between maximum flexural strength (A) or strain (B) and $M_{n}$ for 15 $\mathrm{wt} \%$ Ormosil with different functional groups............................................... 30

Figure 24. Flexural stress-strain behavior of Aspen's Ormosil incorporated with 20wt\% PMDS as a function of target density. 30

Figure 25. The effect of PDMS content and target density on the maximum flexural strength (left) and strain (right) at break. 
Figure 26. Comparison of transparency between TMOS (Tetramethoxysilane) and Silbond (polyethylsilicate) as function of target density.

Figure 27. Thermal conductivity and shrinkage of aerogel monoliths prepared with TMOS silica precursor in terms of target density (left) and final density (right). 33

Figure 28. IR spectra of a) 3-isocyanatopropyl-triethoxysilane and b) product obtained with Poly-303. 36

Figure 29. Stress-strain curve for $10 \mathrm{wt} \%$ D12000 Poly-303/silica aerogel $\left(\rho_{\text {actual }}=0.09\right)$......... 38

Figure 30. Three point bending test of Poly-303/silica aerogel monolith. ............................... 38

Figure 31. Different transmission spectral components collected by an integrating sphere. ...... 41

Figure 32. Transmittance spectra of Poly-303/Silica hybrid prepared using Poly-303 D2000, 10\% load, $1.065 \mathrm{~cm}$ thick, target density $=0.05 \mathrm{~g} / \mathrm{cc}$, and final density $=$ $0.08 \mathrm{~g} / \mathrm{cc}$.

Figure 33. Transmittance spectra of Poly-303/Silica hybrid aerogel using Poly-303 D4000, $10 \%$ load, $0.5 \mathrm{~cm}$ thick, target density $=0.075 \mathrm{~g} / \mathrm{cc}$, final density $=0.1 \mathrm{~g} / \mathrm{cc} \ldots \ldots \ldots . . .42$

Figure 34. Schematic of Teflon coated aluminum molds...................................................... 44

Figure 35. Aging of a 12"x 12" x 0.5 " transparent aerogel in new mold. ................................. 44

Figure 36. New 2'x 1' closed mold and perforated steel plates used to hold the gel. ................ 45

Figure 37. Schematic of Teflon coated aluminum molds...................................................... 46

Figure 38. 2'x 2' mold. ............................................................................................ 46

Figure 39. Large pieces of crack free Ormosil aerogel monolith with size of $10 \times 20 \times 1.1$

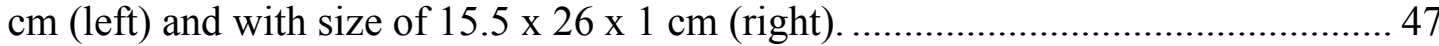

Figure 40. Panel of Ormosil Poly-303/ $\mathrm{SiO}_{2}$ aerogel under flexural stresses............................ 47

Figure 41. Transparent aerogel panels made during the last quarter: a) one of the first attempts which contained cracks and $b$ ) the most recent attempt is crack free. 48

Figure 42. Hydrophobic and transparent Poly-303/silica aerogel panel (1x1 ft) made using Poly-303 D4000. 48

Figure 43. Hydrophobic and transparent Poly-303/silica aerogel panels (1x1 ft) made using Poly-303 D2000. 


\section{List of Tables}

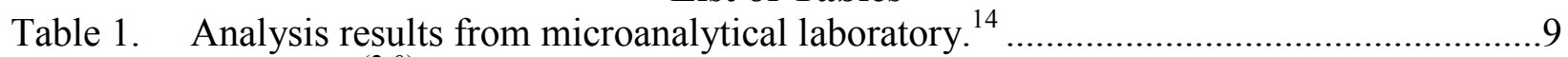

Table 2. Example $3^{(2-0)}$ full factorial design, 2 variables, no block, 9 runs. ............................13

Table 3. Experimental design for 18 monolithic aerogels. (*two samples was prepared for each formulation and aged at different temperatures)...........................................14

Table 4. Properties of monolithic aerogels aged at $50^{\circ} \mathrm{C}$ for 8 days after fast supercritical drying process. .................................................................................................. 14

Table 5. Properties of monolithic aerogels aged at $25^{\circ} \mathrm{C}$ for 8 days after fast supercritical drying process............................................................................................... 15

Table 6. Effect and regression coefficients obtained from the DOE analysis program for samples aged at $50^{\circ} \mathrm{C}$ for 8 days

Table 7. Comparison of gel time, $\rho_{\text {Final }}$, shrinkage factor, and TC predicted by correlation equation with experimental for samples aged at $50^{\circ} \mathrm{C}$ for 8 days

Table 8. Effect and regression coefficients for monolithic samples aged at $25^{\circ} \mathrm{C}$ for 8 days obtained from the DOE analysis program.

Table 9. Comparison of gel time, $\rho_{\text {Final, }}$, shrinkage factor, and TC predicted by correlation equation with experimental for monolithic samples aged at $25^{\circ} \mathrm{C}$ for 8 days.

Table 10. The effect of target density, and water and catalyst content on gel time, and the comparison between experimental and predicted gel times to indicate fitting accuracy of DOE method.

Table 11. Aerogels made using PDMS as resilient additive using a modification of the

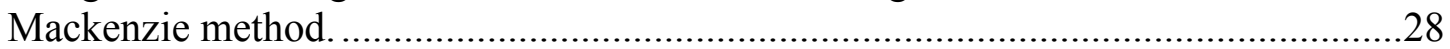

Table 12. PDMS types and their corresponding viscosity and molecular weight. ........................28

Table 13. Effect of precursor types on relative transparency and density of silica aerogels.........32

Table 14. Synthetic conditions and relative transparency of TMOS aerogels................................32

Table 15. Effect of Poly-303 molecular weight (Loading $10 \mathrm{wt} \%$ ) on hybrid aerogel properties with target density $=0.075 \mathrm{~g} / \mathrm{cc}$.

Table 16. Effect of polymer loading on properties of $0.075 \mathrm{~g} / \mathrm{cc}$ Poly-303/silica hybrid aerogel $\left(\mathrm{M}_{\mathrm{n}}=2000\right)$.

Table 17. Effect of target density on properties of D2000 Poly-303/silica hybrid aerogel (Loading $10 \mathrm{wt} \%$ ).

Table 18. Effect of target density on properties of D4000 Poly-303/silica hybrid aerogel (Loading $10 \mathrm{wt} \%$ ).

Table 19. Optical properties of Poly-303/aerogel composites.

Table 20. Key properties of aerogels made with D4000 Poly-303 


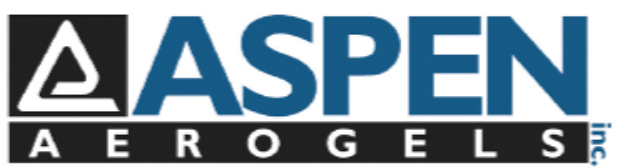

\title{
Affordable Window Insulation with R-10/inch Rating
}

\author{
Final Report
}

\section{Executive Summary}

The primary objective of this project was to develop transparent, resilient, hydrophobic silica aerogels that have a performance rating of R-10/inch and are used to produce aerogel insulated double-glazing windows with an R-6/inch rating. To meet this objective we developed a process and equipment to produce panels of transparent, resilient, hydrophobic aerogel. We focused on silica and organically-modified silica aerogels (Ormosils) due to the appreciable expertise in silica sol-gel processing available with the personnel at Aspen Aerogels, and also due to the quantity of knowledge available in the scientific literature. The project was conducted in three phases.

During Phase 1, we set out to optimize silica aerogel formulations, building upon previous, proprietary poly-303-silica aerogel technologies developed at Aspen Aerogels. The success criteria were established by the Department of Energy (National Energy Technology Laboratory) to include $85-90 \% / \mathrm{cm}$ visible light transmittance while maintaining durable hydrophobicity. For mechanical property enhancement, the criteria were to improve brittleness and compressive strengths by adding $2 \%$ resiliency. Different strategies to enhance resiliency were investigated: doping the silica aerogels with hydroxyl-terminated polydimethylsiloxane (PDMS) at the preparation step to make PDMS Ormosils; using sterically-imposing, hydrophobicity-imparting organosilazane reagents to derivatize the gel surfaces; and advancing techniques for aging and strengthening aerogels.

In order to make hydrophobic aerogels during Phase 1, we investigated using an intrinsically hydrophobic precursor. The aerogels were prepared using HF as the catalyst, but these aerogels did not have the desired long-term stability. We also conducted experiments to prepare a PDMSmodified Ormosil and used a Design of Experiments (DOE) approach to optimize the formulation.

During Phase 2, the formulations were optimized using DOE statistical techniques. Commercially available Statisca ${ }^{\mathrm{TM}}$ (StatSoft ${ }^{\circledR}$ ) software for DOE was utilized to design experiments and interpret the results. We demonstrated that Design of Experiments is a powerful statistical tool to determine the effects of important variables on the aerogel's transparency. The silica precursors, which are the most important component of silica aerogels, were compared in terms of advantages and disadvantages for product properties, including optimization of transparency. 
The effects of target density and $\left[\mathrm{H}_{2} \mathrm{O}\right] /\left[\mathrm{SiO}_{2}\right]$ ratio on transparency, final density, shrinkage factor, and thermal conductivity were investigated. A DOE method with 3 levels, 2 variables, and a full factorial design was utilized, and the software was used to quantitatively interpret the results.

Results were generally consistent and showed that both target density and $\mathrm{H}_{2} \mathrm{O}$ concentration played important roles in determining transparency, gel time, final density, and shrinkage factor. However, the effects of these variables on thermal conductivity were less clear. The effect of $\mathrm{H}_{2} \mathrm{O}$ concentration on properties under the specified experimental conditions used in this study was significant and further indicated that the $\mathrm{H}_{2} \mathrm{O}$ and/or $\mathrm{NH}_{4} \mathrm{OH}$ catalyst concentrations should be optimized for a specific target density. Also, the thermal conductivities were between 9 and $16 \mathrm{~mW} / \mathrm{m}-\mathrm{K}$, and mainly between 10 and $12 \mathrm{~mW} / \mathrm{m}-\mathrm{K}$ at $40^{\circ} \mathrm{C}$, which are among the best values for aerogels tested at Aspen Aerogels. Although monolithic samples showed good transparency and thermal conductivity, uniformly dispersed white spots within the samples occurred during/after supercritical drying. These white spots were identified as ammonium carbonate/carbamate and could be removed by heating the aerogel to above the decomposition temperature of ammonium carbonate.

Prototype gel-forming and scale-up strategies were investigated at the laboratory level to select the best approaches for making large panels. Two approaches were investigated: batch scale using molds, and a semi-continuous gel formation method. Due to the structural fragility of the gel, it was found that the best results were realized if no strong flexural or compressive forces took place during gelation and aging. Aging of the wet gels is required to strengthen them in preparation for supercritical drying, and the structural molds were found to be the best approach for producing monolithic aerogels.

During Phase 3 we continued to improve the strength and resilience of the aerogels by making a hybrid aerogel containing both organic and inorganic components. The organic component was synthesized by reacting a linear di-functional polymer (Poly-303) with 3-isocyanatopropyl triethoxysilane. The triethoxysilane end-groups readily react with the silica precursor to make a hybrid aerogel with improved mechanical properties. We succeeded in making aerogels that survived $16.2 \%$ strain before failure. The best formulation was used to make large transparent aerogel panels, and we succeeded in making 1 'x1'x 0.5 " transparent panels.

\section{Background}

\subsection{Introduction}

The United States consumes roughly 97 quadrillion Btus (quads) of primary energy per year, and the Nation's 87 million homes and commercial buildings consume $36 \%$ or 34.2 quads of this total. Buildings also use two-thirds of all electricity generated nationally. More than $\$ 230$ billion is spent each year in the U.S. to provide heating, cooling, lighting and related energy services for buildings. Even if the energy intensity of buildings remains constant, as more buildings are constructed, energy consumption and associated economic and environmental costs will continue to escalate. Energy consumption in buildings is a major cause of acid rain, smog, and greenhouse gas emissions in the United States, representing 35\% of carbon dioxide emissions, $48 \%$ of sulfur dioxide emissions, and $21 \%$ of nitrogen oxide emissions. 
A large portion of energy in buildings and homes is lost through windows whose R-value is only a small fraction of those of the walls and roof. There have been steady improvements in windows over the years: currently, windows have U-values ranging from $\mathrm{U}-2.7 \mathrm{~W} / \mathrm{m}^{2} \mathrm{~K}$ for double glazing with low E-glass to U-1 for triple glazing with all the advanced features such as spectrally-selective low E-coating, Krypton gas fill, and thermal breaks. (N.B.: U-values are typically expressed in metric units, while R-values are most often in English units. When they are expressed in equivalent units, $\mathrm{U}$-value $=1 / \mathrm{R}$-value) Even though this is a far cry from the double-glazing windows of twenty years ago, even the best windows do not compare with insulating values for walls or roofs. Besides, the price for the lowest U-value window glazing is so high that most houses do not use triple or quadruple glazing. Even the Energy Star requirement for windows used in the Northern Zone of the USA is only U-2. However, if all the residential windows in the U.S. were replaced with the more efficient Energy Star qualifying models, we'd save $\$ 7$ billion in energy costs over the next 15 years. ${ }^{1}$

Superinsulating windows with U-values below $1 \mathrm{~W} / \mathrm{m}^{2} \mathrm{~K}$ can be constructed in several ways. Most common is triple-glazed systems using coatings with low emissivity and noble gas filling of the gap between the transparent layers. By increasing the number of glass panes in the window, the U-value can be reduced even further. However, the compromise for the very low U-value will be a low transmission of solar energy and, to a lesser extent, daylight, both of which will have a negative impact on the total energy balance of the window, especially in heatingdominated climates. Hutchins et $a .^{2}$ showed that the center U-value of an evacuated glazing with two hard low-E coatings is about $1.3 \mathrm{~W} / \mathrm{m}^{2} \mathrm{~K}$. The edge seal in the vacuum glazing is critical, and it was found that the edge seal increases the overall $\mathrm{U}$-value for a $1.0 \times 1.0 \mathrm{~m}^{2}$ glazing by about $0.3 \mathrm{~W} / \mathrm{m}^{2} \mathrm{~K}$. By applying more advanced coatings it may be possible to obtain overall U-values of about $1.0 \mathrm{~W} / \mathrm{m}^{2} \mathrm{~K}$, but again the consequence for this is a relatively low solar gain. So far it has not been possible to construct a glazing that has both a very high thermal resistance and a high transmittance of solar energy and light.

A material that has a high transparency and a high R-factor (low U-value) is needed to make super insulated windows readily available. If such a material were used to make superinsulated windows with U-values less than $1 \mathrm{~W} / \mathrm{m}^{2} \mathrm{~K}$, then buildings would be highly energy efficient. If such windows were widely available and used in new and existing buildings, the magnitude of energy savings would be very significant.

A material called aerogel exists that has both a high thermal resistance and a high transmittance of solar energy and light. Therefore, this project addressed using aerogels to make superinsulating windows. The main goals of this project were to develop a low cost approach for making optically transparent and thermally insulating aerogels, and to construct glazings with a R-value at $6 /$ inch ( $\mathrm{U}$-value $=\sim 1 \mathrm{~W} / \mathrm{m}^{2} \mathrm{~K}$ ). The process to manufacture these superinsulating windows was demonstrated by making prototype transparent aerogel panes in Aspen Aerogels' new production facility. It is projected that there will be huge energy savings and associated environmental benefits around the world. 


\subsection{Silica aerogels}

Silica aerogels, first discovered in 1931 by Kistler, ${ }^{3,4}$ are prepared via sol-gel processing ${ }^{5}$ by gelling soluble silica precursors and then replacing the entrained solvent with air. Aerogels are among the first recognized "nanoengineered materials" because their pore structures and solid features are extremely small (Figure 1). These materials exhibit extremely low density, high surface area, and attractive optical, dielectric, thermal and acoustic properties. Their transparency and insulating properties have attracted much attention for use in many important potential applications such as windows, skylights and light transmitting structural panels, Cherenkov radiation detectors, ICF targets, radioluminescent light and power systems, catalyst supports, filters for air and water, optical fibers, thermal insulators, etc.

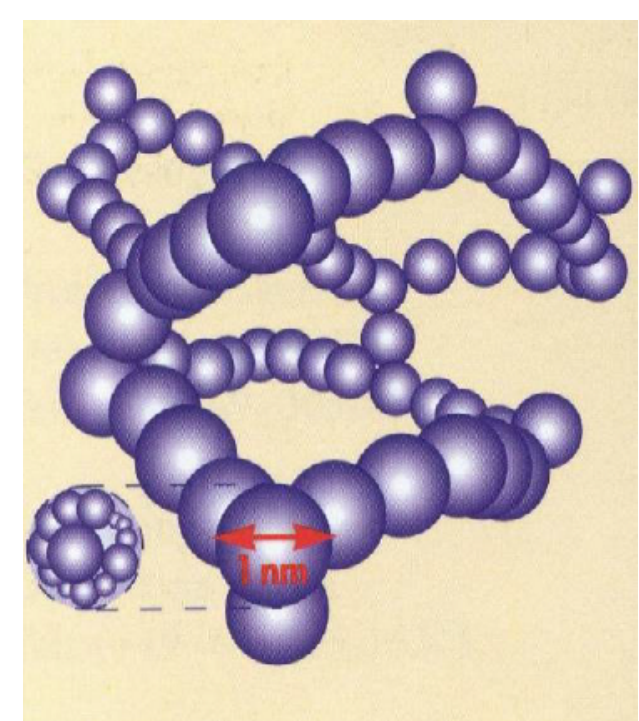

Figure 1. Silica aerogel structures have pore sizes between 2 and $50 \mathrm{~nm}$ (averaging about $10 \mathrm{~nm}$ ) and high surface areas.

The silica particles are so small and so loosely connected that void space can make up over $98 \%$ of an aerogel's volume. As an example, a silica aerogel contains particles that are on the order of $1 \mathrm{~nm}$ in diameter and each particle is connected to two or three other particles on average. Such a material has a typical density of about $0.1 \mathrm{~g} / \mathrm{cc}$ and accessible surface area of $\sim 800 \mathrm{~m}^{2} / \mathrm{g}$. Almost all applications for silica aerogels are based on the unique properties associated with this highly porous network structure. For example, the very low thermal conductivity of silica aerogel occurs because of the nanometer pore sizes and the tenuous solid connections between the silica particles making up the solid structure.

The sol-gel process begins with the nucleation and growth of sol particles which forms a low viscosity sol. As the sol begins to aggregate, the viscosity increases and ultimately forms a continuous cross-linked solid network referred to as a gel. The microstructure and the resulting properties of the final aerogel may be tailored for a specific application by controlling the variables and conditions for sol-gel processing. Variables may include the type and molecular weight of silica precursors, total solid concentration, catalyst type and concentration, ratio of water to silica, solvent type, $\mathrm{pH}$ (acidic, neutral, and basic conditions), gelation temperature, aging period and temperature, and operation conditions for supercritical drying. These variables 
can play very important roles in determining polymerization (i.e., gel formation) kinetics, bulk density, shrinkage factor, and optical, thermal, and mechanical properties.

In addition to good transparency, aerogel panels are required to show good resilience in order to be used as insulation between windowpanes in double-glazed windows. More resilient aerogel panels have been prepared by incorporating organic polymers, such as hydroxyl-terminated polydimethylsiloxane (PDMS) and triethoxysilate-Poly-303, into silicon alkoxides under suitable synthesis conditions. For organically modified silicate (Ormosil) preparation, a simplified reaction scheme between TEOS and hydroxyl-terminated polydimethylsiloxane (PDMS) is illustrated in Figure 2. The resultant silica aerogels are reported to exhibit rubbery elasticity. ${ }^{6-10}$ In addition, incorporation of these organic polymers into gels should make them stronger so that they can be dried without cracking.

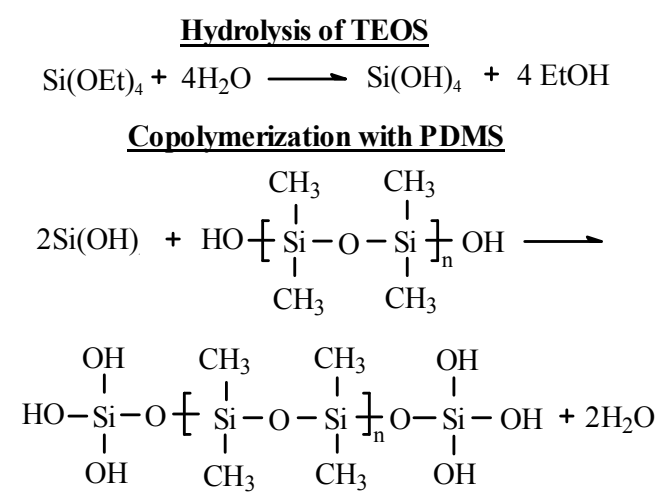

Figure 2. Preparation of Ormosils.
The microstructure of organically modified silicates (i.e., Ormosils) can be controlled to produce opaque or transparent aerogels depending on miscibility, material, and processing variables. Variables that influence the microstructure of Ormosils, which subsequently affect Ormosil properties, would be categorized as follows: 1) organic modifier: chemical composition, chemical structure, molecular weight, end group for co-polymerization, and miscibility with the silica precursor, 2) polymerization: water content, solvent and catalyst type and concentration, duration of reaction, and temperature, 3) hydrophobicity:

reagent, catalyst, concentration, time and temperature, and 4) aging: temperature, time, and duration.

It is well known that the aerogel should be hydrophobic, since moisture absorption degrades the transparency as well as the thermal conductivity of aerogels. Therefore, for window insulation it is very crucial for the aerogel to be hydrophobic in order to maintain transparency. As illustrated in Figure 3, a hydrophobic silica aerogel can be prepared by treating the aerogel with a hydrophobic chemical reagent, which modifies the aerogel's surface with trimethylsilyl $\left(-\mathrm{Si}\left(\mathrm{CH}_{3}\right)_{3}\right)$ groups,

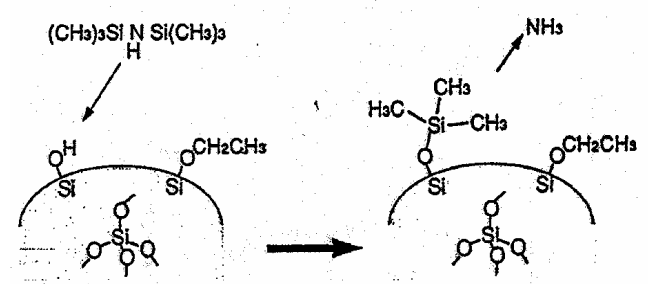

Figure 3. Modification of the $\mathrm{SiO}_{2}$ surface for hydrophobicity. followed by supercritical drying. The resultant trimethylsilyl modified silica aerogel is hydrophobic, while simultaneously decreasing shrinkage during supercritical drying. Also, note that both hydrophobicity and non-flammability, which are important for improved fire resistance, could be achieved by using a perfluoroalkyl trialkoxysilane as the hydrophobic reagent.

In addition to optimizing solution chemistry and reaction variables, successfully obtaining large panels of the transparent silica aerogel requires removing the solvent within the gel's pores without affecting the gel's microstructure (i.e., open-celled foam). However, it was not until the 
1980's that making aerogels became practical when a relatively low cost drying method was developed that used supercritical carbon dioxide. ${ }^{11}$

Aspen Aeorgels holds a process patent ${ }^{12}$ for an improved aerogel drying method utilizing a unique supercritical reactor design and internal flow configuration. Aspen Aerogels' process drying times for our aerogel panels and blankets are on the order of a few hours, independent of the process scale and therefore reactor size (but still dependent on the aerogel thickness). As we improve our processing technology to increase energy efficiency, we expect to save a considerable amount of money and, therefore, further lower projected costs of aerogels.

In the drying process, the temperature and the pressure are increased beyond the critical point where the phase boundary between the liquid and vapor phase disappears. The supercritical drying step is controlled by two important phenomena: permeability and capillary stress. The temperature of supercritical drying (low temperature $\mathrm{CO}_{2}$ extraction or high temperature methanol extraction) strongly influences the structural characteristics of the aerogel. $\mathrm{CO}_{2}$ is generally used as the supercritical extraction fluid since $\mathrm{CO}_{2}$ has a much lower critical temperature than alcohol solvents, and the process can be performed at near ambient temperature. During supercritical drying, once the critical point is passed, there is no distinction between the liquid and vapor phase and the solvent can be removed without introducing a liquidvapor interface and the associated capillary pressure which causes the gel to shrink during drying.

\subsection{Objectives}

The primary objective of this project was to develop transparent, resilient, hydrophobic silica aerogels having a performance rating of R-10/in for use in aerogel-insulated double-glazing windows having an R-6 rating. A secondary objective, but perhaps even more vital, was to use low cost raw materials and processing methods to produce transparent aerogels that can be used to make insulating windows at prices affordable for use in most homes and buildings.

\section{Experimental methods}

\subsection{Sample preparation}

Silica304 (a hydrolyzed silica source) was used as the source of silicon for most experiments. Other precursors, such as TEOS (tetraethylorthosilicate - Aldrich), hydrophobic precursor, and TMOS (tetramethylorthosilicate-Aldrich) were also used.

\subsection{Sample drying}

There are two supercritical processes that are used to make aerogels. In the high temperature supercritical drying (HTSD) method, the gels are dried at the supercritical conditions of alcohols (e.g., methanol) which occur at high temperatures and pressures. The low temperature supercritical drying (LTSD) method, using liquid $\mathrm{CO}_{2}$ as the solvent, requires less energy since the operation temperature is close to room temperature $\left(32-40{ }^{\circ} \mathrm{C}\right)$. To obtain monolithic aerogels, all of the solvent must be extracted from the gels. This process is principally limited by the physical diffusion of the $\mathrm{CO}_{2}$ and solvent through the porosity of the gels. Also, numerous factors such as thickness of samples, and temperature and pressure of $\mathrm{CO}_{2}$ particularly influence the drying of the gels. The time required to extract all of the solvent depends on the thickness of the gel, and varies from hours (for $1 / 2 \mathrm{~cm}$ thickness sample) to days $(2-3 \mathrm{~cm}$ thickness samples). 
The 4-liter, windowed system (Figure 4) was used to provide visual feedback on the drying conditions and how the samples change as a function of drying, temperature and pressure changes during the process. The experimental plan was to scale-up formulations that are successful at the 4L scale to the 60L scale (a nominal maximum size of 12 " x 12 " transparent plates) and then to larger panels.

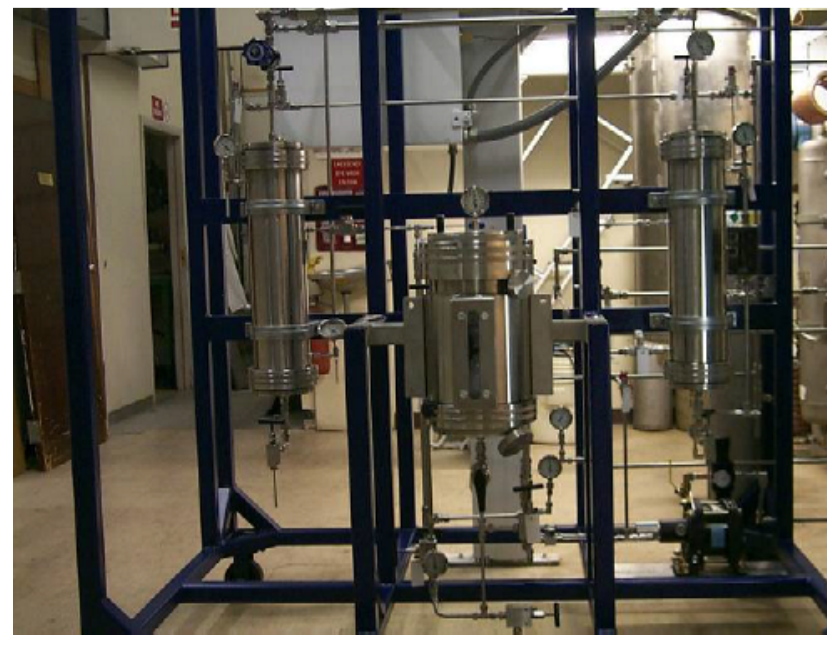

Figure 4. 4L-system for rapid aerogel production process optimization.

We used two processes to dry the aerogels. In this report, we refer to these methods as the 'slow process' and the 'fast process'. Both of these methods used low temperature $\mathrm{CO}_{2}$ drying and are described below.

\subsubsection{Slow process}

If the supercritical drying process is considered in terms of pressure and temperature, it can be divided into the main three steps as shown in Figure 5. The supercritical extraction of solvents with $\mathrm{CO}_{2}$ can be summarized by the followings steps: 1) Placing the gels inside the autoclave in a vertical position to maximize exposure of surfaces for exchanging the solvent with liquid $\mathrm{CO}_{2}$ and filling the autoclave with liquid $\mathrm{CO}_{2}$ 2) Exchange solvent for liquid $\mathrm{CO}_{2}$. This is accomplished by filling the autoclave with liquid $\mathrm{CO}_{2}$ several times to extract the solvent into liquid $\mathrm{CO}_{2}$, followed by flowing $\mathrm{CO}_{2}$ through the autoclave until the solvent has been completely extracted. The duration of this step depends on the amount of solvent within the sample. 3) Heating the system (autoclave and gels) slowly until it exceeds the critical temperature and pressure of $\mathrm{CO}_{2}\left(\mathrm{Tc}=31.05^{\circ} \mathrm{C}\right)$, typically $40{ }^{\circ} \mathrm{C}$, to a pressure on the order of 80 to 100 bar. 4) Allowing a period of isothermal and isobaric stabilization in order to ensure thermal equilibrium between the fluid and the gels, and finally, 5) venting supercritical fluid $\mathrm{CO}_{2}$ while maintaining isothermal conditions.

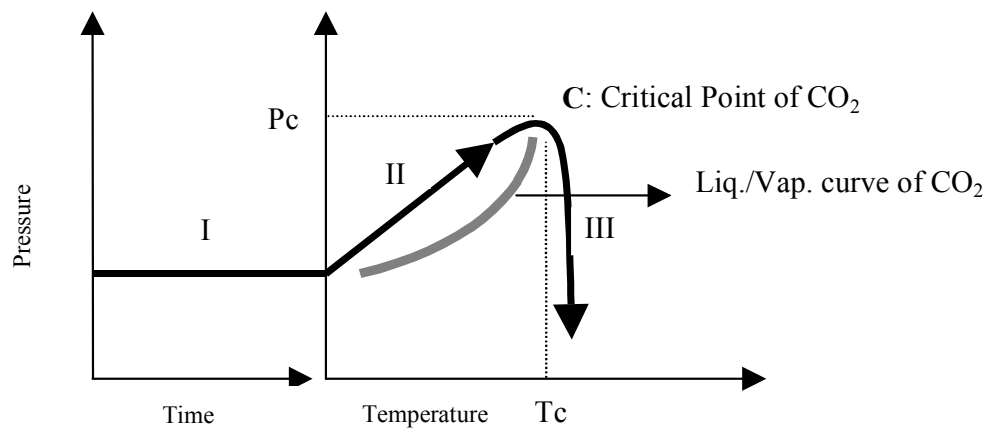

I: Exchanging period solvent/liquid $\mathrm{CO}_{2}$

II: Heating period to reach supercritical conditions of $\mathrm{CO}_{2}$

III: Isothermal depressurization

Figure 5. Three steps of supercritical $\mathrm{CO}_{2}$ drying. 


\subsubsection{Fast process}

The duration of the drying process can be significantly decreased by filling the autoclave and extracting the solvent under supercritical conditions right from the beginning (step 1).

\subsection{Property determination}

Gel time was defined as the time required for the sample to gel after adding catalyst to the sol. The sol has gelled when it does not move at all by gently shaking. Sample thickness and height were measured by a digitized dial caliper, and after measuring several areas of the samples the average dimensions were selected for calculating the final density and shrinkage factor. The shrinkage factor was defined as the ratio of the measured final density of the dried samples to the target density calculated from solid content in the sol by the following simple equation:

Shrinkage Factor $(f)=\frac{\text { Final Density }\left(\mathrm{g} / \mathrm{cm}^{3}\right)}{\text { Target Density }\left(\mathrm{g} / \mathrm{cm}^{3}\right)}$

Thermal conductivity was measured at room temperature and ambient pressure using an 'inhouse' designed thermal conductivity apparatus, which is based on the typical guarded hot plate method where heat flow follows the one dimensional Fourier-Biot law: $\mathrm{q}=-\lambda(\mathrm{dT} / \mathrm{dx})$, where $\mathrm{q}$ is heat flux $\left(\mathrm{W} / \mathrm{m}^{2}\right), \lambda$ is the thermal conductivity coefficient $(\mathrm{W} / \mathrm{m}-\mathrm{K})$, and $\mathrm{dT} / \mathrm{dx}$ is the temperature gradient $(\mathrm{K} / \mathrm{m})$ on the isothermal flat surface of the sample.

\subsubsection{Mechanical properties}

The method used to determine mechanical properties was similar to ASTM D 790 specified for measurement of flexural properties of polymeric materials. A ComTen Industries C-94 series tensile and compression tester (Model: A45KRC0100) with $100 \mathrm{lb}$ load cell was used. Span length of $5 \mathrm{~cm}$ and samples with 46-48 mm width and 10.3-15.0 mm thickness were generally used for measurement. Data were collected automatically with an Auto-Analyzer (Com-Ten Ind. Model: DMC026S) with an accuracy of $\pm 0.5 \%$, and then transferred to Excel and Sigma Plot to convert data to stress-strain behavior. Density-temperature corrections were not made. Force (or load) and deformed distance were measured during 3-point bending with a constant crosshead speed of $2.6 \mathrm{~mm} / \mathrm{min}$. The data were subsequently converted to flexural stress, strain, and tangent and cord modulus by the following relationships described in ASTM D790:

i) Tangent Modulus of Elasticity $\left(E_{B}, M P a\right)=\frac{1}{4} \frac{\operatorname{Span}(\mathrm{mm})^{3} \times \operatorname{Initial~Slope~}(\mathrm{m}, \mathrm{N} / \mathrm{mm})}{\operatorname{Width}(\mathrm{mm}) \times \operatorname{Depth}^{3}\left(\mathrm{~mm}^{3}\right)}$

ii) Flexural Stress $\left(\sigma_{\mathrm{f}}, \mathrm{MPa}\right)=\frac{3}{2} \frac{\text { Force }(\operatorname{at} \operatorname{Max} ., \mathrm{N}) \times \operatorname{Span}(\mathrm{mm})}{\operatorname{Width}(\mathrm{mm}) \times \operatorname{Depth}^{2}\left(\mathrm{~mm}^{2}\right)}$

iii) Flexural Strain $\left(\varepsilon_{\mathrm{f}}\right.$, No Unit, $\%$, or $\left.\mathbf{m} / \mathbf{m}\right)=6 \frac{\operatorname{Depth}(\mathbf{m m}) \times \operatorname{Deflection}(\mathbf{m m})}{\operatorname{Span}^{2}\left(\mathbf{m m}^{2}\right)}$

iv) Chord (Flexural) Modulus $\left(\mathbf{E}_{\mathbf{f}}, \mathbf{M P a}\right)=\frac{\Delta(\text { Flexural Stress }(\mathbf{M P a}))}{\Delta(\text { Flexural Strain })}$ 


\subsubsection{Viscosity}

Solution viscosity was measured by a Brookfield Rheometer (Brookfield Engineering Laboratory, Inc. Model LVDV-III), which can provide quantitative information about the rate of gelation. For example, the onset point of increasing viscosity and the rate of increase can be considered as quantitative indicators of the onset point of gelation and gelation kinetics. If the torque value is measured at a constant spindle speed, the viscosity can be calculated by following equation:

$$
\eta=\frac{\tau}{\gamma}=\frac{M}{\left(2 \pi R_{b}^{2} L\right) \times \text { factor } \times r p m}
$$

\subsubsection{Surface area and pore size determination}

The structure information of aerogels, such as pore size, BET surface area, pore volume, and pore size distribution was obtained using nitrogen absorption measurements via an Accelerated Surface Area and Porosimetry Measurement System (Micromeritics Instrument Co., Model: ASAP 2010). Thermal stability and/or degradation temperatures were determined using simultaneous TG-DTA/DSC analysis (Netzsch Instruments, Inc. Model: STA 449C Jupiter).

\section{Results}

\subsection{HF catalyzed, inherently hydrophobic silica aerogels prepared from hydrophobic precursor}

Transparent silica aerogels intended for window insulation must be stable over time and under any anticipated humidity conditions. Previous work at Aspen has indicated that a commercially available hydrophobic Si precursor appears to be good for making transparent and hydrophobic aerogels. One is a silica precursor that contains fluoroalkyl groups ${ }^{13}$ to make the aerogel hydrophobic. However, long-term aging of silica aerogel monoliths made from this material and high concentrations of HF catalysts have shown some degradation in transparency over time. Our first thought was that HF (catalyst) remained in the aerogel, which caused the loss of transparency by reacting with silica to form tetrafluorosilane $\left(\mathrm{SiF}_{4}\right)$. To study this problem, we investigated: 1) the influence of the HF catalyst concentration during time of aging on transparency of the aerogels, 2) the effect of the aerogel heat treatment (annealing) after drying, and 3) the effect of other catalysts.

\subsubsection{Influence of the concentration of HF on transparency.}

In a previous project, ${ }^{14}$ we analyzed the aerogel and the results are listed in Table 1 . If we refer to the composition of the aerogel listed in Table 1, we can clearly see that the aerogel contained $\sim 6 \%$ fluorine.

Table 1. Analysis results from Microanalytical Laboratory. ${ }^{14}$

\begin{tabular}{|c|c|c|c|c|c|}
\hline mg sample & $\mathbf{\% C}$ & $\mathbf{\% H}$ & $\mathbf{\% S i}$ & $\mathbf{\% F}$ & $\mathbf{\% S i O}$ \\
\hline 4.8052 & 0.47 & 0.95 & - & - & - \\
\hline 10.930 & - & - & 46.42 & - & - \\
\hline 8.195 & - & - & - & 6.08 & - \\
\hline- & - & - & - & - & 82.06 \\
\hline
\end{tabular}


In Figure 6, we illustrate the effect of the concentration of HF on the transparency of the aerogels. Use of lower concentrations of $\mathrm{HF}$ ( $<2 \%$ by volume) to gel the silica sols results in low transparency silica aerogels, and their stability does not exceed 6 months before they turn opaque. With $2 \% \mathrm{HF}$, the transparency is at its maximum (transmittance of $93 \%$ in the visible range) but the samples are less stable. For high concentrations of HF (>2\%), the gels are strong and rigid, which make drying very difficult. In $90 \%$ of the cases, these high $\mathrm{HF}$ aerogels contained many cracks. Figure 7 shows an example of a transparent aerogel freshly made from hydrophobic precursor ( $2 \%$ catalyst) and the state of the same sample (same composition) after 3 months aging at ambient conditions.

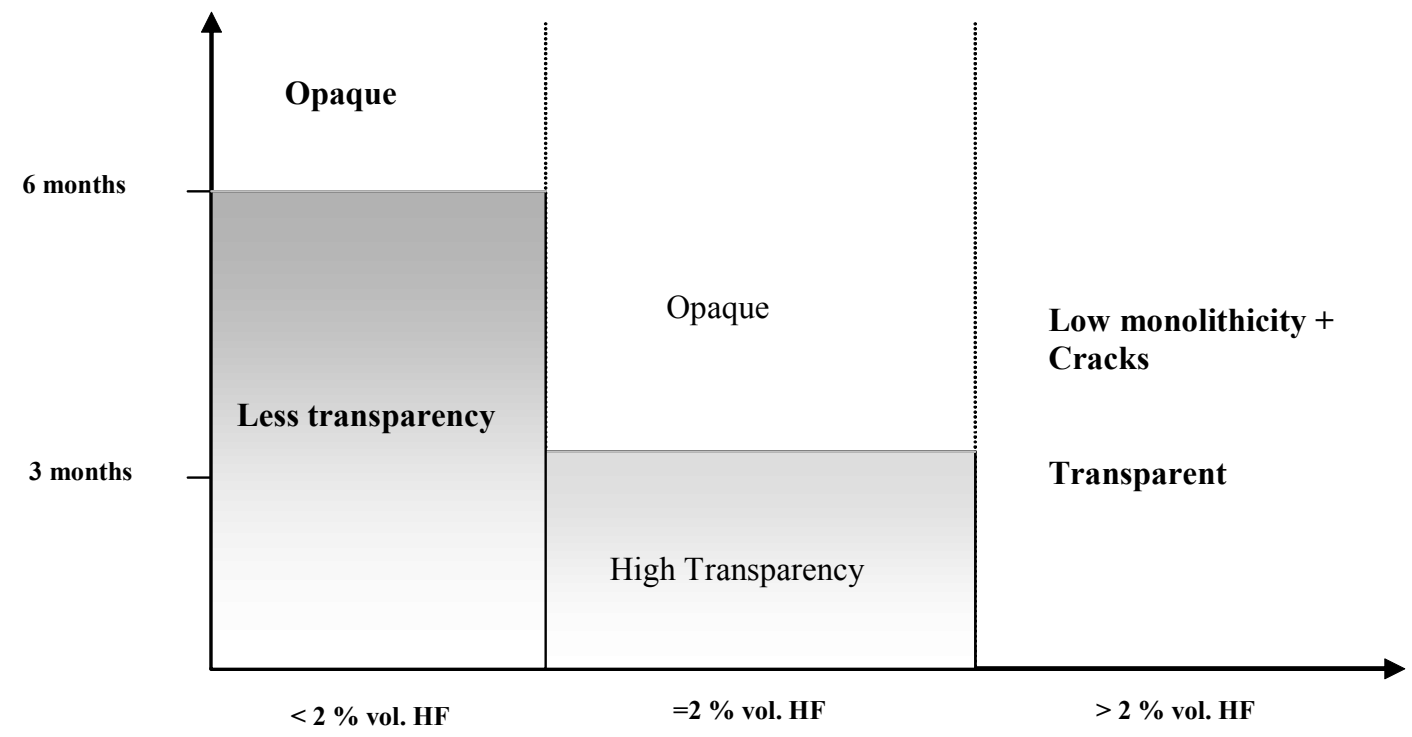

Figure 6. Stability of silica aerogels function the concentration of HF.

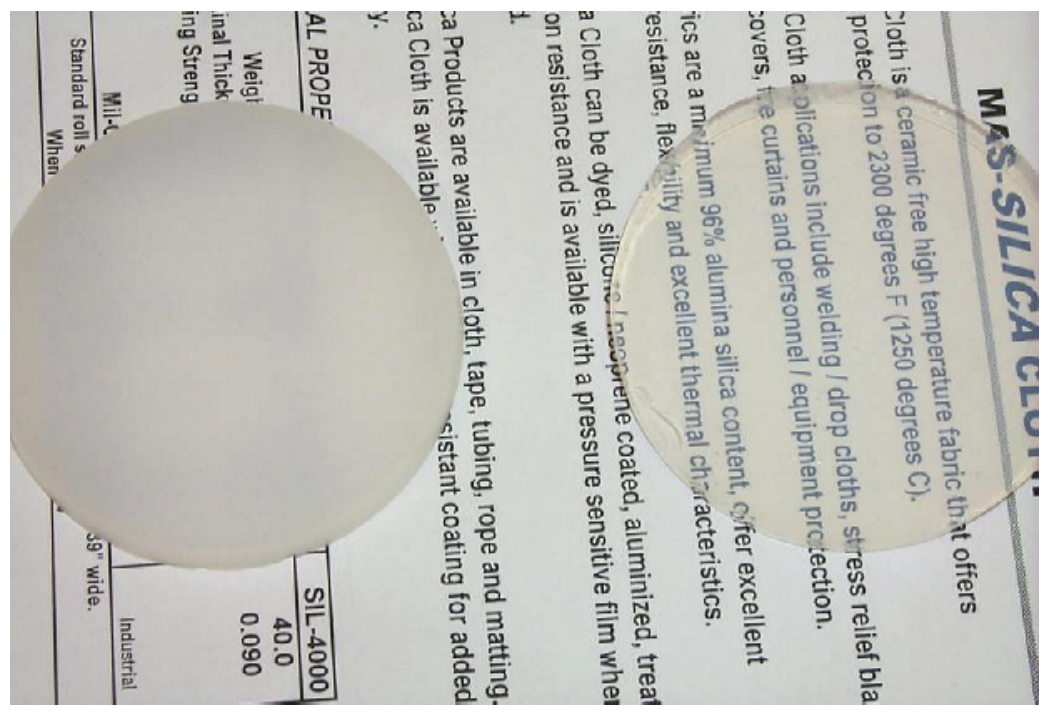

Figure 7. State of a transparent aerogel catalyzed with $2 \% \mathrm{HF}$ after 3 months aging in a storage box (left) and a freshly made sample of the same composition (right). The sample was not thermally treated to drive off all remaining volatiles. 
The origin of the degradation of the optical properties of the sample could only come from secondary reactions between fluorine $\left(\mathrm{F}^{-}\right)$and the silica network, enhanced by trace amounts of water and/or solvent that remained within the aerogels. Any residual HF can react with the silica to form $\mathrm{SiF}_{4}$ (gas) or $\equiv \mathrm{SiR}$, or with surface groups to form $\equiv \mathrm{SiF}$ and $\mathrm{RH}$. This causes opacification (loss of transparency) of the aerogels, based on the reaction of $\mathrm{SiO}_{2}$ with $\mathrm{HF}$ and possible reactions between HF and SiR groups where R can be OEt or $\mathrm{OSiMe}_{3}$.

$$
\begin{aligned}
& \mathrm{SiO}_{2}+4 \mathrm{HF} \quad \longrightarrow \quad \mathrm{SiF}_{4}+2 \mathrm{H}_{2} \mathrm{O} \\
& \equiv \mathrm{SiR}+\mathrm{HF} \quad \longrightarrow \quad \mathrm{SiR}+\equiv \mathrm{SiF}+\mathrm{RH} \\
& \equiv \mathrm{SiF}+\mathrm{H}_{2} \mathrm{O} \quad \leftrightarrows \quad \mathrm{SiOH}+\mathrm{HF}
\end{aligned}
$$

A slight smell of alcohol can occasionally be detected coming from samples just after removal from the supercritical drying apparatus. Thermal analysis of typical gels dried using our standard preparation methods indicates that about $1 \%$ of the mass is volatile up to $220{ }^{\circ} \mathrm{C}$. If the sample is not thermally treated to drive off remaining volatiles (mostly alcohol), there is a risk that the sample will turn opaque after $2-3$ months.

\subsubsection{Effect of Other catalysts.}

The catalyst has always played an important role not only during the sol-gel step but also during supercritical drying. In other words, the porosity and the particle size distribution are fundamentally governed by the nature and the concentration of the catalyst. The particle size distribution is also substantially related to the supercritical drying method (gentler, more effective drying means preserving the monolithicity of the samples).

HF (hydrofluoric acid) is generally considered the best catalyst for synthesis of transparent and monolithic silica aerogels, but it is highly toxic and corrosive and the manufacturing of large panels of silica aerogels at a large scale will be problematic. So, we looked for other catalysts to use while improving the properties of transparent silica aerogels. Two new fluoride-donating catalysts were tested: $\mathrm{HBF}_{4}$ and tetrabutylammonium fluoride. Both catalysts gave reasonably fast gelation times (less than 20 min.) and satisfactory transparency.

We decided that HF was not an acceptable catalyst, since trace amounts of HF remained in the aerogel and affected its long term stability. Additional catalysts, such as nitric acid, ammonia, acetic acid and others were tested with the formulation. Ammonia looked promising so a set of experiments was designed to optimize using ammonia as the catalyst. The experiments and results are described in the next section.

\subsection{Optimized formulation development for monolithic aerogels: Thermal conductivity and transparency}

\subsubsection{Introduction}

The effects of target density and $\left[\mathrm{H}_{2} \mathrm{O}\right] /\left[\mathrm{SiO}_{2}\right]$ ratio on aerogel final density and/or shrinkage factors, and thermal conductivity were investigated. A full factorial statistically-designed 
experiment with 3 levels and 2 variables was utilized to optimize the formula and quantitatively interpret the results.

To determine the optimum sample preparation conditions, target densities in the range of $0.06 \sim 0.08 \mathrm{~g} / \mathrm{cm}^{3}$ and $\left[\mathrm{H}_{2} \mathrm{O}\right] /\left[\mathrm{SiO}_{2}\right]$ ratios in the range of $8 \sim 12$ were studied. Aerogels prepared using these conditions were expected to have the best transparency and TCs. In addition, the effect of aging temperature on the material properties was studied at two levels, 25 and $50^{\circ} \mathrm{C}$.

The primary objectives of the study were:

- To develop the optimum recipe for catalyst with silica precursor, obtaining transparent aerogel panels with low thermal conductivity, small shrinkage factor, good hydrophobicity, and good resilience and strength.

- To understand the basic relationship between the material and processing variables.

- To utilize the DOE techniques for quantitative evaluation of primary material and processing factors and, eventually, to develop the optimum recipe for different kinds of aerogel products with better performance and decreased processing time.

\subsubsection{Experimental}

\subsubsection{Preparation conditions}

One series of monolithic aerogels was prepared with the specific recipes indicated below. The same formulation was used to evaluate the effect of aging temperature on the properties. Ethanol was used as a solvent for density control and aging. All monolithic aerogels were treated with 10 wt \% Hydrophobic Agent in ethanol to provide a hydrophobic surface and to minimize shrinkage and cracking during supercritical drying. The more details on the Hydrophobic Agent treatment, i.e., aging temperature and aging time, can be found in the results tables. The 60L system was used for supercritical drying. The general sample preparation procedures for the DOE experiment are listed below.

The sample preparation procedure used was:

a) Stir the ethanolic solution of Silica Precursor,

b) Stir for another 30 min using a conventional magnetic stirrer at ambient conditions,

c) While stirring, rapidly add catalyst solution,

d) Continue to stir for 10 minutes,

e) Cast sol into sample mold,

f) After the sol gels, add ethanol to prevent the surface from drying,

g) Age with Hydrophobic Agent in ethanol solution for the scheduled period at the specified temperature,

h) Exchange Hydrophobic Agent solution with ethanol to remove unreacted Hydrophobic Agent and catalyst, and

i) supercritical drying in the autoclave with slow or fast processing 


\subsubsection{Property measurements}

The gel time was defined as the time from adding catalyst until the sol became a solid gel. The gel state was defined as the state when the sample did not move at all with gentle shaking. Aerogel thickness and height were measured with a digitized dial caliper, and after measuring several areas of the samples the average dimensions were selected for final density, shrinkage factor, and thermal conductivity calculations. The inner diameter of the casting mold was used as the initial sample diameter to calculate the shrinkage of the diameter after drying. The shrinkage factor was defined as the ratio of the target density calculated from the solid concentration of the sol to the measured final density of the dried monolithic aerogels. Thermal conductivity was measured at $\sim 40^{\circ} \mathrm{C}$ and ambient pressure using our 'in-house' version of the guarded hot plate method.

\subsubsection{Experimental design}

For the Design of Experiments, a $3^{(\mathrm{k}-\mathrm{p})}$ full factorial design was used where 3 is the number of levels, $\mathrm{k}$ is the number of variables (2) and $\mathrm{p}$ is the number of blocks (0). Therefore, 9 experimental formulations were prepared for each series. The experiments and the actual factor values used in the experiments are summarized in Table 2 Table 3.

Table 2. Example $3^{(2-0)}$ full factorial design, 2 variables, no blocks, 9 runs.

\begin{tabular}{|c|c|c|}
\hline $\begin{array}{c}\text { Experimental } \\
\text { Numbers }\end{array}$ & $\begin{array}{c}\text { Factor 1 } \\
\text { Target Density }\end{array}$ & $\begin{array}{c}\text { Factor 2 } \\
{\left[\mathrm{H}_{2} \mathrm{O}\right] /\left[\mathrm{SiO}_{2}\right]}\end{array}$ \\
\hline Exp-1 & $0.06(-1)$ & $6(-1)$ \\
\hline Exp-2 & $0.06(-1)$ & $9(0)$ \\
\hline Exp-3 & $0.06(-1)$ & $12(+1)$ \\
\hline Exp-4 & $0.07(0)$ & $6(-1)$ \\
\hline Exp-5 & $0.07(0)$ & $9(0)$ \\
\hline Exp-6 & $0.07(0)$ & $12(+1)$ \\
\hline Exp-7 & $0.08(+1)$ & $6(-1)$ \\
\hline Exp-8 & $0.08(+1)$ & $9(0)$ \\
\hline Exp-9 & $0.08(+1)$ & $12(+1)$ \\
\hline
\end{tabular}


Table 3. Experimental design for 18 monolithic aerogels. (*two samples were prepared for each formulation and aged at different temperatures).

\begin{tabular}{|c|c|c|c|c|c|}
\hline Sample \# & $\begin{array}{c}\rho_{\text {Target }} \\
\left(\mathrm{g} / \mathbf{c m}^{3}\right)\end{array}$ & $\begin{array}{c}\text { Mole ratio } \\
{\left[\mathrm{H}_{2} \mathrm{O}\right] /\left[\mathrm{SiO}_{2}\right]}\end{array}$ & $\begin{array}{c}\text { mMole of } \\
\text { catalyst }\end{array}$ & $\begin{array}{c}\text { Aging } \\
\text { Temp./Period* }\end{array}$ & Remarks \\
\hline DOE-Exp1 & $\mathbf{0 . 0 6}(-1)$ & $6(-1)$ & 10 & $\begin{array}{l}\text { 1) } 50^{\circ} \mathrm{C} / 8 \text { days } \\
\text { 2) } 25^{\circ} \mathrm{C} / 8 \text { days }\end{array}$ & $\begin{array}{l}\text { Treated in } 10 \% \text { Hydrophobic } \\
\text { Agent in EtOH for } 2 \text { days }\end{array}$ \\
\hline DOE-Exp2 & $0.06(-1)$ & $9(0)$ & 10 & $\begin{array}{l}\text { 1) } 50^{\circ} \mathrm{C} / 8 \text { days } \\
\text { 2) } 25^{\circ} \mathrm{C} / 8 \text { days }\end{array}$ & $\begin{array}{l}\text { Treated in } 10 \% \text { Hydrophobic } \\
\text { Agent in EtOH for } 2 \text { days }\end{array}$ \\
\hline DOE-Exp3 & $0.06(-1)$ & $12(+1)$ & 10 & $\begin{array}{l}\text { 1) } 50^{\circ} \mathrm{C} / 8 \text { days } \\
\text { 2) } 25^{\circ} \mathrm{C} / 8 \text { days }\end{array}$ & $\begin{array}{l}\text { Treated in } 10 \% \text { Hydrophobic } \\
\text { Agent in EtOH for } 2 \text { days }\end{array}$ \\
\hline DOE-Exp4 & $\mathbf{0 . 0 7}(0)$ & $6(-1)$ & 10 & $\begin{array}{l}\text { 1) } 50^{\circ} \mathrm{C} / 8 \text { days } \\
\text { 2) } 25^{\circ} \mathrm{C} / 8 \text { days }\end{array}$ & $\begin{array}{l}\text { Treated in } 10 \% \text { Hydrophobic } \\
\text { Agent in EtOH for } 2 \text { days }\end{array}$ \\
\hline DOE-Exp5 & $\mathbf{0 . 0 7}(0)$ & $9(0)$ & 10 & $\begin{array}{l}\text { 1) } 50^{\circ} \mathrm{C} / 8 \text { days } \\
\text { 2) } 25^{\circ} \mathrm{C} / 8 \text { days }\end{array}$ & $\begin{array}{l}\text { Treated in } 10 \% \text { Hydrophobic } \\
\text { Agent in EtOH for } 2 \text { days }\end{array}$ \\
\hline DOE-Exp6 & $\mathbf{0 . 0 7}(0)$ & $12(+1)$ & 10 & $\begin{array}{l}\text { 1) } 50^{\circ} \mathrm{C} / 8 \text { days } \\
\text { 2) } 25^{\circ} \mathrm{C} / 8 \text { days }\end{array}$ & $\begin{array}{l}\text { Treated in } 10 \% \text { Hydrophobic } \\
\text { Agent in EtOH for } 2 \text { days }\end{array}$ \\
\hline DOE-Exp7 & $\mathbf{0 . 0 8}(+1)$ & $6(-1)$ & 10 & $\begin{array}{l}\text { 1) } 50^{\circ} \mathrm{C} / 8 \text { days } \\
\text { 2) } 25^{\circ} \mathrm{C} / 8 \text { days }\end{array}$ & $\begin{array}{l}\text { Treated in } 10 \% \text { Hydrophobic } \\
\text { Agent in EtOH for } 2 \text { days }\end{array}$ \\
\hline DOE-Exp8 & $\mathbf{0 . 0 8}(+1)$ & $9(0)$ & 10 & $\begin{array}{l}\text { 1) } 50^{\circ} \mathrm{C} / 8 \text { days } \\
\text { 2) } 25^{\circ} \mathrm{C} / 8 \text { days }\end{array}$ & $\begin{array}{l}\text { Treated in } 10 \% \text { Hydrophobic } \\
\text { Agent in EtOH for } 2 \text { days }\end{array}$ \\
\hline DOE-Exp9 & $\mathbf{0 . 0 8}(+1)$ & $12(+1)$ & 10 & $\begin{array}{l}\text { 1) } 50^{\circ} \mathrm{C} / 8 \text { days } \\
\text { 2) } 25^{\circ} \mathrm{C} / 8 \text { days }\end{array}$ & $\begin{array}{l}\text { Treated in } 10 \% \text { Hydrophobic } \\
\text { Agent in EtOH for } 2 \text { days }\end{array}$ \\
\hline
\end{tabular}

\subsubsection{Results and discussion}

Important properties such as gel time, final density, shrinkage, and thermal conductivity were obtained after supercritical drying and are summarized in Tables 4-9 for monolithic aerogels aged at two different temperatures. In order for the reader to easily evaluate the results, the experimental values for the variables are also included in the tables.

Table 4. Properties of monolithic aerogels aged at higher temperatures

\begin{tabular}{|c|c|c|c|c|c|c|}
\hline Exp. No. & $\begin{array}{c}\rho_{\text {Target }}\left(\mathrm{g} / \mathrm{cm}^{3}\right) / \\
\left.\mathrm{H}_{2} \mathrm{O}\right] /\left[\mathrm{SiO}_{2}\right]\end{array}$ & $\begin{array}{c}\rho_{\text {Final }} \\
\left(\mathrm{g} / \mathrm{cm}^{3}\right)\end{array}$ & $\begin{array}{c}\text { Shrinkage } \\
\text { Factor }\end{array}$ & $\begin{array}{c}\text { Gel Time } \\
(\mathrm{min})\end{array}$ & $\begin{array}{c}\text { Thermal } \\
\text { Conductivity } \\
(\mathrm{mW} / \mathrm{m}-\mathrm{K})\end{array}$ & Remarks \\
\hline Exp-1 & $0.06 / 6$ & 0.090 & 1.50 & 25 & 12.9 & White Spots \\
\hline Exp-2 & $0.06 / 9$ & 0.085 & 1.41 & 20 & 13.0 & White Spots \\
\hline Exp-3 & $0.06 / 12$ & 0.091 & 1.51 & 17 & 12.4 & White Spots \\
\hline Exp-4 & $0.07 / 6$ & 0.102 & 1.46 & 16 & 13.2 & White Spots \\
\hline Exp-5 & $0.07 / 9$ & 0.102 & 1.46 & 12 & 15.2 & Fewer Spots (Clear) \\
\hline Exp-6 & $0.07 / 12$ & 0.104 & 1.48 & 9 & 14.2 & White Spots \\
\hline Exp-7 & $0.08 / 6$ & 0.117 & 1.47 & 10 & 11.4 & White Spots \\
\hline Exp-8 & $0.08 / 9$ & 0.119 & 1.49 & 8 & 12.4 & Fewer Spots (Clear) \\
\hline Exp-9 & $0.08 / 12$ & 0.119 & 1.49 & 7 & 14.6 & White Spots \\
\hline
\end{tabular}


Table 5. Properties of monolithic aerogels aged at lower temperatures

\begin{tabular}{|c|c|c|c|c|c|c|}
\hline Exp. No. & $\begin{array}{c}\rho_{\text {Target }} \\
\left(\mathrm{g} / \mathrm{cm}^{3}\right) / \\
\left.\mathrm{H}_{2} \mathrm{O}\right] /\left[\mathrm{SiO}_{2}\right]\end{array}$ & $\begin{array}{c}\rho_{\text {Final }} \\
\left(\mathrm{g} / \mathrm{cm}^{3}\right)\end{array}$ & $\begin{array}{c}\text { Shrinkage } \\
\text { Factor }\end{array}$ & $\begin{array}{c}\text { Gel Time } \\
(\mathrm{min})\end{array}$ & $\begin{array}{c}\text { Thermal } \\
\text { Conductivity } \\
(\mathrm{mW} / \mathrm{mK})\end{array}$ & Remarks \\
\hline Exp-1 & $0.06 / 6$ & 0.097 & 1.61 & 25 & 11.6 & White Spots \\
\hline Exp-2 & $0.06 / 9$ & 0.096 & 1.60 & 20 & 11.1 & White Spots \\
\hline Exp-3 & $0.06 / 12$ & 0.091 & 1.51 & 17 & 10.0 & White Spots \\
\hline Exp-4 & $0.07 / 6$ & 0.111 & 1.59 & 16 & 10.2 & White Spots \\
\hline Exp-5 & $0.07 / 9$ & 0.111 & 1.58 & 12 & 12.5 & Fewer Spots $($ Clear $)$ \\
\hline Exp-6 & $0.07 / 12$ & 0.106 & 1.51 & 9 & 10.9 & White Spots \\
\hline Exp-7 & $0.08 / 6$ & 0.124 & 1.55 & 10 & 10.6 & White Spots \\
\hline Exp-8 & $0.08 / 9$ & 0.127 & 1.59 & 8 & 10.4 & White Spots \\
\hline Exp-9 & $0.08 / 12$ & 0.125 & 1.56 & 7 & 10.6 & White Spots \\
\hline
\end{tabular}

As listed in Table 4 and Table 5, the thermal conductivity was lower than $14 \mathrm{~mW} / \mathrm{m}-\mathrm{K}$, meeting one criterion for success. However, uniformly dispersed white spots existed in some monolithic samples after supercritical drying. The white spots were identified as ammonium carbonate/ammonium bicarbonate and found to make up the majority of the precipitated powder that was visible. These white spots could be removed by heating the monoliths in an oven to over $100^{\circ} \mathrm{C}$ for a few hours. Samples that had the least amount of powdery inclusions (primarily near the surface) gave the best transparency after heat treatment. The aerogels prepared had shrinkage factors in the range of 1.3-1.6 and thermal conductivity values in the range of 9.6-15.2.

Before discussing the analysis results, a brief explanation will be given to define important statistical terms included in this section of the report. The $3^{(\mathrm{k}-\mathrm{p})}$ DOE method used in this study can represent quadratic effects (i.e., $\mathrm{x}^{2}$ squared function) as well as linear effects due to 3 variable levels (coded as $-1,0$, and 1 ). This is an obvious advantage of this $3^{(\mathrm{k}-\mathrm{p})}$ DOE method. However, note again that this method requires more experiments than a partial factorial design. For example, a general equation can be represented as follows:

$$
\text { Gel Time }=C_{0}(\text { mean/intercept })+C_{1} X_{1}+C_{2} X_{2}+C_{11} X_{1}^{2}+C_{22} X_{2}^{2}
$$

where $X_{1}$ is a linear function of target density $\left(\mathrm{g} / \mathrm{cm}^{3}\right), X_{2}$ indicates a linear function of the $\left[\mathrm{H}_{2} \mathrm{O}\right] /\left[\mathrm{SiO}_{2}\right]$ ratio, and $\mathrm{X}_{1}{ }^{2}$ and $\mathrm{X}_{2}{ }^{2}$, are quadratic components or effects of $\mathrm{X}_{1}$ and $\mathrm{X}_{2}$. Note that the linear effects, $X_{1}$ and $X_{2}$, represent the difference between the low and high factor setting for the respective factor and quadratic effects, $\mathrm{X}_{1}{ }^{2}$ and $\mathrm{X}_{2}{ }^{2}$, represents the difference between the respective centered setting results and the average results of low and high settings.

a) Effect: It is also called a parameter estimate. These values are obtained from the experimental measurements.

b) Coefficient and regression coefficient: These are defined as the constant values of $\mathrm{C}_{1} \sim \mathrm{C}_{22}$ in equation (1). We can easily calculate gel time at the mid-value of all factors (0), which is equal to the mean/intercept value. Note that this is only the case if the factor values are coded as -1 
and +1 . These coefficients cannot be used to obtain the relationships between variables and the predicted gel time as a function of real experimental values (i.e., target density 0.06 and 0.08 $\left.\mathrm{g} / \mathrm{cm}^{3}\right)$. The equation coefficients must be converted from program coding $(-1$ and +1$)$ to real experimental values $\left(0.06\right.$ and $\left.0.08 \mathrm{~g} / \mathrm{cm}^{3}\right)$. Regression coefficients are determined using experimental data.

The effect of aging temperature on the shrinkage factor and TC for monolithic aerogels aged 8 days

The effect and regression coefficients for aerogel samples aged at $50^{\circ} \mathrm{C}$ for 8 days were obtained and are listed in Table 6 . The experimental and predicted gel time, final density ( $\rho_{\text {Final }}$ ), shrinkage factor (S.F.), and TC for the samples aged at $50^{\circ} \mathrm{C}$ for 8 days are listed in Table 7.

Table 6. Effect and regression coefficients obtained from the DOE analysis program for samples aged at $50^{\circ} \mathrm{C}$ for 8 days.

\begin{tabular}{|l|c|c|c|c|c|c|c|c|}
\hline & \multicolumn{2}{|c|}{$\begin{array}{c}\text { Gel Time } \\
\left(\mathrm{R}^{2}=0.976\right)\end{array}$} & \multicolumn{2}{c|}{$\begin{array}{c}\rho_{\text {Final }}\left(\mathrm{g} / \mathrm{cm}^{3}\right) \\
\left(\mathrm{R}^{2}=0.99\right)\end{array}$} & \multicolumn{2}{c|}{$\begin{array}{c}\text { S.F. }(f) \\
\left(\mathrm{R}^{2}=0.45\right)\end{array}$} & \multicolumn{2}{c|}{$\begin{array}{c}\mathrm{TC}(\mathrm{mW} / \mathrm{m} \mathrm{K}) \\
\left(\mathrm{R}^{2}=0.57\right)\end{array}$} \\
\hline & Effect & $\mathrm{C}_{0} \sim \mathrm{C}_{22}$ & Effect & $\mathrm{C}_{0} \sim \mathrm{C}_{22}$ & Effect & $\mathrm{C}_{0} \sim \mathrm{C}_{22}$ & Effect & $\mathrm{C}_{0} \sim \mathrm{C}_{22}$ \\
\hline Mean/Intercept & 13.8 & 176.2 & 0.1032 & 0.0545 & 1.474. & 2.27 & 13.3 & -60.7 \\
\hline$(1) \rho_{\text {Target }}(\mathrm{L})$ & -12.3 & -3650 & 0.0302 & 0.2306 & 0.008 & -17.0 & 0.03 & 1985 \\
\hline$(1) \rho_{\text {Target }}(\mathrm{Q})$ & -2.17 & 21667 & -0.0009 & 9.122 & -0.0124 & 124.4 & 1.42 & -14167 \\
\hline$(2)\left[\mathrm{H}_{2} 0\right] /\left[\mathrm{SiO}_{2}\right](\mathrm{L})$ & -6.0 & -2.33 & -0.0015 & -0.0033 & 0.021 & -0.057 & 1.23 & 1.0 \\
\hline$(2)\left[\mathrm{H}_{2} 0\right] /\left[\mathrm{SiO}_{2}\right](\mathrm{Q})$ & -0.67 & 0.07 & 0.0018 & 0.0002 & -0.03 & 0.0034 & 0.42 & -0.05 \\
\hline
\end{tabular}

Table 7. Comparison of gel time, $\rho_{\text {Final, }}$ shrinkage factor, and TC predicted by correlation equation vs. experimental results for samples aged at $50^{\circ} \mathrm{C}$ for 8 days.

\begin{tabular}{|c|c|c|c|c|c|c|c|}
\hline $\begin{array}{c}\text { Exp. Gel } \\
\text { Time (h) }\end{array}$ & $\begin{array}{c}\text { Pred. by } \\
\text { Eqn.(1) }\end{array}$ & $\begin{array}{c}\text { Exp. } \rho_{\text {Final }} \\
\left(\mathrm{g} / \mathrm{cm}^{3}\right)\end{array}$ & $\begin{array}{c}\text { Pred. by } \\
\text { Eqn.(1) }\end{array}$ & $\begin{array}{c}\text { Exp. S. F. } \\
(f)\end{array}$ & $\begin{array}{c}\text { Pred. by } \\
\text { Eqn.(1) }\end{array}$ & $\begin{array}{c}\text { Exp. TC } \\
(\mathrm{mW} / \mathrm{m}-\mathrm{K})\end{array}$ & $\begin{array}{c}\text { Pred. by } \\
\text { Eqn.(1) }\end{array}$ \\
\hline 9 & 9.6 & 0.104 & 0.104 & 1.46 & 1.47 & 14.2 & 14.7 \\
\hline 16 & 15.6 & 0.102 & 0.102 & 1.48 & 1.49 & 13.2 & 13.4 \\
\hline 12 & 11.9 & 0.102 & 0.101 & 1.46 & 1.45 & 15.2 & 14.5 \\
\hline 17 & 17.9 & 0.091 & 0.090 & 1.51 & 1.50 & 12.4 & 13.2 \\
\hline 25 & 23.9 & 0.090 & 0.088 & 1.50 & 1.47 & 12.9 & 12.0 \\
\hline 20 & 20.2 & 0.085 & 0.087 & 1.41 & 1.45 & 13 & 13.0 \\
\hline 7 & 5.6 & 0.119 & 0.120 & 1.49 & 1.50 & 14.6 & 13.3 \\
\hline 10 & 11.6 & 0.117 & 0.118 & 1.47 & 1.48 & 11.4 & 12.0 \\
\hline 8 & 7.9 & 0.119 & 0.117 & 1.49 & 1.46 & 12.4 & 13.1 \\
\hline
\end{tabular}

The effect and regression coefficients for monolithic samples aged at $25^{\circ} \mathrm{C}$ for 8 days were obtained and are listed in Table 8. The experimental and predicted Gel Time, $\rho_{\text {Final }}$, Shrinkage Factor, and TC for monolithic samples aged at $25^{\circ} \mathrm{C}$ for 8 days are listed in Table 9. 
Table 8. Effect and regression coefficients for monolithic samples aged at $25^{\circ} \mathrm{C}$ for 8 days obtained from the DOE analysis program.

\begin{tabular}{|l|c|c|c|c|c|c|c|c|}
\hline & \multicolumn{2}{|c|}{$\begin{array}{c}\text { Gel Time }(\mathrm{min}) \\
\left(\mathrm{R}^{2}=0.976\right)\end{array}$} & \multicolumn{2}{c|}{$\begin{array}{c}\rho_{\text {Final }}\left(\mathrm{g} / \mathrm{cm}^{3}\right) \\
\left(\mathrm{R}^{2}=0.99\right)\end{array}$} & \multicolumn{2}{c|}{$\begin{array}{c}\text { S.F. }(f) \\
\left(\mathrm{R}^{2}=0.65\right)\end{array}$} & \multicolumn{2}{c|}{$\begin{array}{r}\mathrm{TC}(\mathrm{mW} / \mathrm{m} \mathrm{K}) \\
\left(\mathrm{R}^{2}=0.57\right)\end{array}$} \\
\hline & Effect & $\mathrm{C}_{0} \sim \mathrm{C}_{22}$ & Effect & $\mathrm{C}_{0} \sim \mathrm{C}_{22}$ & Effect & $\mathrm{C}_{0} \sim \mathrm{C}_{22}$ & Effect & $\mathrm{C}_{0} \sim \mathrm{C}_{22}$ \\
\hline Mean/Intercept & 13.8 & 176.2 & 0.11 & 0.016 & 1.566. & 1.834 & 10.87 & -16.76 \\
\hline$(1) \rho_{\text {Target }}(\mathrm{L})$ & -12.3 & -3650 & 0.0308 & 0.708 & -0.008 & -13.14 & -0.38 & 667 \\
\hline$(1) \rho_{\text {Target }}(\mathrm{Q})$ & -2.17 & 21667 & -0.0006 & 5.938 & -0.009 & 90.85 & 0.49 & -4900 \\
\hline$(2)\left[\mathrm{H}_{2} 0\right] /\left[\mathrm{SiO}_{2}\right](\mathrm{L})$ & -6.0 & -2.33 & -0.0036 & -0.0042 & -0.058 & -0.06 & -0.313 & 1.33 \\
\hline$(2)\left[\mathrm{H}_{2} 0\right] /\left[\mathrm{SiO}_{2}\right](\mathrm{Q})$ & -0.67 & 0.07 & 0.0024 & -0.0003 & 0.034 & -0.0038 & 0.69 & -0.08 \\
\hline
\end{tabular}

Table 9. Comparison of gel time, $\rho_{\text {Final, }}$, shrinkage factor, and TC predicted by correlation equation with experimental for monolithic samples aged at lower temperature.

\begin{tabular}{|c|c|c|c|c|c|c|c|}
\hline $\begin{array}{c}\text { Exp. Gel } \\
\text { Time (h) }\end{array}$ & $\begin{array}{c}\text { Pred. by } \\
\text { Eqn.(1) }\end{array}$ & $\begin{array}{c}\text { Exp. } \rho_{\text {Final }} \\
\left(\mathrm{g} / \mathrm{cm}^{3}\right)\end{array}$ & $\begin{array}{c}\text { Pred. by } \\
\text { Eqn.(1) }\end{array}$ & $\begin{array}{c}\text { Exp. S. F. } \\
(f)\end{array}$ & $\begin{array}{c}\text { Pred. by } \\
\text { Eqn.(1) }\end{array}$ & $\begin{array}{c}\text { Exp. TC } \\
(\mathrm{mW} / \mathrm{mK})\end{array}$ & $\begin{array}{c}\text { Pred. by } \\
\text { Eqn.(1) }\end{array}$ \\
\hline 9 & 9.6 & 0.106 & 0.107 & 1.51 & 1.52 & 10.9 & 10.8 \\
\hline 16 & 15.6 & 0.111 & 0.110 & 1.59 & 1.58 & 10.2 & 11.1 \\
\hline 12 & 11.9 & 0.111 & 0.111 & 1.58 & 1.58 & 12.5 & 11.7 \\
\hline 17 & 17.9 & 0.091 & 0.092 & 1.51 & 1.53 & 10 & 10.5 \\
\hline 25 & 23.9 & 0.097 & 0.095 & 1.61 & 1.59 & 11.6 & 10.8 \\
\hline 7 & 20.2 & 0.096 & 0.096 & 1.60 & 1.60 & 11.1 & 11.4 \\
\hline 10 & 11.6 & 0.124 & 0.126 & 1.55 & 1.58 & 10.6 & 10.4 \\
\hline 8 & 7.9 & 0.127 & 0.127 & 1.59 & 1.59 & 10.4 & 11.0 \\
\hline
\end{tabular}

The effect of aging temperature on the shrinkage factor and thermal conductivity (TC) was studied as a function of target density and the $\left[\mathrm{H}_{2} \mathrm{O}\right] /\left[\mathrm{SiO}_{2}\right]$ ratio for the monolithic aerogels. The shrinkage factor and thermal conductivities were plotted versus the $\left[\mathrm{H}_{2} \mathrm{O}\right] /\left[\mathrm{SiO}_{2}\right]$ ratio and the results are illustrated in Figure 8 and Figure 9. The shrinkage factors of samples aged at higher temperature were lower and samples aged at lower temperature exhibited better TC properties. 


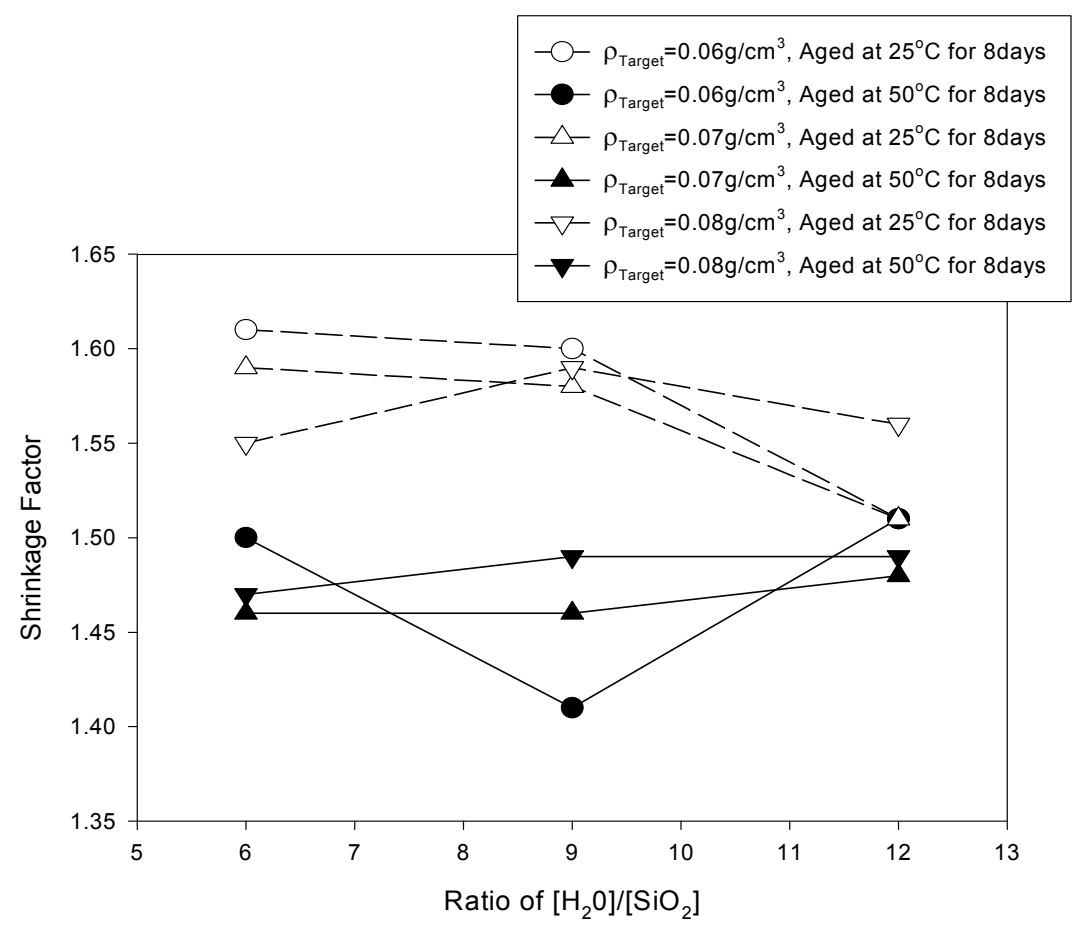

Figure 8. The effect of aging temperature on the shrinkage factor as functions of target density and ratio of $\left[\mathrm{H}_{2} \mathrm{O}\right] /\left[\mathrm{SiO}_{2}\right]$ in the monolithic aerogels.

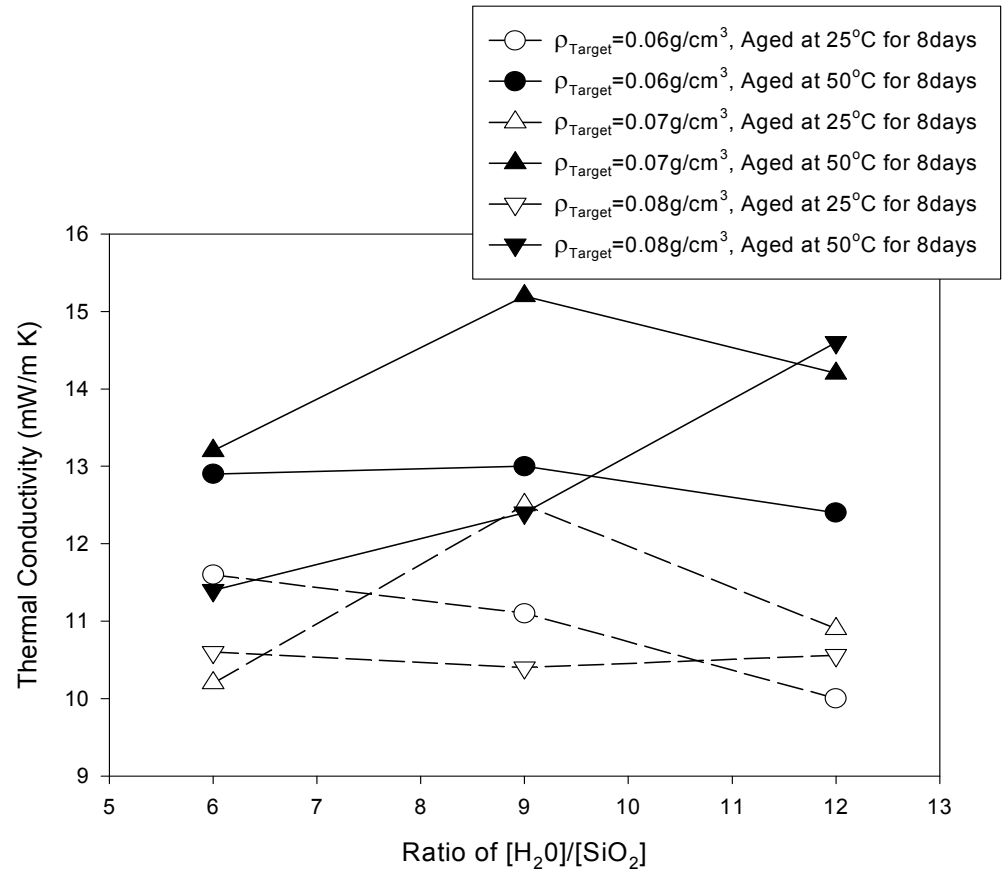

Figure 9. The effect of aging temperature on the thermal conductivity as functions of target density and ratio of $\left[\mathrm{H}_{2} \mathrm{O}\right] /\left[\mathrm{SiO}_{2}\right]$ in the monolithic aerogels. 


\section{Gel Time}

The gel time plays a very important role in determining the manufacturing efficiency for aerogels. If precursors give long gel times, lower productivity will result, while if too short, the sol will gel before it can be poured into molds. Gel time is generally determined by material variables (i.e., chemical reaction), temperature (i.e., thermal energy), and speed of mixing (i.e., rpm, shear rate, mechanical energy).

Table 10 lists the observed effects of important variables such as target density (i.e., solid concentration), and water and catalyst content on gel time obtained using a partial factorial DOE method of $3^{(3-1)}: 3$ levels, 3 variables, 1 block, 9 runs. Results showed over $98 \%$ fitting accuracy between experimental and prediction. All three variables influenced the gel time, and among them, the catalyst content played the most important role in determining gel time, followed by target density. The predicted relationship from the DOE program between three fundamental material variables and gel time is shown in Equation (11). Here, the actual coefficients for each variable are given rather than coded coefficients shown in the table.

Table 10. The effect of target density, and water and catalyst content on gel time, and the comparison between experimental and predicted gel times to indicate fitting accuracy of the DOE results.

\begin{tabular}{|l|c|}
\hline & Effect \\
\hline Mean/Intercept & 1.5239 \\
\hline$(1) \rho_{\text {Target }}(\mathrm{L})$ & -0.9833 \\
\hline$(1) \rho_{\text {Target }}(\mathrm{Q})$ & -0.3550 \\
\hline$(2)\left[\mathrm{H}_{2} 0\right] /\left[\mathrm{SiO}_{2}\right](\mathrm{L})$ & -0.5833 \\
\hline$(2)\left[\mathrm{H}_{2} 0\right] /\left[\mathrm{SiO}_{2}\right](\mathrm{Q})$ & -0.1722 \\
\hline$(3) \mathrm{Mole}\left[\mathrm{NH}_{4} \mathrm{OH}\right](\mathrm{L})$ & -1.0133 \\
\hline$(3)$ Mole $\left[\mathrm{NH}_{4} \mathrm{OH}\right](\mathrm{Q})$ & -0.1211 \\
\hline
\end{tabular}

\begin{tabular}{|c|c|c|}
\hline Exp. Code & $\begin{array}{c}\text { Experimental } \\
\text { Gel Time (hr) }\end{array}$ & $\begin{array}{c}\text { Prediction } \\
\text { by Equation } \\
\text { (hr) }\end{array}$ \\
\hline DOE-1 & 3.13 & 3.03 \\
\hline DOE-2 & 1.17 & 1.17 \\
\hline DOE-3 & 1.15 & 1.25 \\
\hline DOE-4 & 1.55 & 1.64 \\
\hline DOE-5 & 1.12 & 1.01 \\
\hline DOE-6 & 1.68 & 1.67 \\
\hline DOE-7 & 1.65 & 1.63 \\
\hline DOE-8 & 1.5 & 1.58 \\
\hline DOE-9 & 0.55 & 0.43 \\
\hline
\end{tabular}

Gel Time $=12.34-206.3 X_{1}-0.125 X_{2}-5.02 X_{3}+1577.8 X_{1}^{2}+0.0034 X_{2}^{2}+1.514 X_{3}^{2}$

where $X_{1}$ is target density, $X_{2}$ is water content, and $X_{3}$ is the catalyst content. A full factorial design of $3^{2}$ ( 3 levels, 2 variables, 9 runs) can confirm effects of these variables on gel time. Figure 10 shows clearly that the catalyst concentration exhibited a larger effect on the gel time than the water concentration did.

At higher temperatures it is difficult to measure gel time by visual observation. Therefore, viscosity measurements were used to determine the relationship between temperature and gel time. Table 11(A) and (B) show the viscosity behavior as a function of time for two samples measured at temperatures between 10 and $55^{\circ} \mathrm{C}$ at the constant shear rate of $1.3 \mathrm{~s}^{-1}$. When the reaction temperature was increased, the onset of gelation (time of rapid viscosity change) occurred earlier and the rate of viscosity change also increased. 

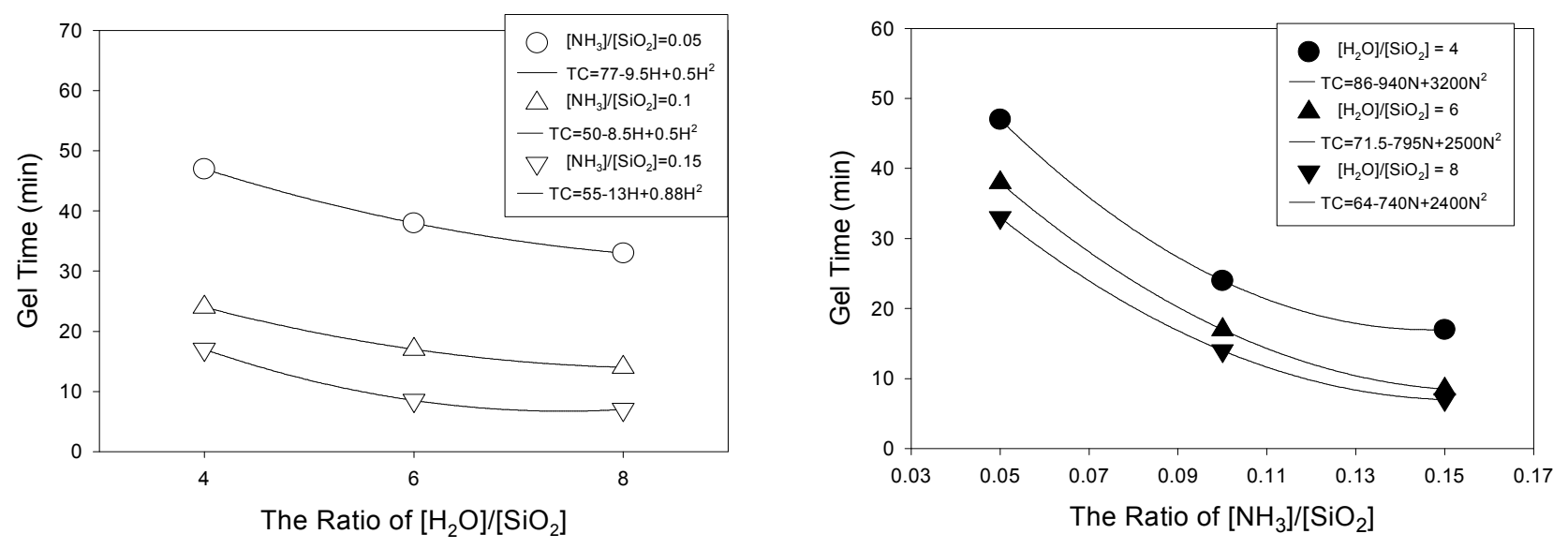

Figure 10. Effects of (left) water and (right) catalyst on gel time at a fixed target density.
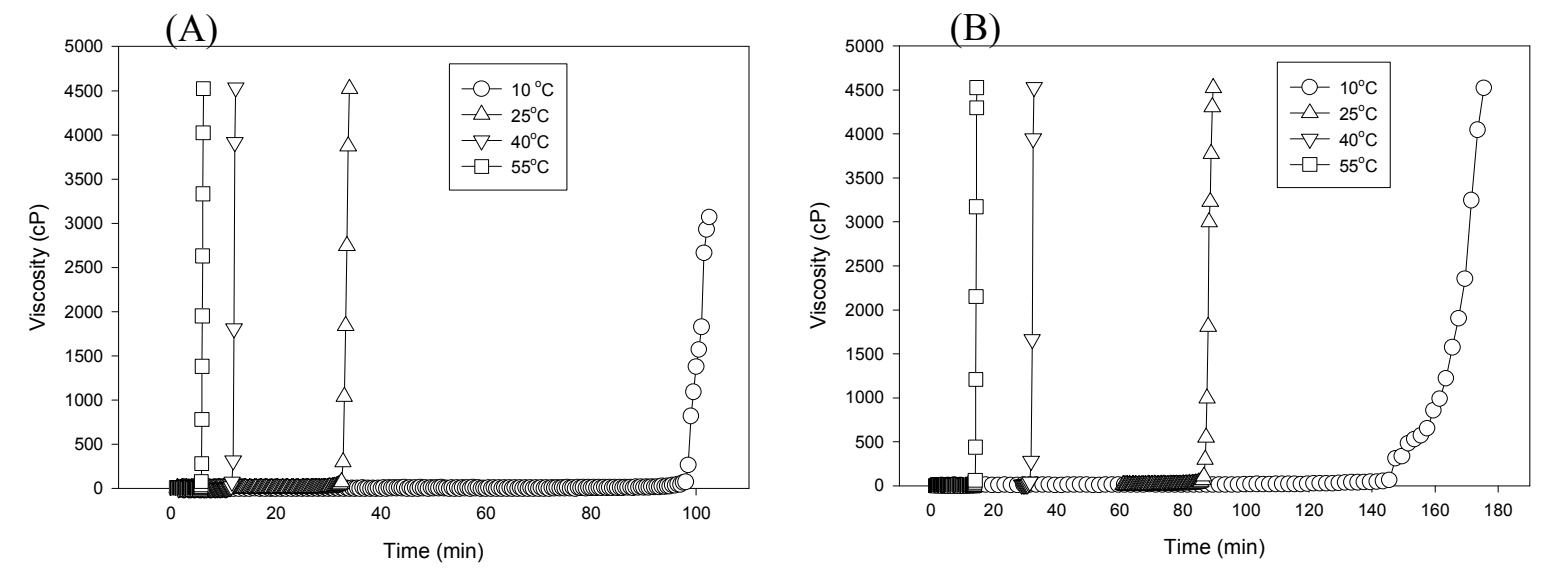

Figure 11. The effects of temperature on the viscosity behavior as a function of time: (A) sample of target density of $0.04 \mathrm{~g} / \mathrm{cm}^{3},\left[\mathrm{H}_{2} \mathrm{O}\right] /\left[\mathrm{SiO}_{2}\right]=8$, and $\left[\mathrm{NH}_{4} \mathrm{OH}\right]$ of $0.001 \mathrm{~mole}$, (B) samples of target density of $0.06 \mathrm{~g} / \mathrm{cm}^{3},\left[\mathrm{H}_{2} \mathrm{O}\right] /\left[\mathrm{SiO}_{2}\right]=8$, and $\left[\mathrm{NH}_{4} \mathrm{OH}\right]$ of $0.0001 \mathrm{~mole}$.

Temperature sensitivity of samples with specific solid content (target density) and catalyst concentration can be quantitatively compared with other samples of different formulations. A constant can be obtained by using the Arrhenius relationship (equation 12) between the onset time of viscosity change and temperature, which is widely used to describe temperature sensitivity and reactivity of polymeric material:

$$
\mathrm{t}_{\text {onset }}(\mathrm{T})=\mathrm{t}_{\text {onset }}\left(\mathrm{T}_{0}\right) \exp \left[-\frac{\Delta \mathrm{E}}{\mathrm{R}}\left(\frac{1}{\mathrm{~T}}-\frac{1}{\mathrm{~T}_{0}}\right)\right]
$$

where, $t_{\text {onset }}\left(T_{0}\right)$ is the onset time of viscosity change at reference temperature $T_{0}, t_{\text {onset }}(T)$ is the onset time of viscosity change at temperature $T, \Delta \mathrm{E}$ is the activation energy of viscous flow, $\mathrm{R}$ is a gas constant, and $\mathrm{T}$ and $\mathrm{T}_{0}$ are temperatures with the unit of ${ }^{\circ} \mathrm{K}$. After simplifying, we can obtain the following equation:

$$
\mathrm{t}_{\text {onset }}(\mathrm{T})=\mathrm{t}_{\text {onset }}\left(\mathrm{T}_{0}\right) \exp \left[-\mathrm{C}\left(\mathrm{T}-\mathrm{T}_{0}\right)\right]
$$




$$
\mathrm{C}=\frac{\Delta \mathrm{E}}{\mathrm{R}}\left(\frac{1}{\mathrm{~T} \times \mathrm{T}_{0}}\right)
$$

Taking the logarithm of both sides of Equation (13), C is the slope of a fitted line in a plot of $\ln \left(\mathrm{t}_{\text {onset }}\right)$ versus Temperature, and depends on the activation energy of the system and the temperature range studied. Centigrade units for $\mathrm{T}$ and $\mathrm{T}_{0}$ can also be used.

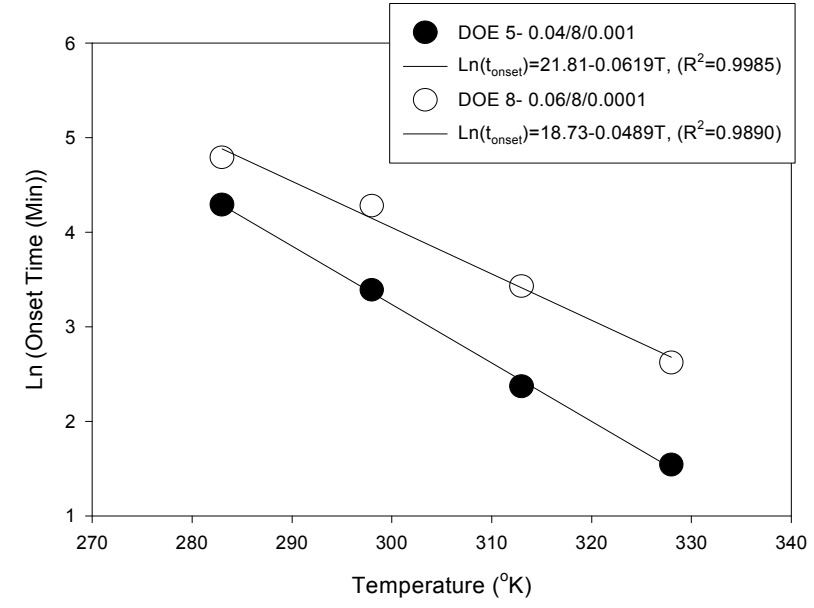

Figure 12. Arrhenius relation between temperature and viscosity where the slope of the fitted line indicates temperature dependence.

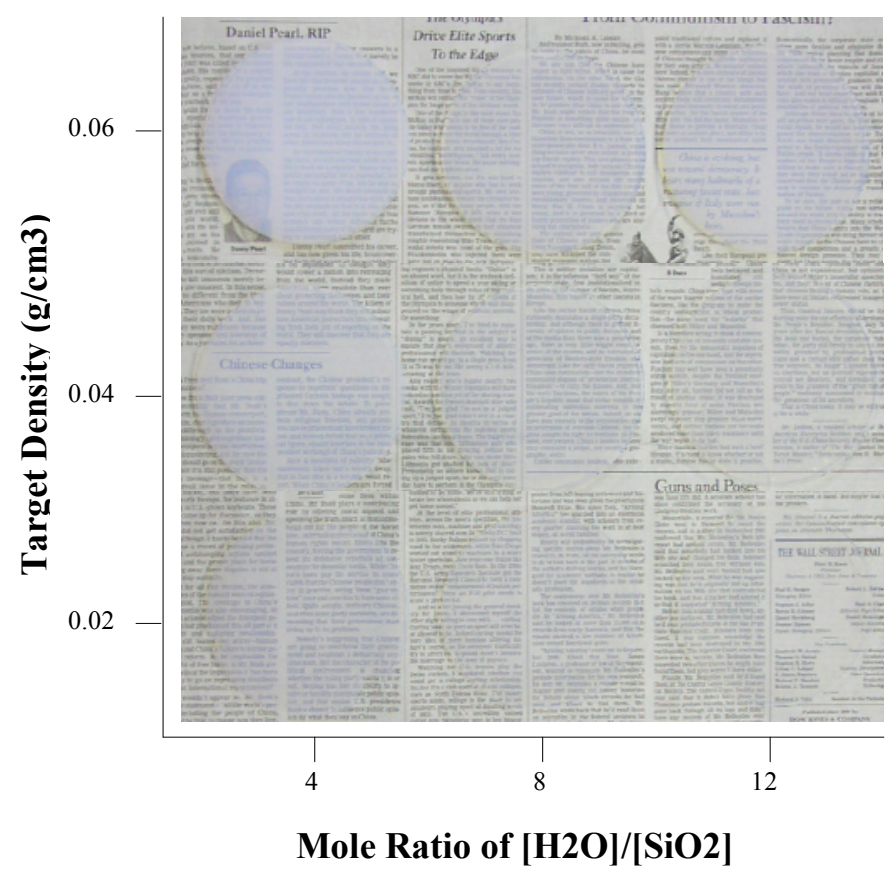

Figure 13. Effects of target density and water concentration on the transparency of aerogels.
As indicated in equations 13 and 14, a larger (absolute) value of $\mathrm{C}$ over the same temperature range indicates more sensitivity to temperature: the change in activation energy of the system is greater. The temperature sensitivities were calculated by equations 12 to 14 and the result is summarized in Figure 12. The sample containing higher catalyst but lower solid concentrations had a steeper slope than the sample that contained lower catalyst but higher solid concentrations. The catalyst concentration played a more important role than target density, which is consistent with the observed gel times. It was found that 30 to 60 minutes would be the optimum gel time and thus, was used as the target gel time for aerogel panels.

\section{Material and Processing Variables vs. Important Properties:}

The degree of transparency is the most important property for aerogels that will be used in window applications. Experiments were designed to determine the effect of $\mathrm{H}_{2} \mathrm{O}$ concentration and target density on the aerogel's transparency. The samples prepared are shown in Figure 13. If a higher target density (i.e., higher solid concentration) was used, the aerogel sample showed better thermal conductivity and shrinkage properties, but the aerogel was less transparent.

The relationships between thermal 
conductivity and target and the final dried densities as a function of aging temperature are given in Figure 14(A) and (B), respectively. The aerogels with lower target densities have the best transparency but a higher thermal conductivity and thus, exhibit worse insulation performance. In addition to having higher thermal conductivities, the lower density aerogels are weaker and problems such as breaking would be more prevalent. Therefore, finding the optimum target density to obtain well-balanced properties between transparency and thermal conductivity was important for aerogel production scale up.
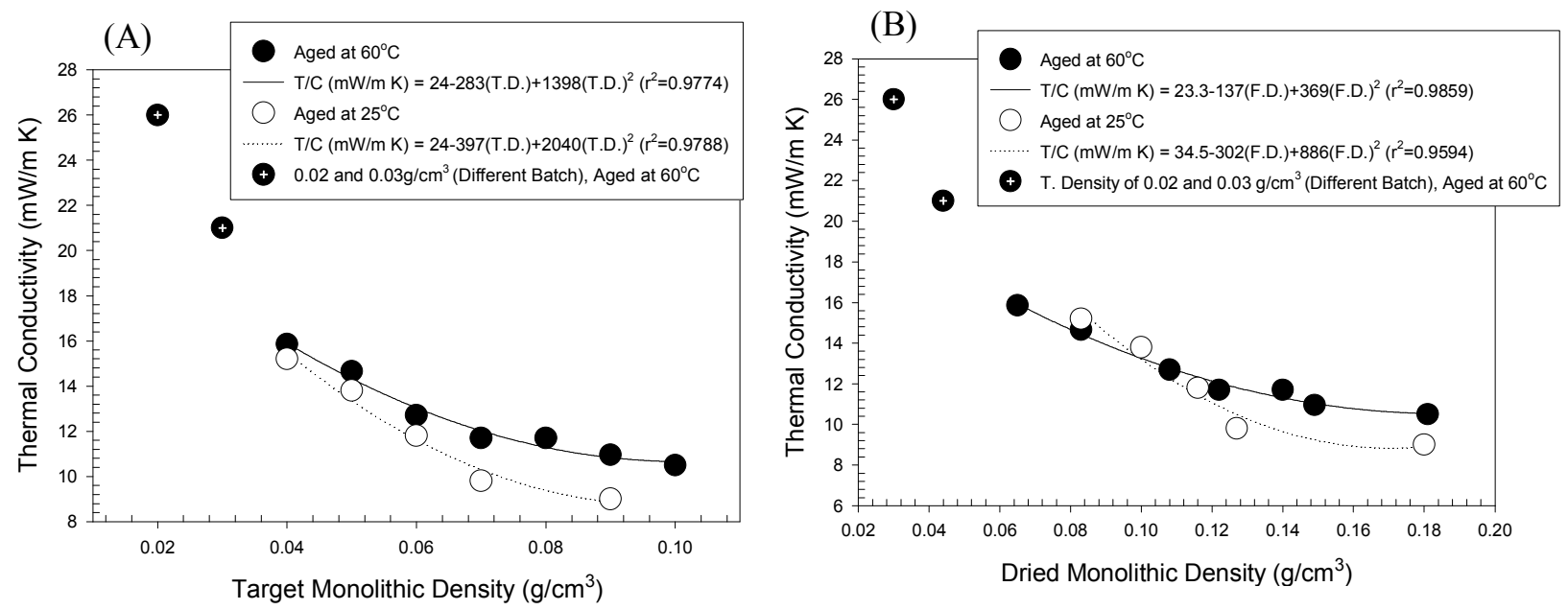

\section{Figure 14. Relationships between thermal conductivity and target and the final dried densities as a function of aging temperature and their fitting equations.}

Figure 15 demonstrates the effects of several key variables such as target density, water content, and aging temperature on the monolith shrinkage factor and thermal conductivity. Note that different $\left[\mathrm{NH}_{3}\right] /\left[\mathrm{SiO}_{2}\right]$ mole ratios of $0.3,0.03$, and 0.005 were used for target densities of 0.02 , 0.04 , and 0.06 , respectively, to give a similar gel time. Smaller values for both variables gave lower shrinkage factors and thermal conductivities, and higher transparency. The most transparent sample was given a value of 1, and the least transparent sample was given a value of 9.

It is clear from Figure 15 that as more water was incorporated and higher temperatures were used for aging, we were able to obtain aerogels with lower shrinkage factors and thermal conductivities, and better transparency. The effects of water content and aging temperature on properties is important for mechanical properties, because more water and higher aging temperature can increase the strength of the gel. However, target density showed a complex effect on the thermal conductivity and transparency.

These properties were dependent upon the pore structure formed during gelation and the aging process, which in turn is a function of processing variables. Figure 16 demonstrates the effects of target density and water content on pore volume and surface area at a fixed aging temperature of $40^{\circ} \mathrm{C}$. Results plotted in Figure 16 indicate that pore volume and diameter are sensitive to variations in water concentration, gelation temperature and aging conditions. Since different catalyst concentrations were used for different target densities to provide similar gel times, the effect of catalyst concentration is combined with the effect of target density. Understanding this 
complex relationship between pore structure and many of the processing variables was important for interpreting and optimizing the research results.
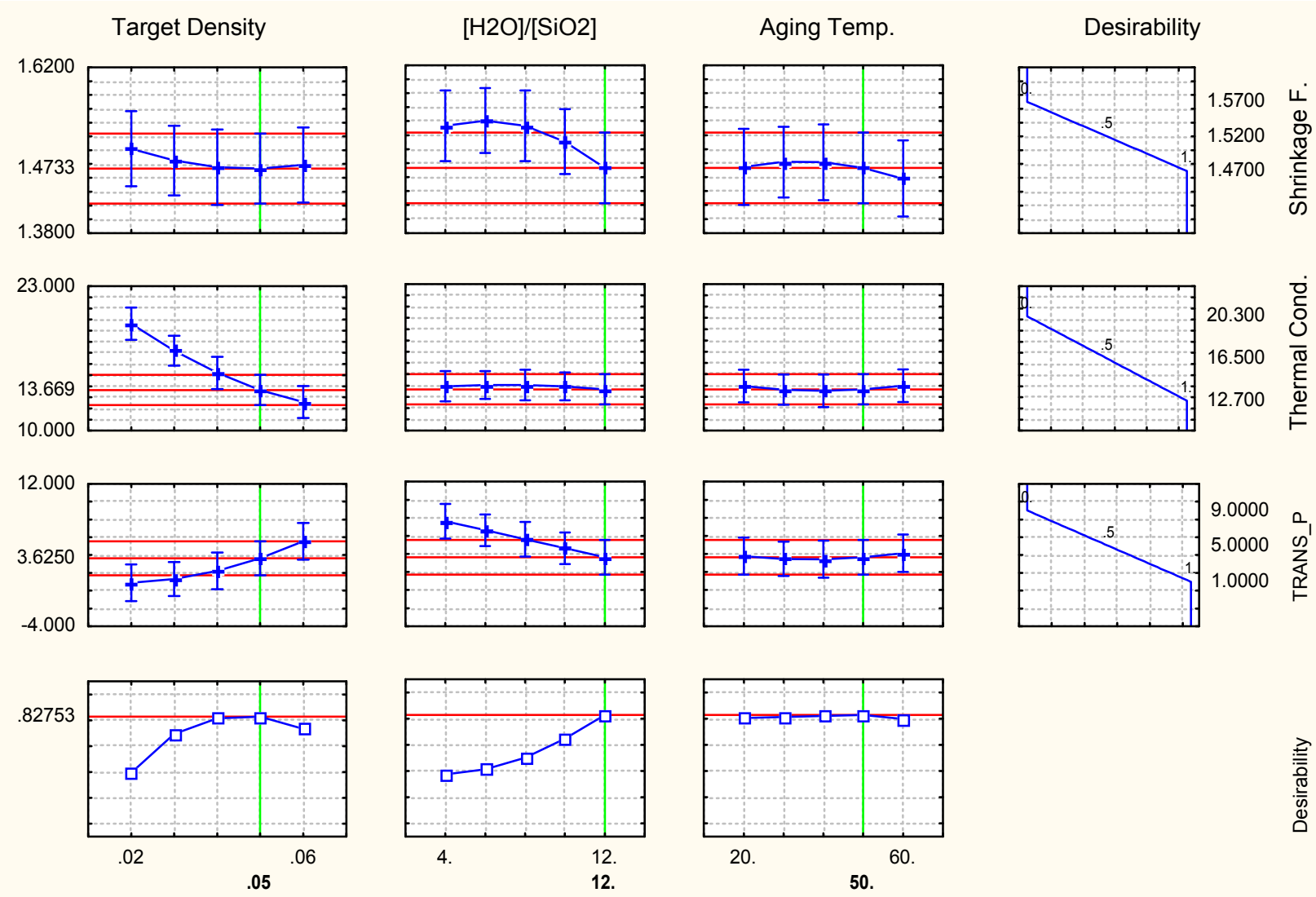

\section{Figure 15. Effects of target density, water content and aging temperature on important bulk, thermal, and optical properties of aerogel monoliths.}

Other processing variables that played a very important role in determining aerogel appearance and properties were aging solution treatment, such as the ammonia and Hydrophobic Agent concentrations, and the aging temperature. The minimum requirement for aging would be to prepare wet gels that are strong enough to overcome capillary forces during drying. The ammonia and Hydrophobic Agent solution treatments cause chemical reactions that form stronger gels and impart hydrophobicity, respectively, and aging at high temperature produces stronger gels and more hydrophobic surfaces in a relatively short time. This reduces processing time and improves throughput.

Figure 17 demonstrates the effect of the different aging solutions on the shrinkage factor and thermal conductivity and indicates that shrinkage decreases by aging at $50^{\circ} \mathrm{C}$ under basic conditions. The effect of the different aging solutions on the strength, modulus, and strain are provided in Figure 18. In Figure 18, samples aged in both $\mathrm{NH}_{4} \mathrm{OH}$ and Hydrophobic Agent solution at $50^{\circ} \mathrm{C}$ for 3 days showed the best flexural strain at breaking as well as the highest breaking strength without a significant increase in modulus (i.e., brittleness). 

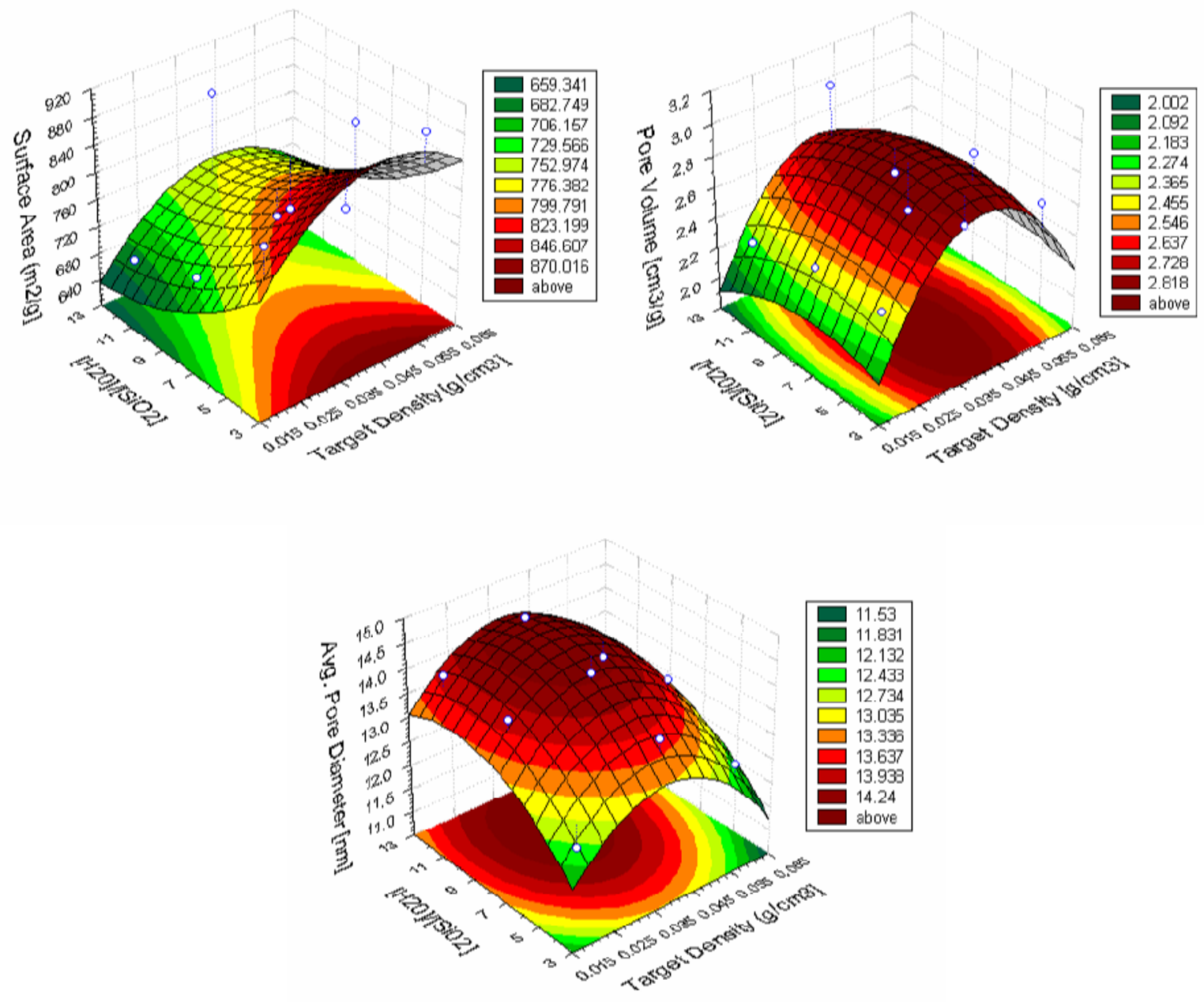

Figure 16. Dependence of pore volume (A), surface area (B), and pore size (C) on the target density and water content at a fixed aging temperature of $40^{\circ} \mathrm{C}$.
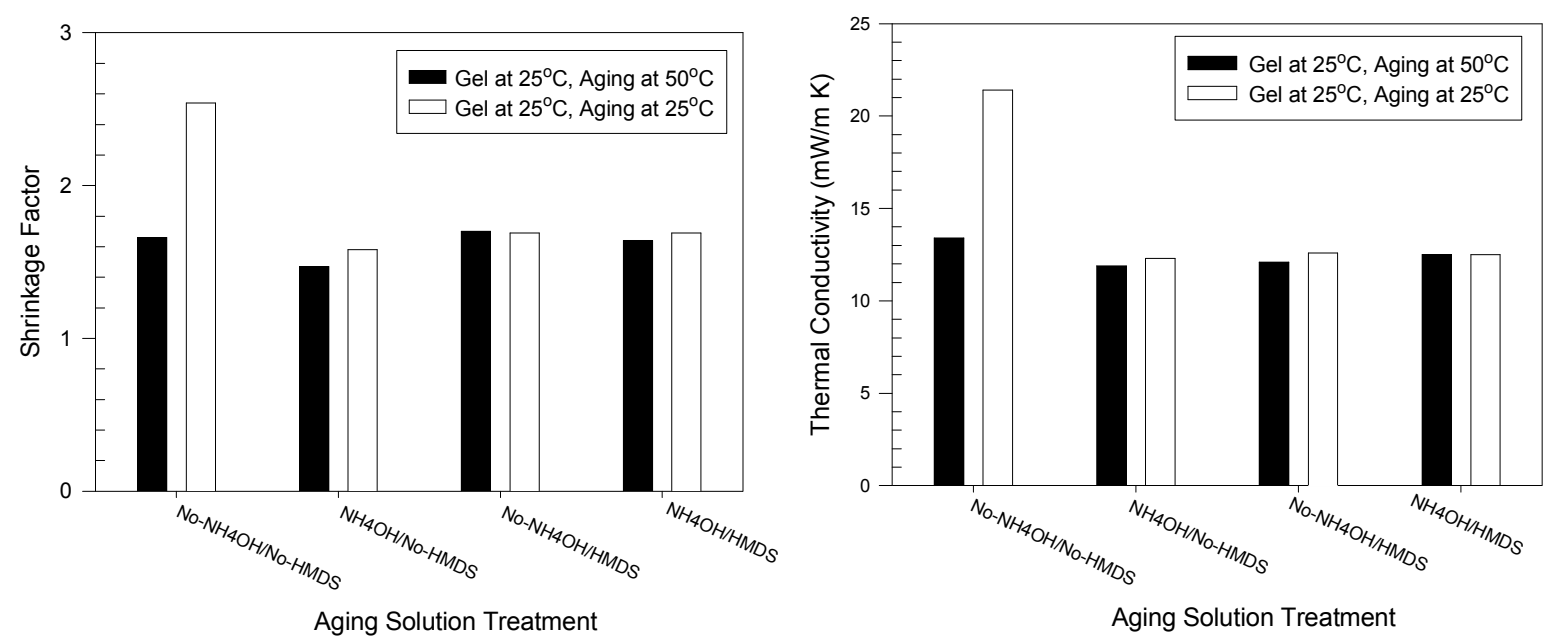

Figure 17. The effect of different aging solutions on the shrinkage factor and thermal conductivity values for aerogel monoliths as a function of aging temperature. 


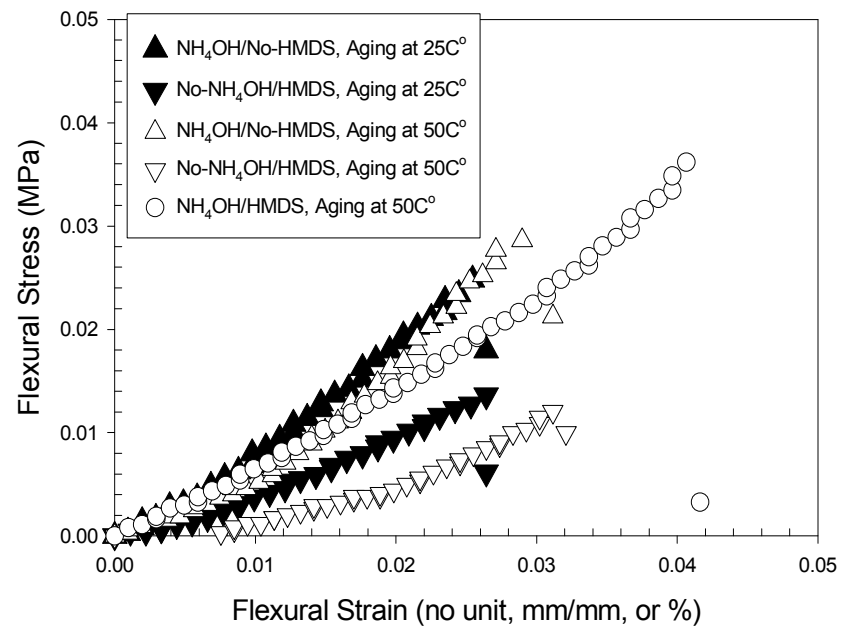

Figure 18. The effect of aging condition on the mechanical properties of aerogels.
Compression Behavior of Aerogels

When used as an insulating fill material for windows, the transparent, hydrophobic, and resilient aerogels will be sandwiched between glass, most likely in a double-glazed configuration. In this case, the presence of compressive forces is inevitable, due to different thermal expansion coefficients between glass and aerogels. Therefore, understanding the compressive behavior of aerogels is valuable.

Compressive forces were applied to aerogels using a ComTen Industries 94-C Series compression tester with a slow speed fixture. The data were converted to compression stress using the simple relation of Stress $=$ Force/Area. After applying a predetermined force, the resultant bulk density, thermal conductivity value, and visual transparency were measured and compared with initial values. The typical compression behavior of density and thermal conductivity of the aerogel monolith is shown in Figure 19 as the ratio of initial values to measured values. As indicated by Figure 19, the aerogel properties did not change appreciably up to $100 \mathrm{psi}$, which is higher than the expected in-use stress when used as insulation in double-glazed windows.

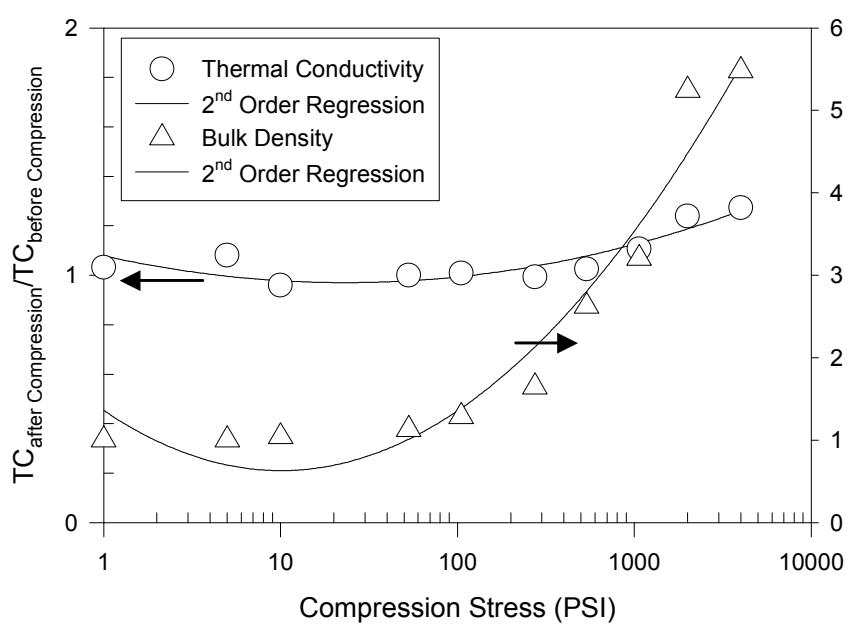

\begin{tabular}{|c|c|c|}
\hline $\begin{array}{c}\text { Compression } \\
\text { Stress (psi) }\end{array}$ & $\begin{array}{c}\text { Density } \\
\left(\mathbf{g} / \mathbf{c m}^{3}\right)\end{array}$ & $\begin{array}{c}\text { TC } \\
(\mathbf{m W} / \mathbf{m} \text { K) }\end{array}$ \\
\hline 0 & 0.1093 & 12.4 \\
\hline 1 & 0.1095 & 12.8 \\
\hline 5 & 0.1098 & 13.4 \\
\hline 10 & $\mathbf{0 . 1 1 3 8}$ & 11.9 \\
\hline 53 & 0.1233 & 12.4 \\
\hline 105 & 0.1405 & 12.5 \\
\hline 274 & 0.1799 & 12.3 \\
\hline 537 & 0.2869 & 12.7 \\
\hline 1064 & 0.3503 & 13.7 \\
\hline 2000 & 0.5730 & 15.4 \\
\hline 4000 & 0.5994 & 15.8 \\
\hline
\end{tabular}

Figure 19. Density and thermal conductivity behavior of aerogels under compression.

The thermal conductivity increased only slightly after the aerogel was compressed at pressures above 100 psi. Therefore, we conclude that the thermal performance of the aerogel insulation will not be affected by slight compression in double-glazed window assemblies. 
After compression at higher pressures, aerogel panels will remain reasonably transparent. The compression behavior of aerogels could be associated with changes in the pore structure before and after compression. The change of pore volume, pore size and distribution, and surface area of aerogels compressed at pressures up to 4000 psi are given in Figure 20 in terms of their relationship to bulk density and thermal conductivity. It is clear from Figure 20 that compression reduced the size of the larger pores. The average pore size decreased, as also illustrated in Figure 20. Most likely, the elimination of the larger pores after compression relates to the increase in bulk density, while the negligible change in small pores allows stable thermal conductivity.

\begin{tabular}{|c|c|c|}
\hline Pore Properties & Initial & $\begin{array}{c}\text { After } \\
\text { Compression }\end{array}$ \\
\hline Density $\left(\mathrm{cm}^{3} / \mathrm{g}\right)$ & 0.1093 & 0.5994 \\
\hline $\begin{array}{c}\text { Thermal Conductivity } \\
(\mathrm{mW} / \mathrm{mK})\end{array}$ & 12.4 & 15.4 \\
\hline Pore Volume $\left(\mathrm{cm}^{3} / \mathrm{g}\right)$ & 2.86 & 2.34 \\
\hline $\begin{array}{c}\text { Average Pore } \\
\text { Diameter }(\mathrm{nm})\end{array}$ & 13.5 & 11.24 \\
\hline BET surface area $\left(\mathrm{m}^{2} / \mathrm{g}\right)$ & 845 & 834 \\
\hline
\end{tabular}

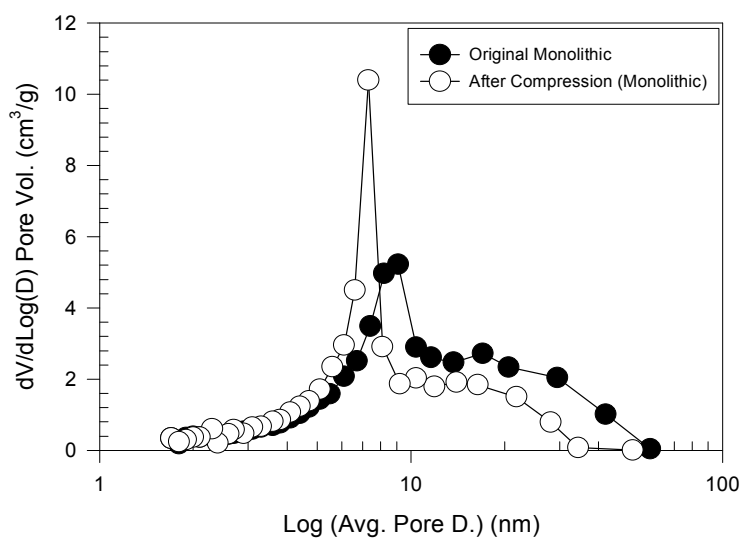

Figure 20. Comparison of pore volume, size, and surface area (left) and size distribution (right) for aerogel before and after compression at 4000 psi.

\subsection{PDMS Ormosil Formulation Development}

\subsubsection{Transparent Ormosil aerogels (HF catalyzed)}

Although aerogels exhibits extremely low density, high surface area, good optical, thermal, and acoustic properties, they also have inherent drawbacks such as weakness and brittleness. Aspen improved mechanical properties by incorporating organic materials into silica aerogels without sacrificing any of the other aerogel properties. Polydimethylsiloxanes with hydroxyl end groups (OH-PDMS) were investigated because of their good thermal stability, hydrophobicity, and potential reactivity with silica precursors.

When making highly transparent and hydrophobic aerogels, brittleness becomes much more acute. We fabricated a highly transparent (Transparency Ratio $=93 \%$ in the visible range) and totally hydrophobic gel using a hydrophobic precursor; however, the samples were fragile and were often broken during transport to the University of Lyon, France where they were sent for transparency characterization. To improve the mechanical properties, we made transparent/hydrophobic/resilient aerogels based roughly on Mackenzie's work. ${ }^{6-10}$ This work from the early 1990's indicated that polydimethylsiloxane polymers could be incorporated into a silica gel to provide mechanical resiliency without totally sacrificing transparency.

Adding polymeric organic materials should result in increased resiliency and increased strain to failure during compression and flexing. An organic component may also impart an additional degree of hydrophobicity, which is critical to preserving the aerogel transparency in humid or wet conditions. Improvements in compressive strength and toughness, better optical 
transparency, and decreased hydrophilicity in silica gel glasses have been reported by Novak and co-workers using a variety of organic polymer dopants (e.g. PMMA). ${ }^{15}$ Mackenzie's work $^{6-10}$ centered on the incorporation of flexible linkages, such as polydimethylsiloxane (PDMS), into sol-gel derived silicate networks to form what Schmidt called ORMOSILs, or organically modified silicates. ${ }^{16,17}$ Mackenzie's group ${ }^{6-10}$ successfully synthesized aerogels containing PDMS in the composition range of $0-20 \%$ utilizing both acid and acid-base catalysis methods. The aerogels made exhibited high mechanical strength and rubbery behavior.

We were not able to duplicate results of the methods described in the literature by Mackenzie et $a l .{ }^{6}$, and created only materials with low mechanical integrity, high shrinkage, low monolithicity and low transparency. In order to demonstrate the Ormosil's resiliency, numerous experiments were performed using a hydrolyzed silica precursor instead of TEOS (as described in the literature). The synthesis approach is illustrated in Figure 21.

We decided that it was not necessary to use TEOS, P900 or a hydrophobic Si precursor as the silica source. We believed that transparency improvements could be made, if necessary, in the latter stages of the formulation development by moving to the intrinsically hydrophobic PCAS precursors. Availability of the precursors in commercial quantity was also a potential concern.

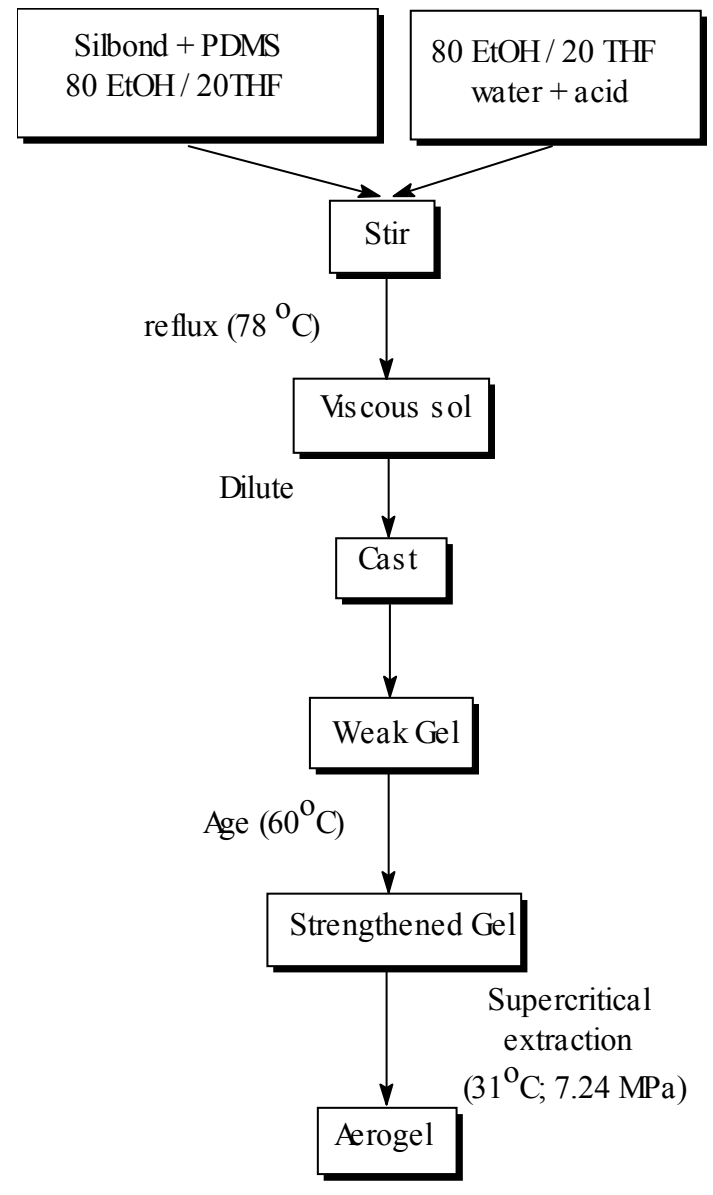

Figure 21. Synthesis of transparent/ hydrophobic/resilient aerogels
Therefore, we concentrated primarily on a hydrolyzed silica precursor.

Ormosils were prepared by incorporating PDMS into the silica network (Table 11). Synthesis of the hybrid aerogel required using THF as a co-solvent with ethanol or 2propanol to dissolve the PDMS and make a homogenous solution. Transparent gels $\left(\left[\mathrm{SiO}_{2}\right] /[\mathrm{PDMS}]=0.8-0.9\right)$ were fabricated using a mixture of $20 \%$ THF and $80 \%$ ethanol. The gels were synthesized using two different approaches and catalysts: $\mathrm{HBF}_{4}$ and HF.

- Method 1. The reaction between different compounds was performed at $70{ }^{\circ} \mathrm{C}$ under reflux for 1.5 hours before pouring the solution into molds for gelation at room temperature.

- Method 2. The gels were synthesized at room temperature by controlling the rate of addition of precursors and catalyst to one another. The gels were aged in ethanol, toluene, or benzene at $50{ }^{\circ} \mathrm{C}$ for 48 hours to enhance bonding between the silica network and PDMS. 
Table 11. PDMS Aerogels made using a modification of the Mackenzie method.

\begin{tabular}{|c|c|c|c|c|}
\hline Precursor & \% PDMS & $\begin{array}{c}\text { Aging } \\
\text { Solvent }\end{array}$ & $\begin{array}{c}\text { State of the gels } \\
\text { before drying }\end{array}$ & After drying \\
\hline \multirow{3}{*}{$\begin{array}{c}\text { Hydrolyzed } \\
\text { precursor/PD } \\
\text { MS 70 }\end{array}$} & 10 & - & Transp. & $\begin{array}{c}\text { Perfectly monolithic and } \\
\text { elastic but less } \\
\text { transparent. }\end{array}$ \\
\cline { 2 - 4 } & 20 & - & Transp. & \multirow{2}{*}{$\begin{array}{c}\text { Samples cracked in } \\
\text { contact with liquid } \mathrm{CO}_{2}\end{array}$} \\
\cline { 2 - 4 } $\begin{array}{c}\text { Hydrolyzed } \\
\text { precursor } \\
\text { /PDMS RT }\end{array}$ & 10 & EtOH & Cloudy & \\
\cline { 2 - 4 } & 20 & EtOH & Cloudy & \\
\cline { 2 - 4 } & 10 & Toluene & Transp. & \\
\cline { 2 - 4 } & 20 & Toluene & Transp. & \\
\cline { 2 - 4 } & 10 & Benzene & Transp. & \\
\hline
\end{tabular}

The hydrolyzed precursor/PDMS RT (blended at room temperature) turned a little bit cloudy after aging. Another series of gels was made, but this time the gels were aged in a non-polar solvent (toluene or benzene). The gels kept their transparency and their resiliency. The hydrolyzed precursor /PDMS 70 remained monolithic during drying and acquired a remarkable resiliency. The general formula, viscosities, and molecular weights of PDMS polymers that Aspen has thus far investigated are summarized in Table 12.

Table 12. PDMS types and their corresponding viscosities and molecular weights.

\begin{tabular}{|c|c|c|}
\hline Type of PDMS & $\begin{array}{c}\text { Viscosity } \\
\text { (cst) }\end{array}$ & $\begin{array}{c}\text { Number Average } \\
\text { Molecular Weight }\left(M_{n}\right)\end{array}$ \\
\hline Hydroxy Terminated PDMS & 25 & 550 \\
\hline Hydroxy Terminated PDMS & 65 & 2750 \\
\hline Hydroxy Terminated PDMS & 120 & 4200 \\
\hline Hydroxy Terminated PDMS & 750 & 18,000 \\
\hline Hydroxy Terminated PDMS & 3500 & 43,500 \\
\hline $\begin{array}{l}\text { Diglycidyl Ether Terminated } \\
\text { PDMS }\end{array}$ & $(<25)$ & 980 \\
\hline
\end{tabular}

*) Molecular weights are those estimated by Aldrich and Gelest

1) General Formula of Hydroxy-Terminated PDMS: $\left(\mathbf{H O}-\left(\mathbf{S i}\left(\mathrm{CH}_{3}\right)_{2} \mathbf{O}\right)_{n}-\mathrm{Si}\left(\mathrm{CH}_{3}\right)_{2} \mathbf{O H}\right)$

2) General Formula of Diglycidyl Ether Terminated PDMS:

$\left.\left(\mathrm{OCH}_{2} \mathrm{CH}_{2} \mathrm{CH}_{2} \mathrm{O} \mathrm{CH}_{2} \mathrm{CH}_{2} \mathrm{CH}_{2}-\mathrm{Si} \mathrm{CH}\right)_{2} \mathrm{O}-\left(\mathrm{Si}\left(\mathrm{CH}_{3}\right)_{2} \mathrm{O}\right)_{\mathrm{n}}-\mathrm{Si}\left(\mathrm{CH}_{3}\right)_{2}-\mathrm{CH}_{2} \mathrm{CH}_{2} \mathrm{CH}_{2} \mathrm{OCH}_{2} \mathrm{CH}_{2} \mathrm{CH}_{2} \mathrm{O}\right)$

Figure 22 demonstrates the typical dependence of shrinkage factor and thermal conductivity for Ormosil samples prepared using 15wt\% PDMS on the molecular weight (viscosity) of hydroxylterminated PDMS, along with comparison to samples prepared with diglycidyl-terminated PDMS and pure silica aerogels (non-Ormosil). 
(A)

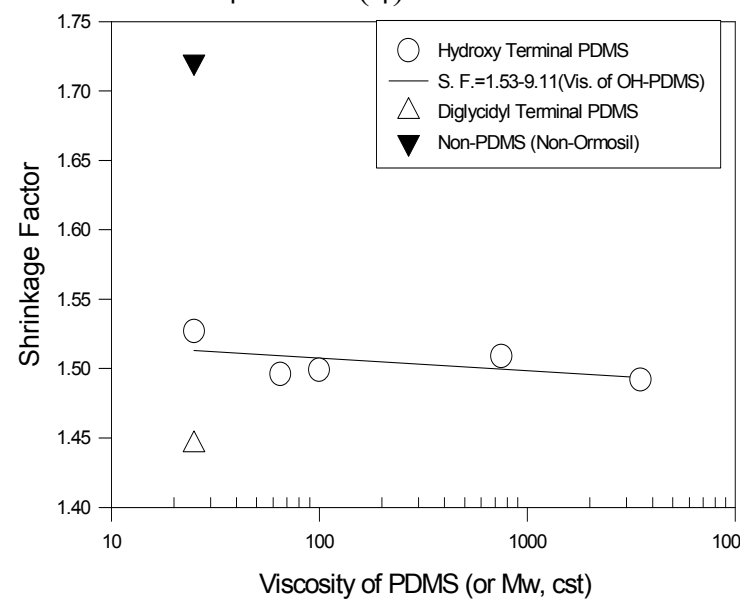

(B)

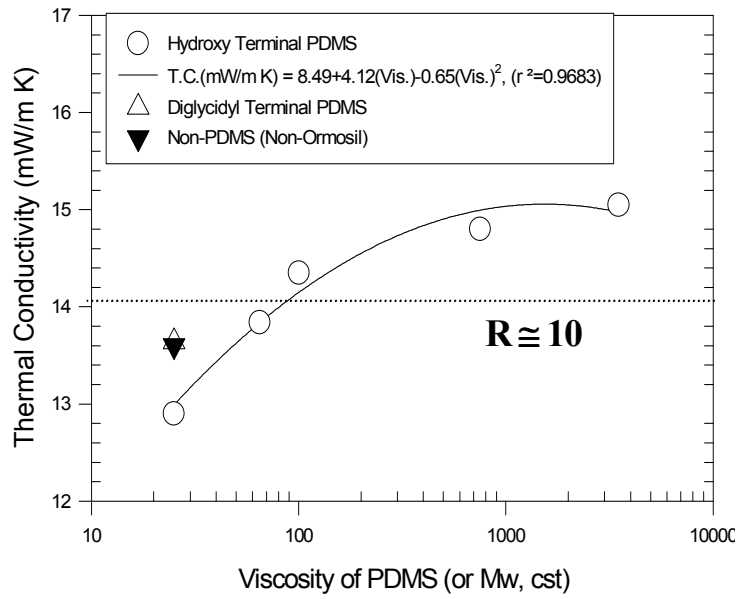

Figure 22. Relationship between shrinkage factor (A) and thermal conductivity (B) for 15 wt\% PDMS Ormosil (and other aerogels) and $M_{n}$.

A slightly smaller shrinkage factor was found for Ormosil samples incorporated with OH-PDMS of larger $M_{n}$, and Ormosil prepared with OH-PDMS with $M_{n}<100$ showed good thermal conductivity. The non-Ormosil system was the most transparent, followed by Ormosil with diglycidyl-PDMS ("epoxy-PDMS") and finally the Ormosil with OH-PDMS of lower $\mathrm{M}_{\mathrm{n}}$. The transparency of Ormosil was inversely proportional to the $\mathrm{M}_{\mathrm{n}}$ of OH-PDMS. The final dried Ormosil monoliths containing OH-PDMS of $\mathrm{M}_{\mathrm{n}}>3640$ were translucent or opaque.

Mechanical properties such as maximum flexural strength and strain at the breaking point are important for this application. Figure 23 illustrates the relationship between flexural strength and strain of Ormosil samples prepared with $15 \mathrm{wt} \%$ PDMS and molecular weight of the PDMS. Results are also given for samples prepared with epoxy-PDMS and silica (non-Ormosil) for comparison. Note that the maximum flexural strength is associated with strength, while flexural strain is related to resilience or deformation to failure. Ormosils prepared with both OH-PDMS of the smallest $\mathrm{M}_{\mathrm{n}}$ and epoxy-PDMS clearly demonstrated an improvement in maximum flexural strain. However, the maximum flexural strength of Ormosils was significantly decreased from that of the non-Ormosil sample.

Higher $\mathrm{M}_{\mathrm{n}}$ hydroxyl-terminated PDMS (OH-PDMS) is not recommended for Ormosils, because both the maximum flexural strength and strain decreased significantly as the $M_{n}$ increased. This may be due to phase separation between PDMS and the silica precursor, caused by the lower solubility of PDMS. The decrease in maximum flexural strength of Ormosils was more significant for samples prepared with higher target densities, as shown in Figure 24. Here, the flexural stress-strain behavior of Ormosil with 20wt $\%$ OH-PDMS of $\mathrm{M}_{n}=550$ as a function of target density is shown. 

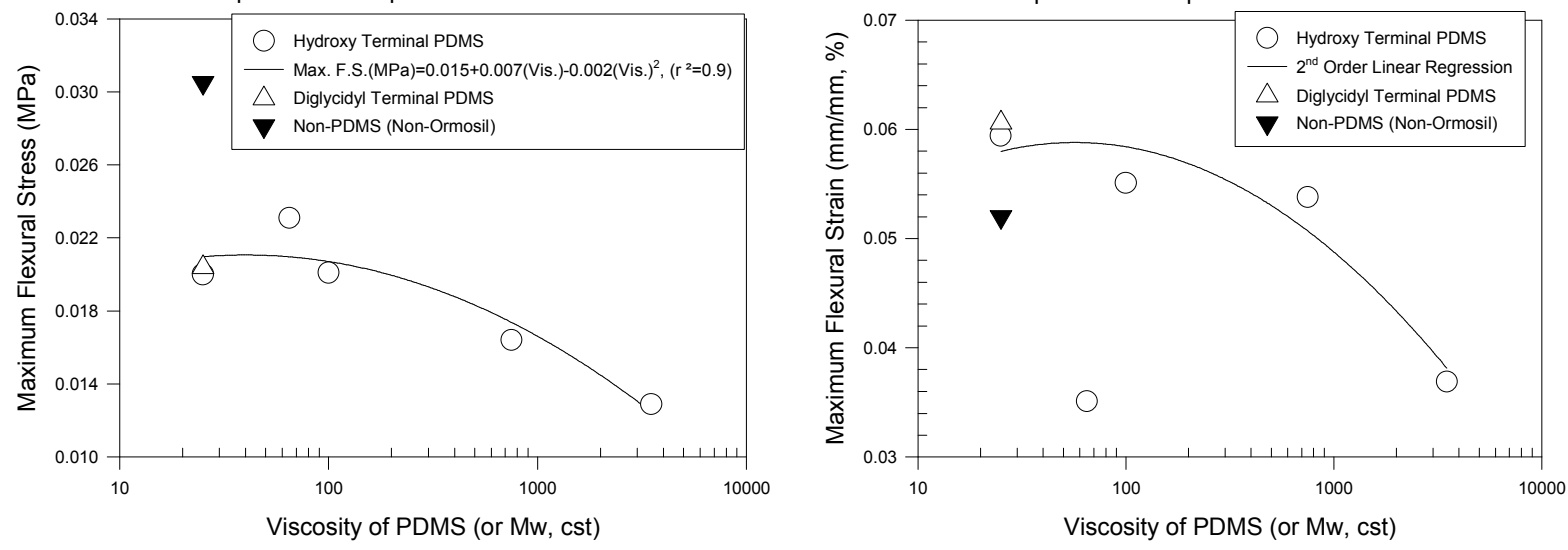

Figure 23. Relationship between maximum flexural strength (A) or strain (B) and $M_{n}$ for 15 wt\% Ormosil with different functional groups.

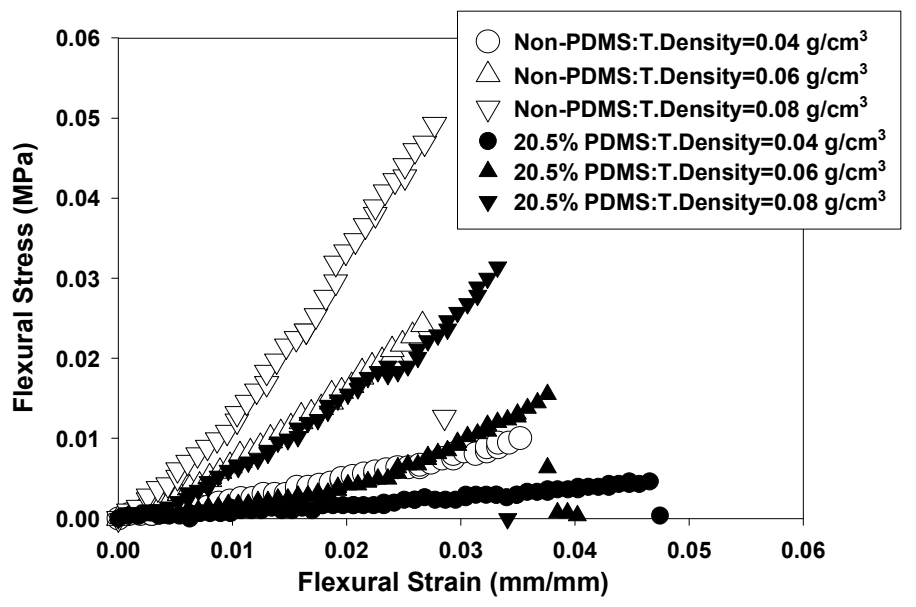

Figure 24. Flexural stress-strain behavior of Aspen's Ormosil incorporated with 20wt\% PMDS as a function of target density.

Figure 24 also clearly illustrates that whenever PMDS of $20 \mathrm{wt} \%$ was incorporated in aerogels, regardless of the target density, flexural strain increased (e.g., more elasticity), while flexural strength decreased (e.g., more weakness), which is not desirable. The effect of incorporating PDMS into aerogels seemed to be similar to that of decreasing density (i.e., lower solid concentration). Recently, Aspen solved the problem of decreasing strength by increasing the target density without sacrificing resilience. This is shown in Figure 25.

Higher density aerogels made with OH-PDMS and epoxy-PDMS showed better maximum flexural strength and strain than those made with silica alone (non-Ormosil). This is due to the effects of higher target density and bonding between PDMS and the silica precursor. OH-PDMS showed better mechanical properties than epoxy-PDMS, while better transparency was observed with epoxy-PDMS. Compared with silica aerogels (non-Ormosil), they also showed lower shrinkage factors and similar thermal conductivities. Although mechanical properties were much improved through the Ormosil approach, there still remained an important problem to be solved: decreased transparency. It was already observed that as target density increased (i.e., solid content increased), thermal conductivities (see Figure 14) and mechanical properties (see Figure 24 and Figure 25) decreased, and much less transparency was observed (Figure 13). The lower transparency of these silica and/or Ormosil monoliths was a critical disadvantage for window applications. This will be discussed further in a later section of this report. 

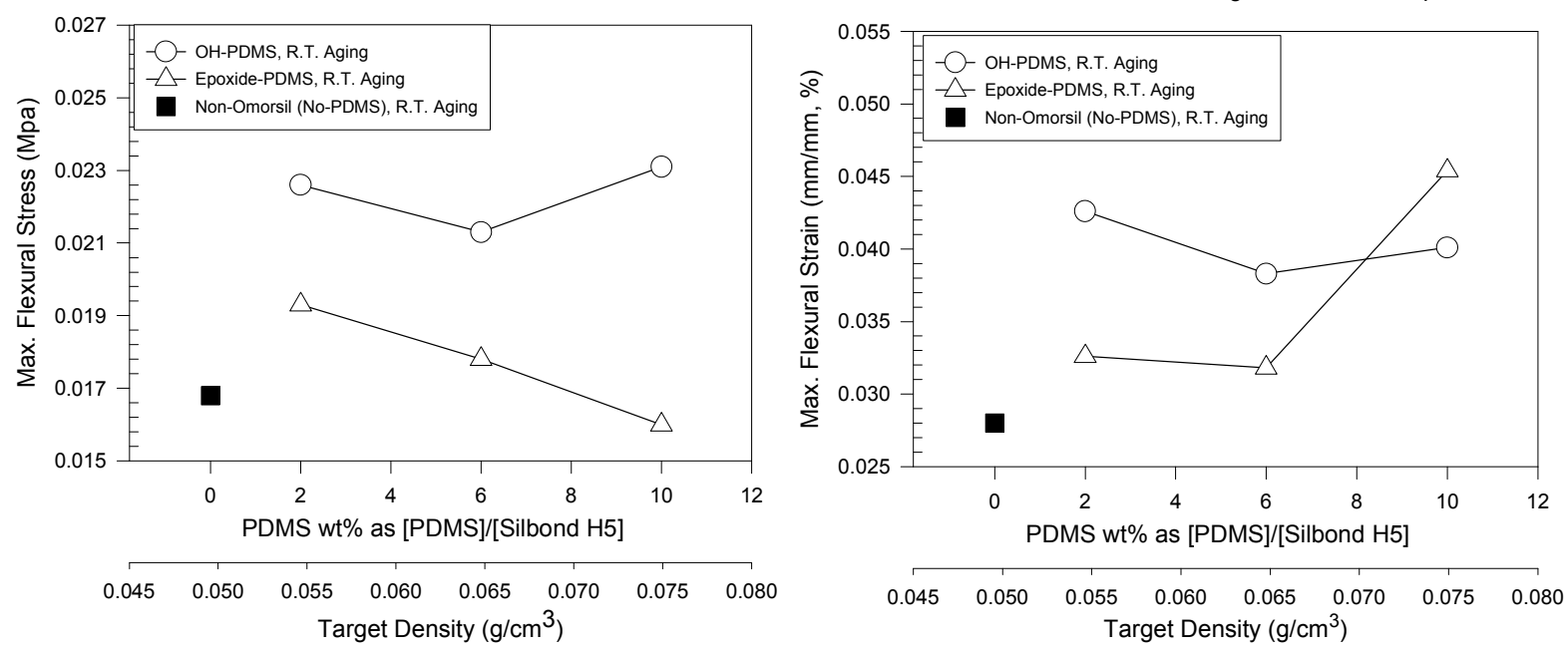

Figure 25. The effect of PDMS content and target density on the maximum flexural strength (left) and strain (right) at break.

\subsection{Pure Silica Precursors For High Transparency Aerogels}

\subsubsection{Silica aerogels prepared from TMOS}

Formulation work was conducted to find a reproducible, well-controlled route to highly transparent silica aerogel monolith materials. Previously, we concentrated on preparing aerogels using a relatively low-cost precursor for window applications that require a high R- value, mechanical properties that meet the contract goals (2-5\% resiliency,) and good transparency.

The yield of high transparency materials was unacceptably low for a commercial production application, due to complex variable dependence on processing and environmental factors that are difficult to control. We sought an approach that would give us highly transparent materials on a routine basis. We settled on utilizing silica prepared via hydrolysis of tetramethoxysilane, TMOS. Although the material is toxic in its purified state, and therefore expensive to produce and ship, the silica gel structures formed via TMOS hydrolysis in the presence of water and methanol have smaller pores versus TEOS precursors. These materials also have a narrow pore size distribution, and lack the larger particles or pores that cause Rayleigh scattering (blue haze appearance). The balanced chemical equation for the formation of a silica gel from TMOS is:

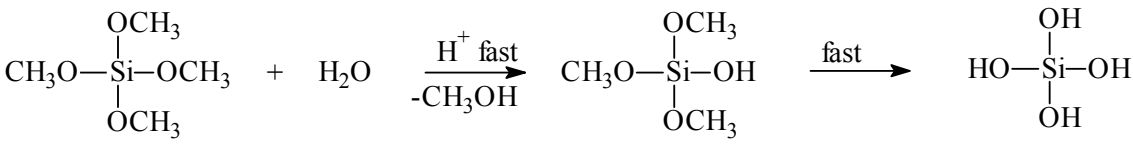

$$
\begin{aligned}
& -\mathrm{H}_{2} \mathrm{O} \downarrow \text { slow } \quad-\mathrm{H}_{2} \mathrm{O} \downarrow \text { slow } \\
& \begin{array}{cccc}
\mathrm{OCH}_{3} & \mathrm{OCH}_{3} & \mathrm{OH} & \mathrm{OH} \\
\text { I } & \text { I } & \text { I } \\
\mathrm{CH}_{3} \mathrm{O}-\mathrm{Si}-\mathrm{O}-\mathrm{Si}-\mathrm{OCH}_{3} & \mathrm{HO}-\mathrm{Si}-\mathrm{O}-\mathrm{Si}-\mathrm{OH} \\
\text { ! } & \text { I } & \text { I } & \text { I } \\
\mathrm{OCH}_{3} & \mathrm{OCH}_{3} & \mathrm{OH} & \mathrm{OH}
\end{array}
\end{aligned}
$$


In order to find the ideal set of conditions for high transparency and suitably rapid production capability (relatively short gel times, short aging times, short drying times), different precursors were formulated or mixed according to previously derived relationships. Results of the trials described are shown in Table 13 and Table 14. The results indicate that TMOS produces the most transparent aerogels.

Table 13. Effect of precursor types on relative transparency and density of silica aerogels.

\begin{tabular}{|l|c|c|c|c|c|}
\hline $\begin{array}{l}\text { Sample } \\
\text { ID }\end{array}$ & Precursors & $\begin{array}{c}\text { date of preparation } \\
\text { report }\end{array}$ & cracks & $\begin{array}{c}\text { apparent } \\
\text { density }\left(\mathrm{g} / \mathrm{cm}^{3}\right)\end{array}$ & $\mathrm{TR}^{\mathrm{a}}$ \\
\hline TM4-6/20 & TMOS & $6-24$ & $\mathrm{X}$ & 0.08 & 1 \\
\hline T37-5/22 & $\begin{array}{c}\text { Hydrophobic } \\
\text { precursor- } \\
\text { hydrolyzed } \\
\text { TEOS }\end{array}$ & $5-27$ & $\mathrm{X}$ & 0.09 & 3 \\
\hline T35-4/30 & $\begin{array}{c}\text { TEOS- } \\
\text { Hydrophobic } \\
\text { precursor }\end{array}$ & $5-6$ & $\mathrm{X}$ & 0.1 & 2 \\
\hline
\end{tabular}

a : Relative degree of transparency in samples listed ; $1>2>3$

TMOS was mixed with methanol, and water was added to the mixture. The mixture was stirred for more than an hour to obtain a homogeneous solution. Most of the solutions prepared gelled within 1.5 hours, and they were catalyzed by ammonia or ammonia/ammonia fluoride. The gels were aged in ethanol/ammonia and in ethanol approximately 14 hours. Samples were loaded into the autoclave with a certain amount of ethanol so that the diffusion rate between liquid $\mathrm{CO}_{2}$ and alcohol in the wet gels can be controlled properly. Ethanol was used to see the effects of solvent type on transparency of gel and different types of samples were prepared from hydrolyzed precursors and TEOS to make a comparison. The results are listed in Table 14, which shows that the most transparent sample was prepared using a basic catalyst.

Table 14. Synthetic conditions and relative transparency of TMOS aerogels.

\begin{tabular}{|c|c|c|c|c|c|c|}
\hline \multirow[b]{2}{*}{ Sample ID } & \multicolumn{5}{|c|}{ Molar ratio of reactants (BASIS : 1mol TMOS) } & \multirow{2}{*}{$\begin{array}{l}\text { Relative transparency } \\
\text { after supercritical } \\
\text { drying process }^{\mathrm{a}}\end{array}$} \\
\hline & $\mathrm{MeOH}$ & $\mathrm{EtOH}$ & $\mathrm{H}_{2} \mathrm{O}$ & $\begin{array}{c}\text { Basic } \\
\text { Solution }\end{array}$ & $\mathrm{NH}_{4} \mathrm{~F}$ & \\
\hline TM1 & 12.27 & - & 8.63 & 0.03 & 0.06 & 4 \\
\hline TM2 & - & 8.53 & 8.63 & 0.06 & - & 4 \\
\hline TM3 & 12.27 & - & 2.17 & 0.06 & - & 2 \\
\hline TM4 & 18.40 & - & 8.63 & 0.06 & - & 1 \\
\hline TM5 & 12.27 & - & 8.63 & 0.03 & 0.03 & 3 \\
\hline TM4-0.08 & 10.66 & - & 8.63 & 0.06 & - & \\
\hline TM4-0.1 & 6.09 & - & 8.63 & 0.06 & - & \\
\hline
\end{tabular}

a : Relative degree of transparency in samples listed / 1: the best, $4:$ the worst

As shown in Figure 26 and Figure 27, we have demonstrated high transparency, a small shrinkage factor, and excellent thermal conductivity properties. A wide range of densities and solvent compositions were used and compared with samples similarly prepared with TEOS precursor. The better transparency of samples made with TMOS may be associated with its 
higher reactivity and the resultant pore structure. Because the initial casting molds were of the same size, the amount of shrinkage observed for samples prepared with TMOS can be easily compared with samples prepared from TEOS precursor (samples on the left of Figure 26). The most important observation was that the transparency of samples prepared with TMOS was not as sensitive to the target density (i.e, solid content), which was a critical problem observed for the TEOS system. As a result, aerogel panels prepared with TMOS could possibly yield improved mechanical strength and thermal conductivity without sacrificing transparency.
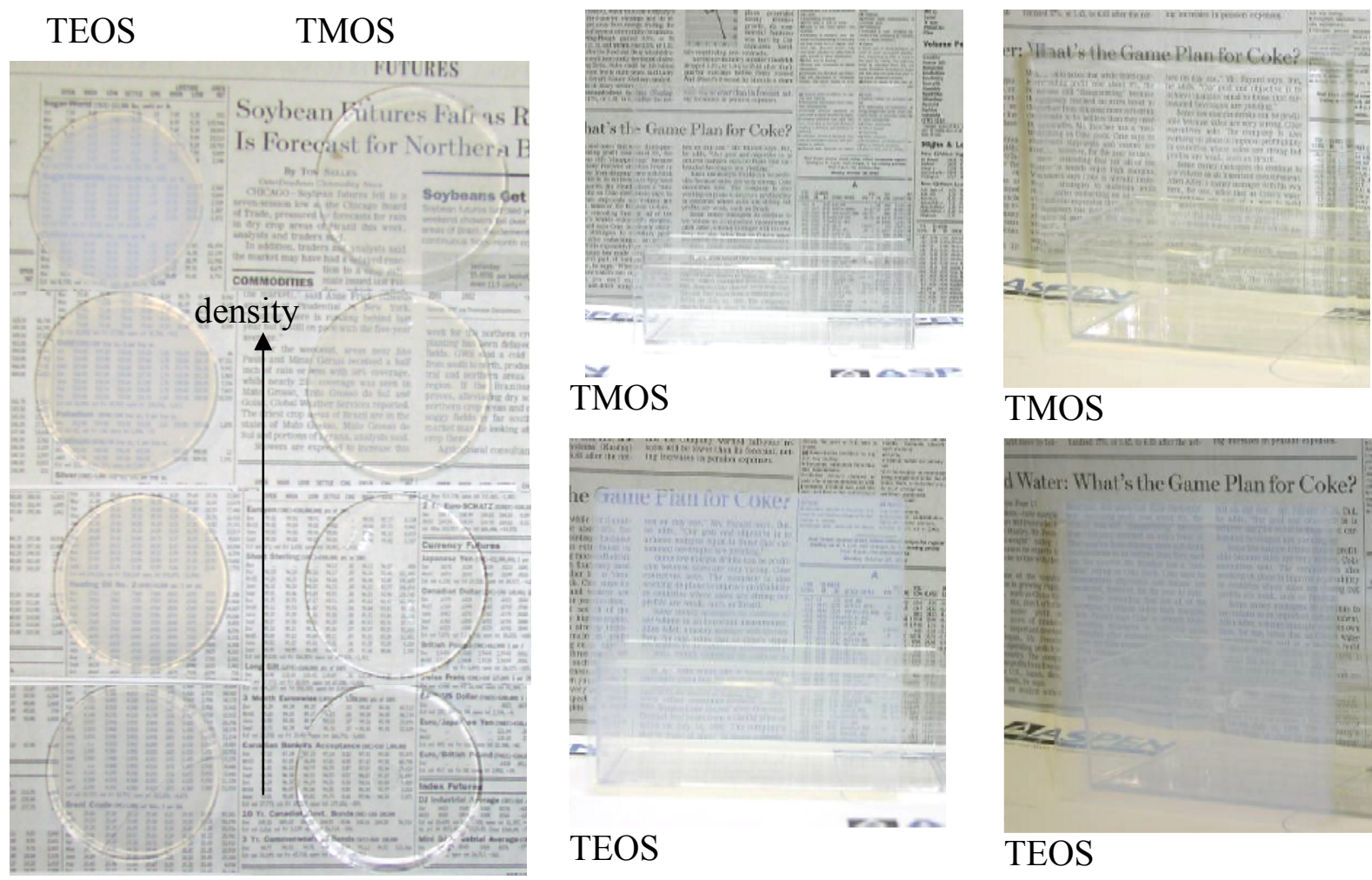

TMOS
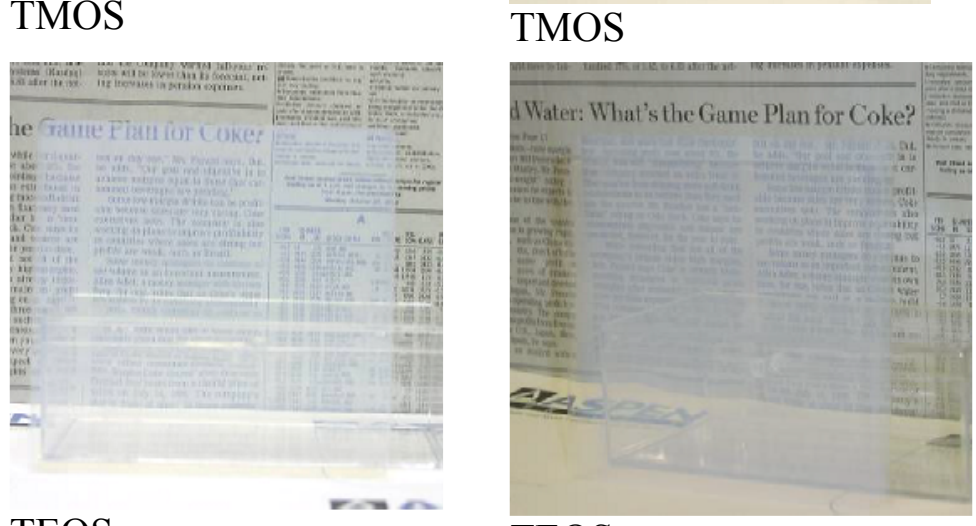

TEOS

TEOS

Figure 26. Comparison of transparency between TMOS (Tetramethoxysilane) and TEOS (polyethylsilicate) as function of target density.
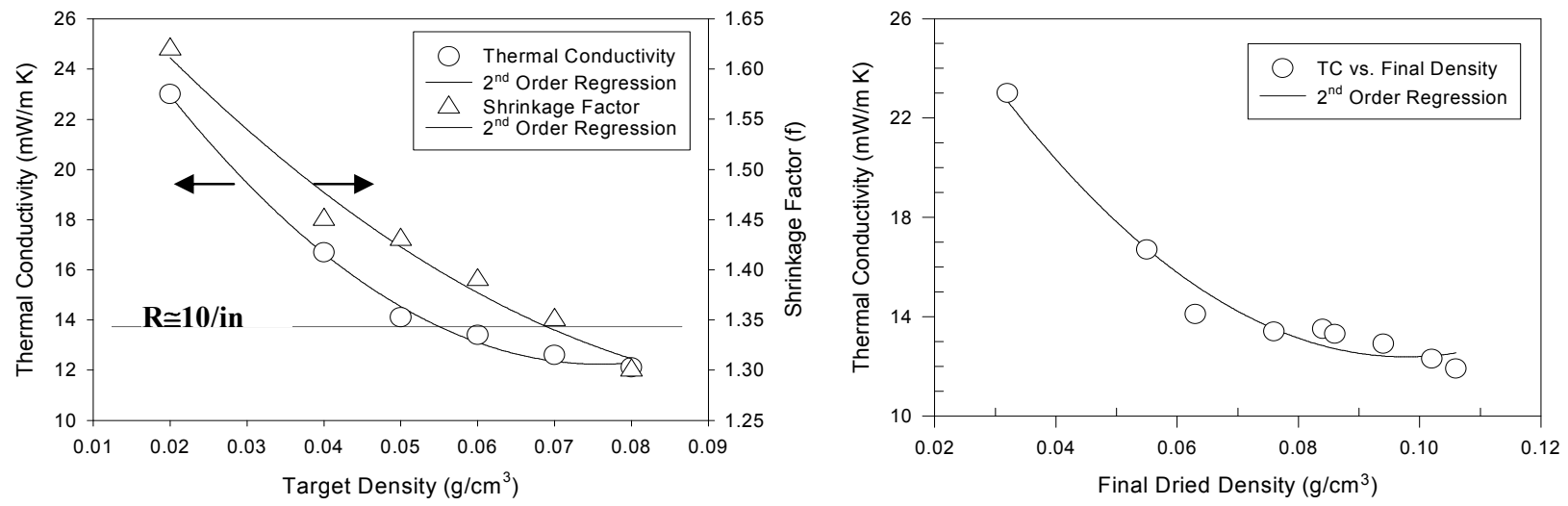

Figure 27. Thermal conductivity and shrinkage of aerogel monoliths prepared with TMOS silica precursor in terms of target density (left) and final density (right). 


\subsubsection{Cost Reduction: TMOS Derivatives and the Direct Process}

TMOS can be produced in high yield under mild conditions by the reaction of methanol and silicon metal. This process is known as the "Direct Process", distinguishing it from step-wise reaction sequences featuring reactions of chlorosilanes with alcohols in the presence of a base. Montle et al. (US Patent 4,323,690) described the use of alkali metal carboxylate salts to catalyze the reaction between silicon and methanol at $150-190 \mathrm{psi}$ and $160-200{ }^{\circ} \mathrm{C}$ giving a yield greater than $90 \%$ TMOS. This patent was issued in 1982 and is no longer protected. Because Aspen Aerogels specializes in high-pressure chemistry, it makes sense for us to make our own TMOS precursor using the direct process and to convert it to a methanol-containing silica sol right from the reactor (simply by adding water). The advantages of using methanol are obvious (see Figure 22); the pore morphology in the TMOS related system is superior for transparency. From that point, our standard strengthening and hydrophobicity surface treatments are implemented without any sacrifice of transparency. A "vertical" process would involve Aspen scaling up the direct synthesis of TMOS and using a water rinse/filtration method to generate our gel precursor directly. From that point in the process, all other steps are identical to what we have already demonstrated.

\subsection{Silica/POE hybrid development using TMOS}

\subsubsection{Introduction}

Although silica aerogels have many excellent properties such as ultra-low density, high surface area and very good dielectric, thermal and acoustic properties, their commercialization has so far been limited because of their low strength, brittleness and high cost. ${ }^{18}$ There have been numerous efforts devoted to overcoming the weakness and brittleness of silica aerogels. Development of the flexible-fiber reinforced silica aerogel composite blankets by Aspen Aerogels is one of most promising approaches. The practicality of the flexible aerogel composite blankets overcomes the low-strength and brittleness limitations inherent in monolithic silica aerogel materials, making them ideal candidate insulations for thermal systems at low and high temperature, or cryogenic pipe insulation. ${ }^{19}$ It is inherently impossible to produce transparent aerogel composites, due to the presence of macro-scale phase separation in these materials. Different reinforcement methods are needed to produce stronger transparent aerogel monoliths for insulating double-glazed windows. In the past two decades, many investigators have attempted to improve the mechanical properties of silica in order to reduce its tendency to crack during the formation of monolithic aerogels by incorporating a nano-reinforcement component into the silica matrix. ${ }^{20}$ These efforts led to the preparation of organically modified silica aerogel (Aerormosils), ${ }^{6}$ a completely new category of aerogel based materials.

Improvements in compressive strength and toughness, optical transparency, and hydrophobicity have been reported by Novak for a silica aerogel/polyvinylpyridine composite. ${ }^{15}$ Linear polymers, such as PDMS, have been frequently used to increase the flexible properties of the silica xerogels. Mackenzie's group ${ }^{6-10}$ claimed to produce a rubbery aerogel with $30 \%$ recovery of compressive strain from a PDMS/silica hybrid material, yet no one has reported a similar material in the past 7 years despite frequent citation of this work.

One possible explanation for lack of reproducibility is that it is difficult to fully incorporate the PDMS chains into the siloxane network. It was observed previously that the reaction between monosilanol and alkoxysilyl groups was less straightforward, when bulky functional groups such 
as butyl are attached to the silanol. The polymeric PDMS may somehow prevent the condensation of its hydroxysilyl end groups into the silica network due to steric hindrance. When large portions of the PDMS chains were not attached to the silicate network structure at both ends, there was little improvement in the flexibility and rubbery property of the resulting aerogels. The main visual observation was the reduction in transparency in PDMS/silica hybrid aerogels caused by the presence of large PDMS domains. The unattached PDMS chains usually are washed out during supercritical extraction. The polymer leach-out phenomena was also observed by Novak in poly(vinylpyridine)/silica aerogel. ${ }^{15}$ In order to avoid these problems and achieve significant improvement in the mechanical properties of the Ormosil aerogel, the polymeric functional groups need to be chemically bonded into the silica network. ${ }^{21}$

Schubert et al. successfully incorporated organic groups into the silica aerogel network by cocondensing $\mathrm{Si}(\mathrm{OR})_{4}$ with $\mathrm{RSi}(\mathrm{OR})_{3} .{ }^{22}$ Loy et al. have formed novel aerormosil materials by inserting organic bridges into the silicate network, through the hydrolysis-condensation of trialkoxylsilyl-terminated organic molecules such as p-triethoxylsilylbenzne. ${ }^{23}$ Due to higher functionality (i.e., 3 in triethoxysilyl vs. 1 in silanol), all of the organic functional groups were attached to the silica network by C-Si covalent bonds in both cases, which was proven by ${ }^{29} \mathrm{Si}$ solid-state NMR results. The leaching out of organic ingredients can be prevented completely by using this approach. Aspen Aerogels has successfully incorporated linear polymers as a nanoreinforcement into the silica network of aerogels based on this approach. The polymer chains were also bonded into the silica network by C-Si linkage in this type of aerogel.

Amine terminated polyether (polyoxyethylene) ("POE") linear polymers were used as the nanoreinforcement component, due to their low cost and commercial availability. The general formula of the POE diamine used for this study is represented by the structure in Scheme 1. Various values for the number-average molecular weight of the oligomer are available.<smiles>CC(CCN)OCCCC(C)OCCN</smiles>

Scheme 1

New compounds with terminal triethoxylsilyl groups can be readily grafted onto the amine end groups of the polyoxyethylene chains by reacting them with 3-isocyanatopropyl-triethoxysilane, to form a ureasil. ${ }^{24}$

The completion of this reaction can be monitored by IR spectroscopy. We observed that the strong and narrow band at $2274 \mathrm{~cm}^{-1}$ assigned to the vibration of isocyanate group of the 3 isocyanatopropyltriethoxysilane disappears upon completion of the reaction as shown by the IR spectra in Figure 28. 

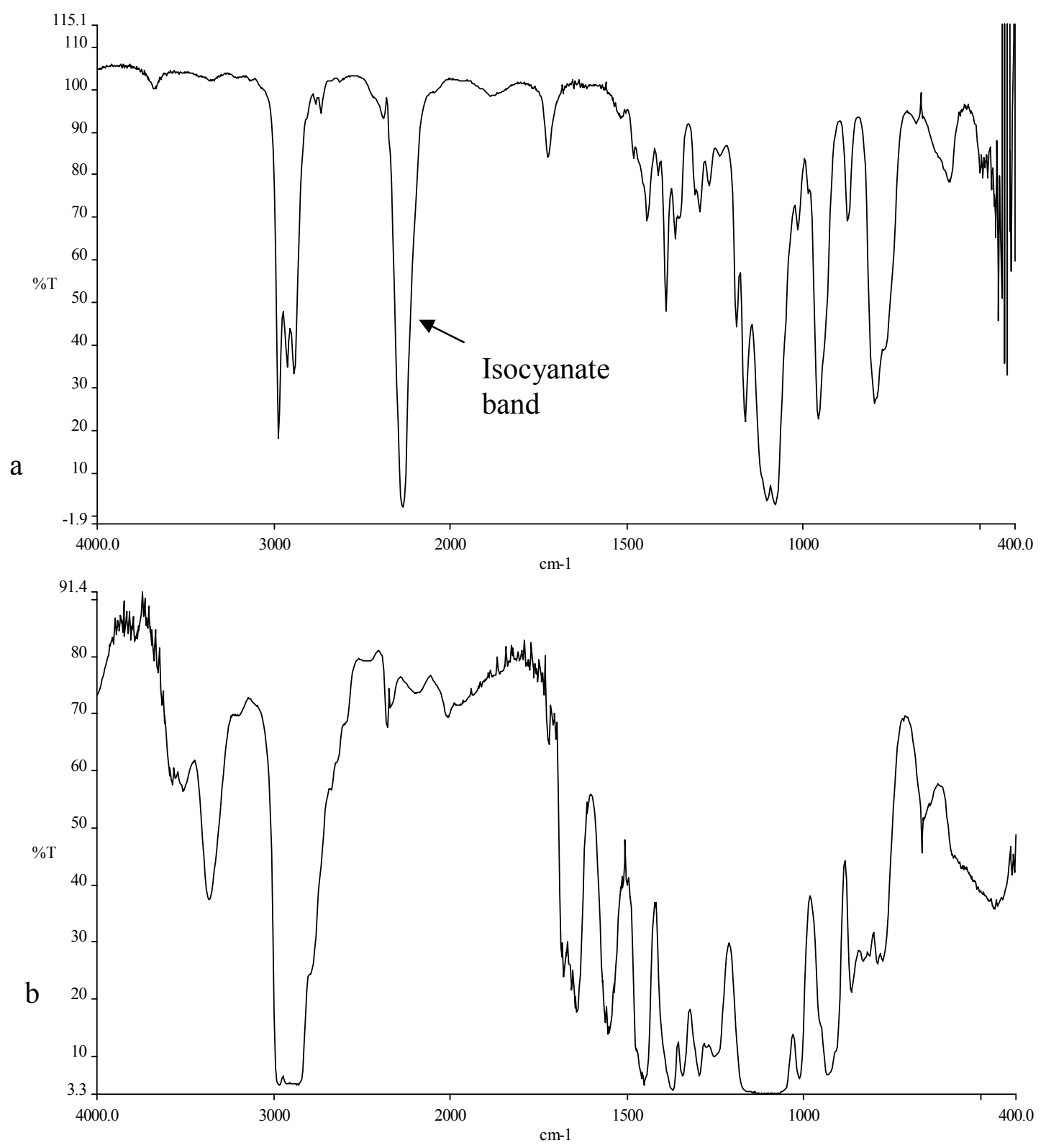

Figure 28. IR spectra of a) 3-isocyanatopropyl-triethoxysilane and b) product obtained with POE.

These triethoxysilyl terminated POEs were co-condensed with tetramethoxysilane following a procedure similar to the preparation of Schubert's Ormosil aerogel. ${ }^{22}$ A simplified reaction scheme for the sol-gel process is outlined as the follow:

Hydrolysis:

$$
\mathrm{Si}(\mathrm{OR})_{4}+4 \mathrm{H}_{2} \mathrm{O} \longrightarrow \mathrm{Si}(\mathrm{OH})_{4}+4 \mathrm{ROH}
$$

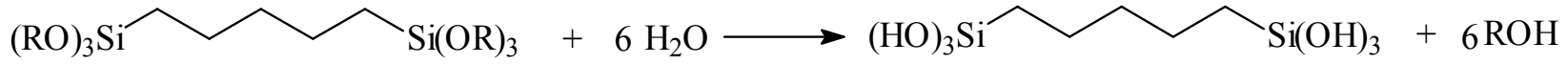


Polycondensation:

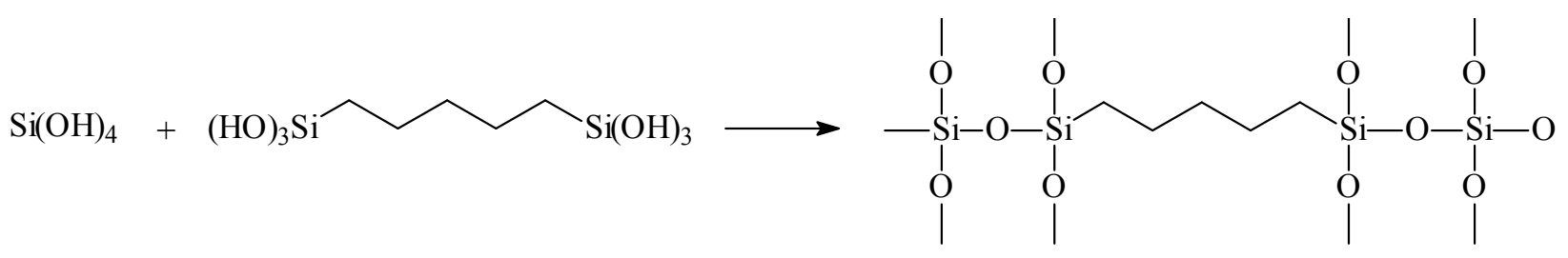

Although, only the di-triethoxysilyl terminated POEs are shown in the above scheme, the reaction for the tri-triethoxysilyl terminated POE were expected to follow the same scheme. Basically, this is very similar to that shown in textbooks for the pure sol-gel systems except that two species are present in the current systems. Both of these species, tetra-alkoxysilane precursor, and the trialkoxysilyl terminated linear polymer, can undergo hydrolysis and form hydroxides. Then in the second step, these hydroxides can co-condense to form a network structure. The flexible linear polymeric chain is thus covalently bonded into the rigid silica network as the result of this reaction. The introduction of a polymeric phase will not lead to phase separation in the resulting Ormosil gel. Unlike most of the Ormosil material, this Ormosil gel with a low polymer content $(<20 \%)$ will remain optically transparent after $\mathrm{CO}_{2}$ supercritical extraction. The improved flexibility of this family of Ormosil gels will improve the handleability of their monoliths during the preparation process, and reduce the tendency of cracking during $\mathrm{CO}_{2}$ extraction.

\subsubsection{Formulation studies.}

\subsubsection{Effect of molecular weight}

A series of POE/silica hybrid aerogels were prepared using different molecular weight oligomers, in order to identify the most suitable linear polymer size and functionality to incorporate into the silica network. To determine the effect of the polymer's molecular weight, the target density was fixed at $0.075 \mathrm{~g} / \mathrm{cm}^{3}$ and polymer loadings were fixed at $10 \mathrm{wt} \%$. The characterization results are summarized in Table 15.

Thermal conductivities of this series of hybrid aerogels were in the range between 11.8 and 13.1 $\mathrm{mW} / \mathrm{m}-\mathrm{K}$. The aerogel prepared using a Mn of 12000 gave a higher TC because it contained defects. The molecular weight of POE did not appear to affect the thermal conductivities of the resulting hybrid aerogel monolith. The hybrid gel prepared with lower molecular weight POE $(<1000)$ shrank more during aging than those prepared with the higher molecular weight POEs $(>2000)$. The hybrid aerogels containing higher molecular weight POE gave higher flexural strain and lower flexural strength at the point of rupture. The POE silica hybrid aerogel containing $10 \%$ of the $12000 \mathrm{~g} / \mathrm{mole}$ POE was the most flexible and had the highest flexural strain $(16.2 \%)$ prior to the breaking point, as shown in Figure 29 Figure 30. POE of Mn 2000 and 4000 were selected for further studies based on their overall performance and their cost. 


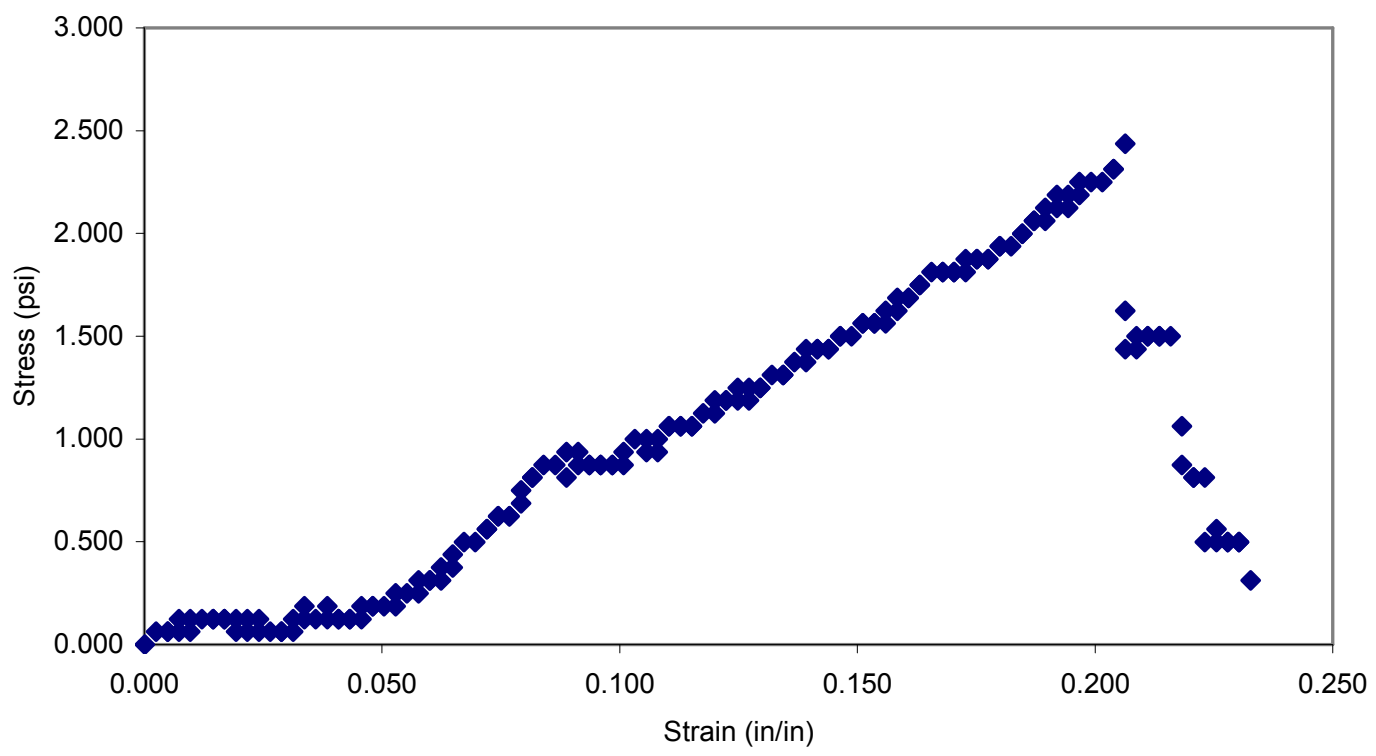

Figure 29. Stress-strain curve for $10 \mathrm{wt} \%$ POE with Mn 12000 in POE/silica aerogel $\left(\rho_{\text {actual }}=\mathbf{0 . 0 9}\right)$ (three-point bending test).

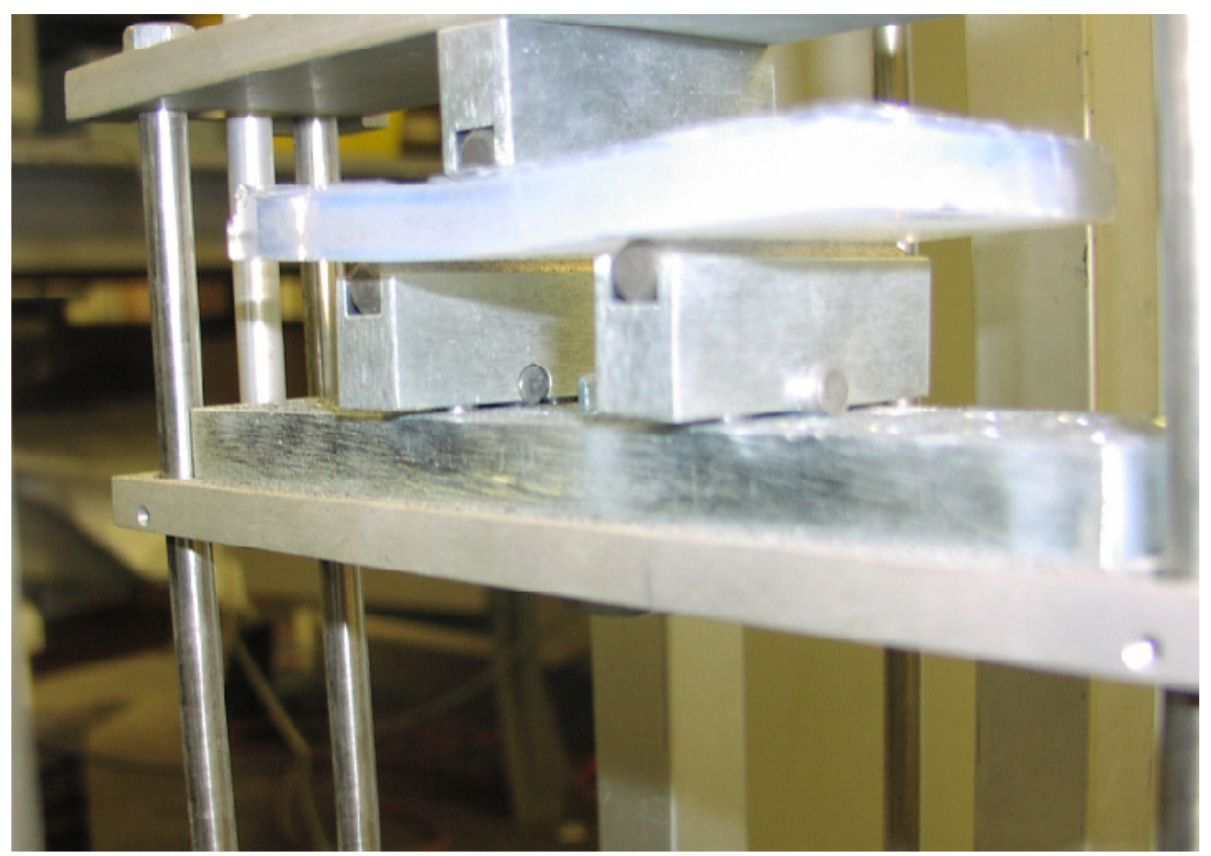

Figure 30. Three point bending test of POE/silica aerogel monolith.

The transparency of Mn $2000 \mathrm{POE} /$ silica hybrid aerogel monolith decreased when the polymer loading reached $15 \mathrm{wt} \%$. A $10 \mathrm{wt} \%$ loading of $\mathrm{Mn} 2000$ gave the best overall performance in this series. 
Table 15. Effect of POE molecular weight (Loading $10 \mathrm{wt} \%$ ) on hybrid aerogel properties with target density $=0.075 \mathrm{~g} / \mathrm{cc}$.

\begin{tabular}{|c|c|c|c|c|}
\hline POE Mn & $\begin{array}{c}\boldsymbol{\rho}_{\text {Final }} \\
\left(\mathbf{g} / \mathbf{c m}^{\mathbf{3}}\right)\end{array}$ & $\begin{array}{c}\text { TC } \\
(\mathbf{m W} / \mathbf{m}-\mathbf{K})\end{array}$ & $\begin{array}{c}\text { Flexural strain at } \\
\text { rupture (\%) }\end{array}$ & $\begin{array}{c}\text { Flexural stress at } \\
\text { rupture (psi) }\end{array}$ \\
\hline 600 & 0.11 & 11.8 & 3.2 & 7.2 \\
\hline 2000 & 0.10 & 13.1 & 4.3 & 8.1 \\
\hline 4000 & 0.10 & 12.9 & 8.4 & 6.3 \\
\hline 12000 & 0.09 & 14.0 & 16.2 & 3.9 \\
\hline $3000^{*}$ & 0.10 & 11.8 & 3.4 & 5.2 \\
\hline $5000^{*}$ & 0.10 & 13.1 & 10.8 & 2.4 \\
\hline
\end{tabular}

*These have tri-functional amine end groups. All others are difunctional.

\subsubsection{Effect of the amount of polymer loading}

A series of $0.075 \mathrm{~g} / \mathrm{cm}^{3}$ target density, Mn $2000 \mathrm{POE} /$ silica hybrid aerogels with different amounts of polymer loading were prepared, and the characterization results are summarized in Table 16.

Table 16. Effect of polymer loading on properties of $0.075 \mathrm{~g} / \mathrm{cc} \mathrm{POE} / \mathrm{silica}$ hybrid aerogel $\left(M_{n}=2000\right)$.

\begin{tabular}{|c|c|c|c|c|}
\hline $\begin{array}{c}\text { Polymer } \\
\text { loading (wt\%) }\end{array}$ & $\begin{array}{c}\boldsymbol{\rho}_{\text {Final }} \\
\left(\mathbf{g} / \mathbf{c m}^{\mathbf{3}}\right)\end{array}$ & $\begin{array}{c}\text { TC (mW/m- } \\
\mathbf{K})\end{array}$ & $\begin{array}{c}\text { Flexural strain } \\
\text { at rupture (\%) }\end{array}$ & $\begin{array}{c}\text { Flexural stress at } \\
\text { rupture (psi) }\end{array}$ \\
\hline 5 & 0.11 & 13.3 & 3.0 & 6.2 \\
\hline 10 & 0.10 & 13.1 & 4.3 & 8.1 \\
\hline 15 & 0.10 & 14.5 & 7.0 & 2.0 \\
\hline 20 & 0.10 & 13.6 & $/$ & $/$ \\
\hline
\end{tabular}

Perfect monolithic hybrid aerogels using higher loadings of Mn 2000 (>15 wt\%) were difficult to prepare due to de-molding problem. These higher polymer-loading hybrid aerogels shrink very little in the wet gel stage. The transparency of Mn 2000/silica hybrid aerogel monolith appears to be reduced when polymer loading reaches $15 \mathrm{wt} \%$. Thermal conductivities of this series of hybrid aerogel were in the range between 13.0 and 14.5. The polymer loading did not affect thermal performance of this series of hybrid polymer. A $10 \mathrm{wt} \%$ loading of $\mathrm{Mn} 2000$ gives the best overall performance in this series.

\subsubsection{Effect of target density}

A series of Mn 2000 POE/silica hybrid aerogels with 10\% loading of Mn 2000 were prepared with several different target densities, and their physical characterization results are summarized in Table 17. 
Table 17. Effect of target density on properties of Mn $2000 \mathrm{POE} /$ silica hybrid aerogel (Loading 10 wt\%).

\begin{tabular}{|c|c|c|c|c|}
\hline $\begin{array}{c}\rho_{\text {target }} \\
\left(\mathrm{g} / \mathrm{cm}^{3}\right)\end{array}$ & $\begin{array}{c}\rho_{\text {Final }} \\
\left(\mathrm{g} / \mathrm{cm}^{3}\right)\end{array}$ & $\begin{array}{c}\text { TC } \\
(\mathrm{mW} / \mathrm{m}-\mathrm{K})\end{array}$ & $\begin{array}{c}\text { Flexural strain at } \\
\text { rupture (\%) }\end{array}$ & $\begin{array}{l}\text { Flexural stress at } \\
\text { rupture (psi) }\end{array}$ \\
\hline 0.05 & 0.07 & 13.4 & 10.6 & 2.7 \\
\hline 0.075 & 0.10 & 13.1 & 4.3 & 8.1 \\
\hline 0.10 & 0.13 & 13.1 & 8.0 & 4.1 \\
\hline 0.12 & 0.17 & 12.5 & 4.2 & 4.9 \\
\hline
\end{tabular}

Thermal conductivities of this series of hybrid aerogels were in the range between 12.5 and 13.4 $\mathrm{mW} / \mathrm{m}-\mathrm{K}$, and the shrinkage factors were between 1.3 and 1.4. The aerogel with a target-density of $0.12 \mathrm{~g} / \mathrm{cm}^{3}$ had slightly lower flexural strain and a higher flexural stress at rupture. The $\mathrm{Mn}$ $2000 \mathrm{POE} /$ silica hybrid aerogels prepared with 0.075 and $0.1 \mathrm{~g} / \mathrm{cm}^{3}$ target densities had a flexural stress and a flexural strain at rupture that seem anomalous and do not agree with the trend established by the other samples. We need to determine the mechanical properties of more than one sample per target density to determine the properties of these aerogels.

A series of Mn $4000 \mathrm{POE} /$ silica hybrid aerogels with $10 \mathrm{wt} \%$ loading of Mn 4000 were prepared with various target densities, and the results are summarized in Table 18.

Table 18. Effect of target density on properties of Mn $4000 \mathrm{POE} /$ silica hybrid aerogel (Loading 10 wt\%).

\begin{tabular}{|c|c|c|c|c|}
\hline $\begin{array}{c}\boldsymbol{\rho}_{\text {target }} \\
\left(\mathbf{g} / \mathbf{c m}^{3}\right)\end{array}$ & $\begin{array}{c}\boldsymbol{\rho}_{\text {Final }} \\
\left(\mathbf{g} / \mathbf{c m}^{3}\right)\end{array}$ & $\begin{array}{c}\mathbf{T C} \\
(\mathbf{m W} / \mathbf{m}- \\
\mathbf{K})\end{array}$ & $\begin{array}{c}\text { Flexural strain at } \\
\text { rupture (\%) }\end{array}$ & $\begin{array}{c}\text { Flexural stress at } \\
\text { rupture (psi) }\end{array}$ \\
\hline 0.05 & 0.07 & 13.4 & 10.6 & 2.7 \\
\hline 0.075 & 0.10 & 12.9 & 8.4 & 6.3 \\
\hline 0.10 & 0.13 & 13.7 & 10.0 & 5.5 \\
\hline 0.12 & 0.19 & 12.7 & 7.2 & 4.2 \\
\hline
\end{tabular}

Thermal conductivities of this series of hybrid aerogels were in the range between 12.7 and 13.7 $\mathrm{mW} / \mathrm{m}-\mathrm{K}$. The shrinkage factors of this series of aerogels were between 1.3 and 1.5 . Again, both 0.075 and $0.1 \mathrm{~g} / \mathrm{cm}^{3}$ target density samples gave the best overall performance in this series of Mn $4000 \mathrm{POE} /$ Silica hybrid aerogel.

\subsubsection{Optical characterization of silica/POE hybrid aerogels}

Considering the objective of the program, i.e. "aerogel insulated double glazed windows", we characterized aerogels by sending two samples to Optical Data Associates. This lab has a Cary 500E UV-VIS-NIR and a Nicolet 560 FTIR spectrometer, and both instruments were equipped with a Labsphere Spectralon integrating sphere. These instruments produce spectra of Normal/Hemispherical transmission (direct + diffuse). It is also possible to get the Total Diffuse transmission by eliminating the direct part of the transmitted radiation as shown in Figure 31. 

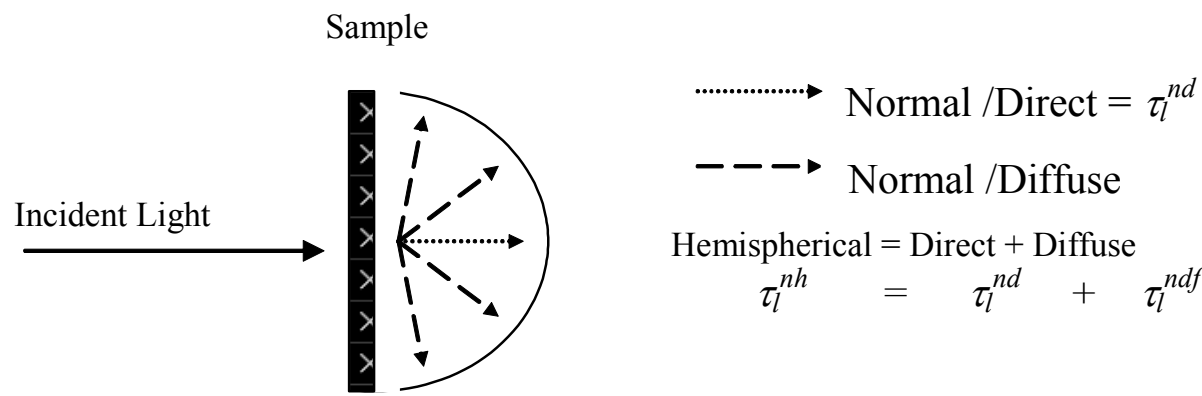

Hemispherical $=$ Direct + Diffuse

$$
\tau_{l}^{n h}=\tau_{l}^{n d}+\tau_{l}^{n d f}
$$

Figure 31. Different transmission spectral components collected by an integrating sphere.

We evaluated the transparency of the aerogel by determining the Direct-to-Hemispherical ratio, also called the "transparency ratio" $(T R)$. This parameter is defined in the visible range as:

$$
T R=\left[\left(\tau_{l}^{n h}-\tau_{l}^{n d f}\right) / \tau_{l}^{n h}\right] \times 100=\tau_{l}^{n d} / \tau_{l}^{n h} \times 100
$$

The transmittance quantities are values integrated over the range: $380-780 \mathrm{~nm}$. The higher the TR, the better is the transparency and clarity of the image seen through the aerogel. The TR values are between 0 and 1 and are expressed in percentage as listed in Table 19. The ratio does not take into account the influence of light absorption: it does not permit separation of the forward scattering contribution from the isotropic one. The values represent the influence of scattered light on the transparency, and they only represent the necessary conditions to be met in order to obtain good transparent aerogels.

Rayleigh scattering effects, which depend on the thickness of the sample, strongly affect the transparency of the aerogel. A simple method can be used to quantitatively measure the relative contributions of Rayleigh scattering for silica aerogel prepared with different recipes. The extinction coefficient, $E$, of an aerogel panel of known thickness is measured for the Normal/Direct transmittance $\tau_{l}^{\text {nd }}$ (often, calculated at $550 \mathrm{~nm}$ due to the maximum sensitivity of the eye in the visible range). The relationship of $E$ to the transparency is: the smaller the value of $\boldsymbol{E}$, the higher the clarity and transparency of the aerogel. The relation is given by:

$$
E=(-1 / d) * \ln \left(\tau_{l}^{n d}\right)
$$

Where:

$\tau_{l}^{n d}=$ Normal/Direct transmittance, and $d=$ sample thickness.

The results of the characterization are listed in Table 19.

Table 19. Optical properties of POE/aerogel composites.

\begin{tabular}{|c|c|c|c|c|c|c|}
\hline Sample ID & $\begin{array}{c}\boldsymbol{\rho}_{\text {Target }} \\
\left(\mathbf{g} / \mathbf{c m}^{\mathbf{3}}\right)\end{array}$ & $\begin{array}{c}\boldsymbol{\rho}_{\text {Final }} \\
\left(\mathbf{g} / \mathbf{c m}^{\mathbf{3}}\right)\end{array}$ & Hydrophobic & $\begin{array}{c}\text { Thickness } \\
(\mathbf{c m})\end{array}$ & TR (\%) & $\mathbf{E}\left(\mathbf{m}^{\mathbf{- 1}}\right)$ \\
\hline $\mathbf{2 0 0 0} \mathbf{1 0} \%$ & 0.05 & 0.08 & Yes & 1.065 & 74.7 & 31.5 \\
\hline $\mathbf{4 0 0 0} \mathbf{1 0} \%$ & 0.075 & 0.1 & Yes & 0.5 & 90.1 & 27.05 \\
\hline
\end{tabular}


Visually, the samples look transparent but sample 2000 is less transparent due to significant scattering (Total Diffuse) as indicated in Figure 32. TR is relatively low for this sample even if the Total Hemispherical signal is close to 1, as we can see in Figure 32. The low value of TR is due to the large difference between the Total Direct and the Total Hemispherical spectra. For sample $2(4000,10 \%)$, the transparency is much higher (Figure 33, TR $=90 \%$ ) with nonnegligible Rayleigh scattering since $E$ is quite high $\left(27 \mathrm{~m}^{-1}\right)$ if we compare it to the best sample made so far (TMOS aerogel, $E=5 \mathrm{~m}^{-1}$ ). Other factors such as state of the surface of the sample and cleanness of the aerogel strongly affect the optical properties of the material.

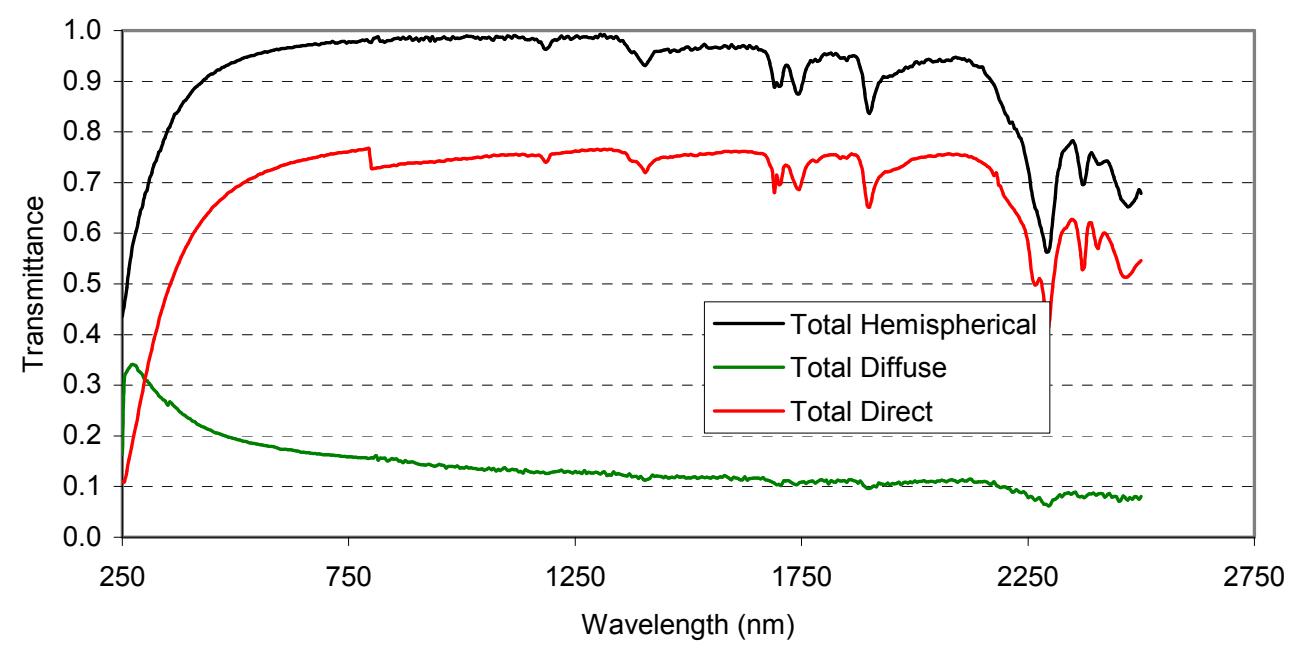

Figure 32. Transmittance spectra of POE/Silica hybrid prepared using Mn 2000, 10\% load, $1.065 \mathrm{~cm}$ thick, target density $=0.05 \mathrm{~g} / \mathrm{cc}$, and final density $=0.08 \mathrm{~g} / \mathrm{cc}$.

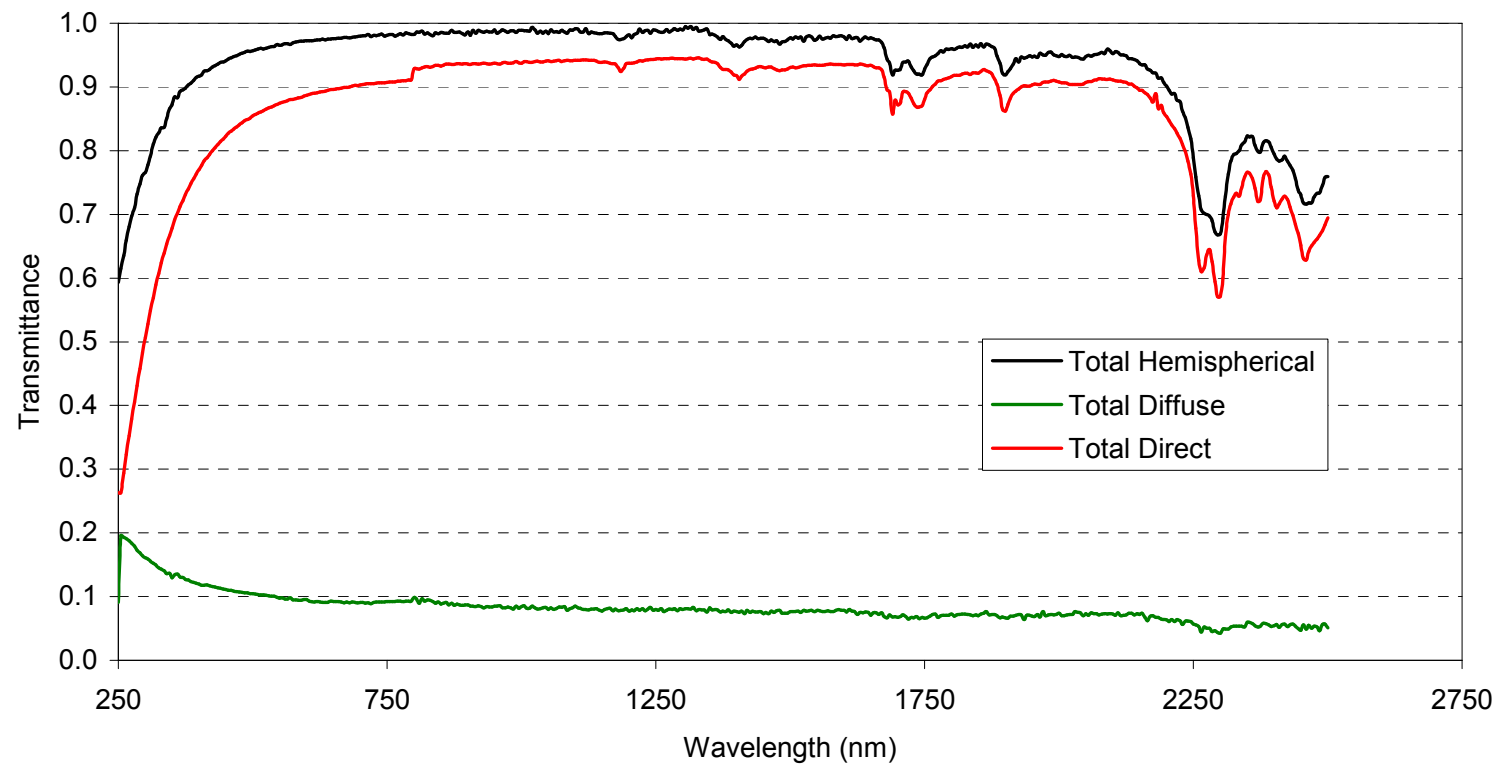

Figure 33. Transmittance spectra of POE/Silica hybrid aerogel using Mn 4000, 10\% load, $0.5 \mathrm{~cm}$ thick, target density $=0.075 \mathrm{~g} / \mathrm{cc}$, final density $=0.1 \mathrm{~g} / \mathrm{cc}$. 


\subsubsection{Selection of composition for scale-up}

The optical and thermal properties for the aerogel are very important characteristics, and the aerogel panels prepared in this effort were considered as candidate transparent insulation materials that will be inserted between two glass panes to make a super-insulating double-glazed windows.

Our main focus was to maximize the aerogels' transparency since this property is considered to be the most important in making a clear window. Secondly, the thermal resistance was investigated. For the aerogel panels, it was expected to be between 11 and $14 \mathrm{~mW} / \mathrm{m}-\mathrm{K}$. A low thermal conductivity will allow fabrication of insulated double glazed windows with a significant increase in their thermal resistance. The purpose in measuring the thermal conductivity is merely to check that the thermal conductivity remains in the range expected for aerogels.

A number of aerogel samples were investigated and reported. POE formulations were selected for scale up to produce large aerogel panels. Key parameters for the aerogels are listed in Table 20 .

Table 20. Key properties of aerogels made with Mn 4000 POE

\begin{tabular}{|c|c|c|c|c|c|c|}
\hline Type & $\begin{array}{c}\text { Density } \\
(\mathrm{g} / \mathrm{cc})\end{array}$ & $\begin{array}{c}\text { Thermal } \\
\text { Conductivity } \\
(\mathrm{mW} / \mathrm{m}-\mathrm{K})\end{array}$ & $\begin{array}{c}\text { Thickness } \\
(\mathrm{cm})\end{array}$ & $\begin{array}{c}\mathrm{TR}^{(\mathbf{1})} \\
(\%)\end{array}$ & $\mathrm{E}^{(\mathbf{2})}\left(\mathrm{m}^{-1}\right)$ & Hydrophobicity \\
\hline TMOS/POE & 0.09 & 12.6 & 0.5 & 90.1 & 27.05 & Yes \\
\hline
\end{tabular}

(1): $\mathrm{TR}=$ Transparency Ratio. The higher the TR, the better is the transparency of the aerogel.

(2): $\mathrm{E}=$ the extinction coefficient. The smaller the value of $\mathrm{E}$, the higher is the clarity of the image seen through the aerogel.

The value of the Transparency Ratio, TR, is a simple way of quantifying the scattering phenomenon. For the sake of comparison, ordinary float glass with a thickness of $4 \mathrm{~mm}$, has a TR value of about 0.99 , where the TR value for the investigated samples $(5-15 \mathrm{~mm}$ thick) were in the range of 0.85 to 0.90 . The thickness and the state of surface (flatness, cleanness, etc.) are very important aerogel properties and affect their optical properties, partly because of absorption and partly because of light scattering.

\subsection{Mold Design}

\subsubsection{Design for 12" $x$ 12" and 12" x 24" molds}

We designed and fabricated two types of larger molds for increasing the size of the aerogel panels. The target dimensions for the large aerogel panels were $60 \mathrm{~cm} \times 60 \mathrm{~cm} \times 1 \mathrm{~cm}$, but we tested our mold designs on smaller sizes. We made one new mold and made 12"x12"x0.5" gels as shown in Figure 34 Figure 35. These molds were easy to fabricate, and the top was open during gelation as illustrated in the diagrams in Figure 34. The precursor was poured into the mold and allowed to gel. After gelation, the bottom plate was removed and the top and bottom were fitted with perforated metal sheets that allowed access of aging fluids and $\mathrm{CO}_{2}$ during supercritical drying. Figure 35 shows the mold containing a gel being aged. This mold held the 
gel during all processing steps so that the gel never needed to be transferred or handled until it was completely dried.

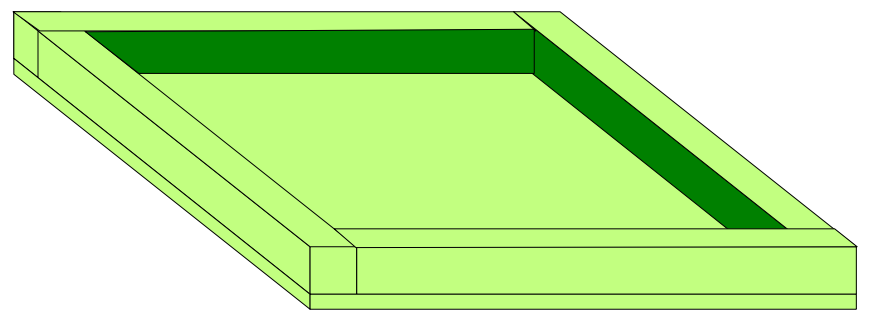
Mold made of Teflon coated aluminum: solid bottom sheet.

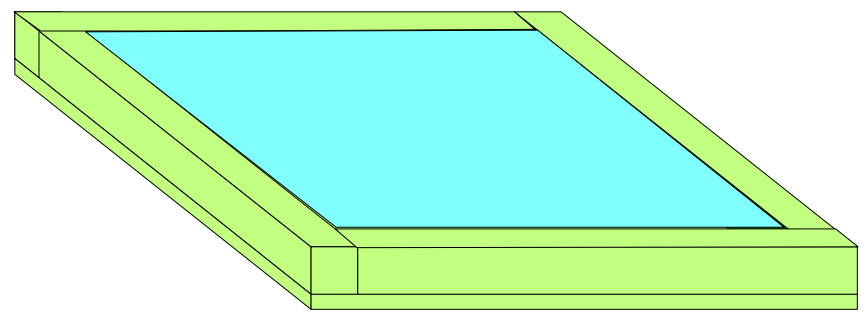

Hybrid precursors poured into mold and gelled.

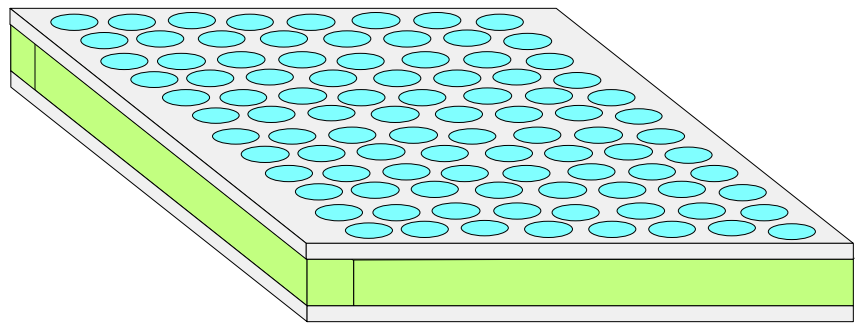

After gelation, the bottom plate was removed and the top and bottom were fitted with perforated metal sheets. The holes allowed facile access of solvents during aging and of $\mathrm{CO}_{2}$ during supercritical drying.

Figure 34. Schematic of Teflon coated aluminum molds.

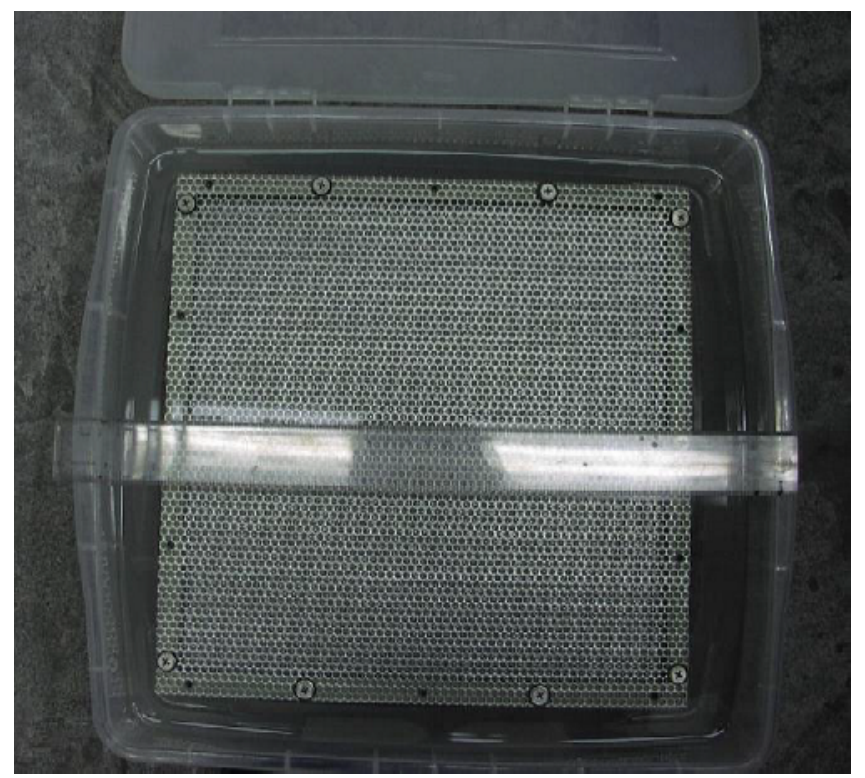

Figure 35. Aging of a 12"x 12" x 0.5" transparent aerogel in new mold. 
Another set of molds was designed and fabricated using Teflon coated aluminum (Figure 36). These molds were similar to the previous design, but a top plate was added and both the top and bottom surfaces were completely Teflon coated, which assured a much better quality surface (smoothness and adhesion-free) than obtained using the molds made with anodized aluminum. These molds were used as holders for the gel during aging and drying so that the gels did not need to be handled at any time during processing. Gelation occurred in the mold and later (after aging), the front and back plates were removed and replaced by perforated plates to hold and expose the gel's surface to the solvent for aging, and to $\mathrm{CO}_{2}$ for supercritical drying.
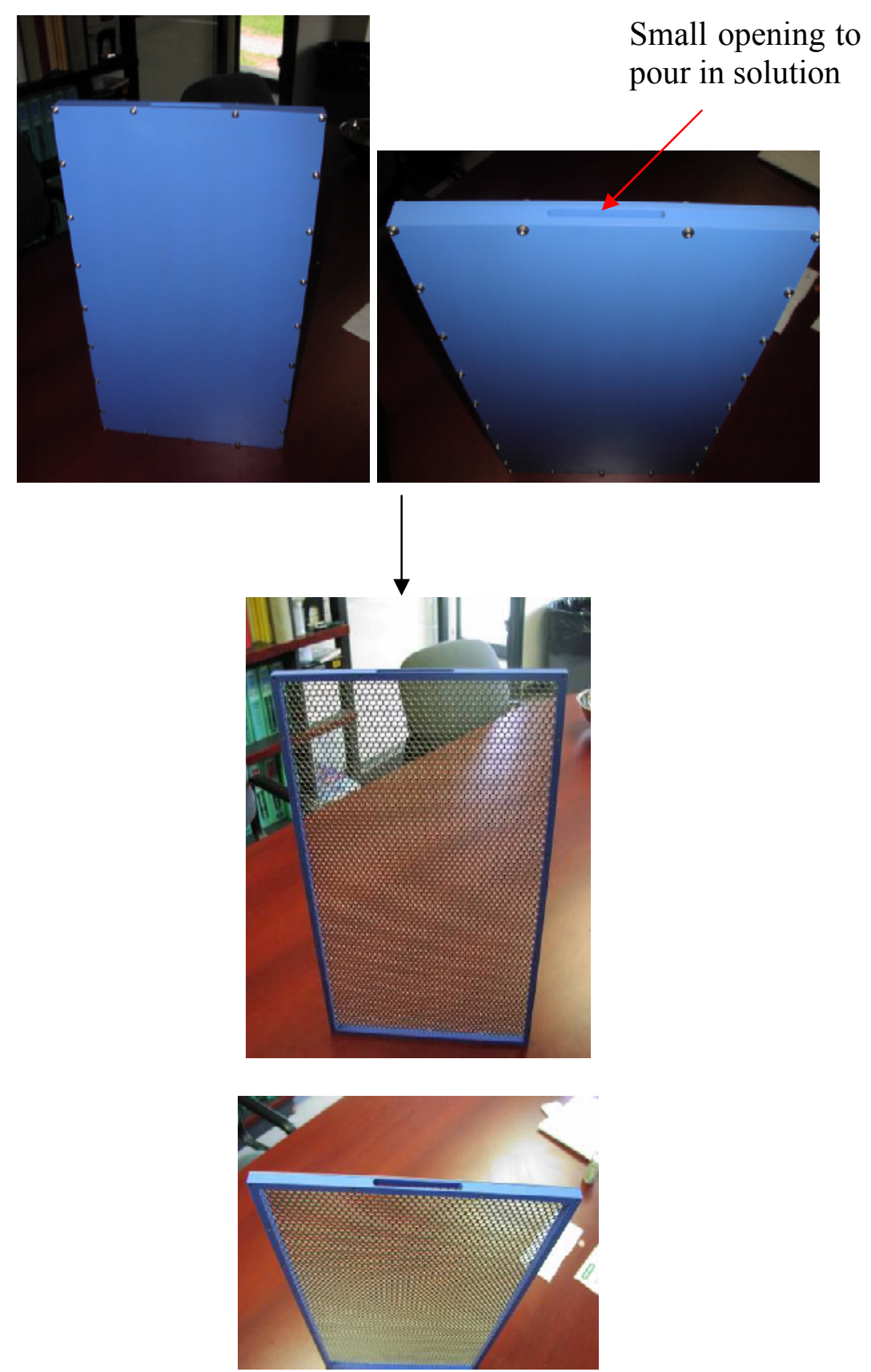

Figure 36. New 2'x 1' closed mold and perforated steel plates used to hold the gel. 


\subsubsection{Design of 2'x 2' molds}

Two Teflon coated aluminum molds ( 20 "x20"x5/8") were designed and fabricated. The molds were a little smaller than the desired $2 \mathrm{ft} \times 2 \mathrm{ft}$ because of the diameter constraint $(2 \mathrm{ft})$ of the $1000 \mathrm{~L}$ autoclave. To eliminate dust contamination and improve flatness of the aerogel surface we added an additional plate to the mold that was described in Figure 34. A schematic of the mold is shown in Figure 37. Two Teflon coated aluminum molds $(24 \times 24 \times 5 / 8$ in, and $20 \times 20$ $\mathrm{x} 5 / 8 \mathrm{in}$ ) identical in design to the 1 by $1 \mathrm{ft}$ mold have been made as shown in Figure 38 and were used to make 2'x 2' x 0.5 " aerogels.

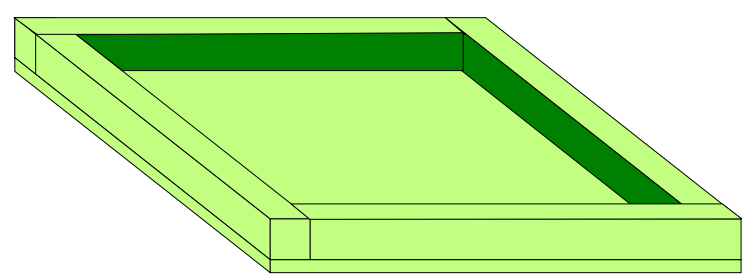

Mold made of Teflon coated aluminum. Solid bottom sheet.

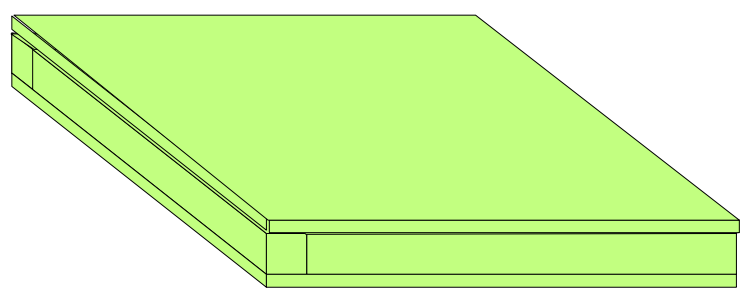

Top plate is placed on mold and the precursors allowed to gel.

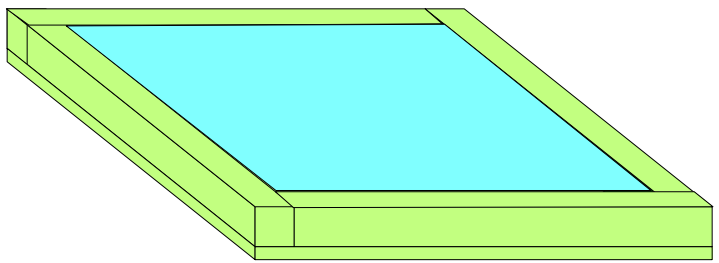

Hybrid precursors poured into mold.

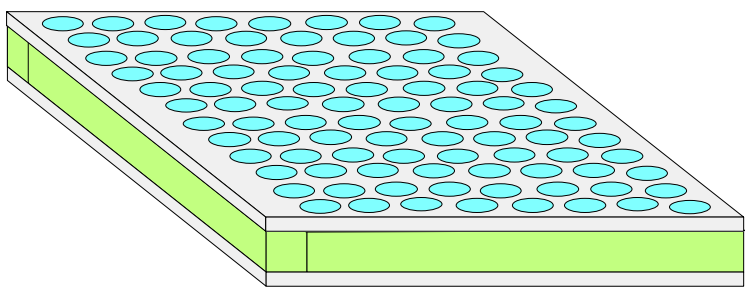

After gelation, the top and bottom plates are removed and the top and bottom are fitted with perforated metal sheets. The holes allow facile access of solvents during aging and of $\mathrm{CO}_{2}$ during supercritical drying.

\section{Figure 37. Schematic of Teflon coated aluminum molds.}

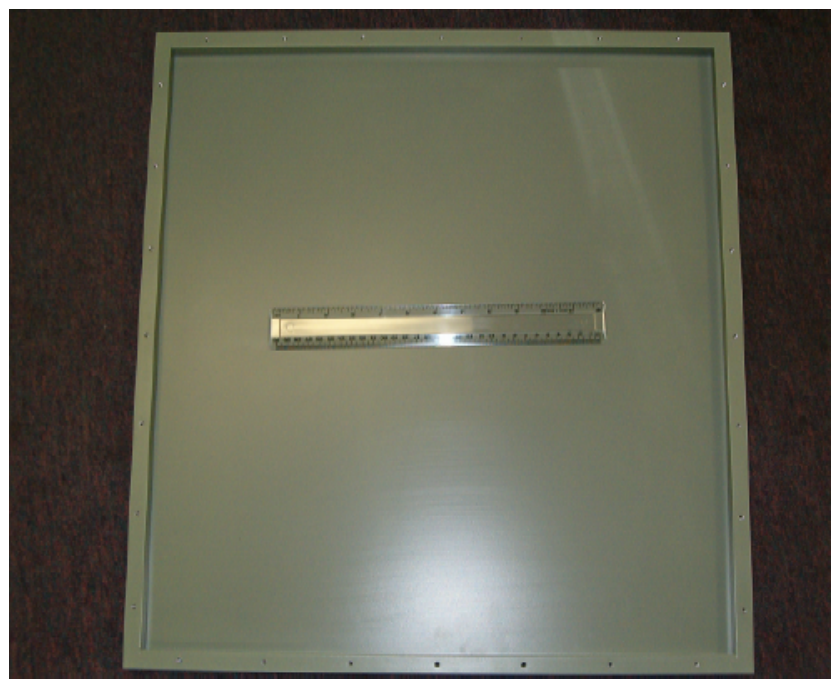

Figure 38. 2'x 2' mold. 


\subsection{Large panel preparation}

\subsubsection{Aerogel size scale-up in 60L autoclave.}

To develop the supercritical drying conditions, we produced larger pieces of transparent aerogel panels using polypropylene molds. Two recipes (10 weight percent loading of Mn 2000 and Mn 4000 POE, 0.075 target density) were selected for large panel preparation. Both formulations led to relatively strong aerogels, which were less likely to crack during the processing. Transparent monoliths with $10 \times 20 \times 1 \mathrm{~cm}$ and $15.5 \times 26 \times 1 \mathrm{~cm}$ dimensions were produced and are shown in Figure 39 and Figure 40. The aging conditions were 1 day in diluted ammonia/ethanol solution and 1 day in diluted hydrophobic agent solution. The total extraction time in the 60L extractor was under 9 hours, which is a relatively fast supercritical drying process.
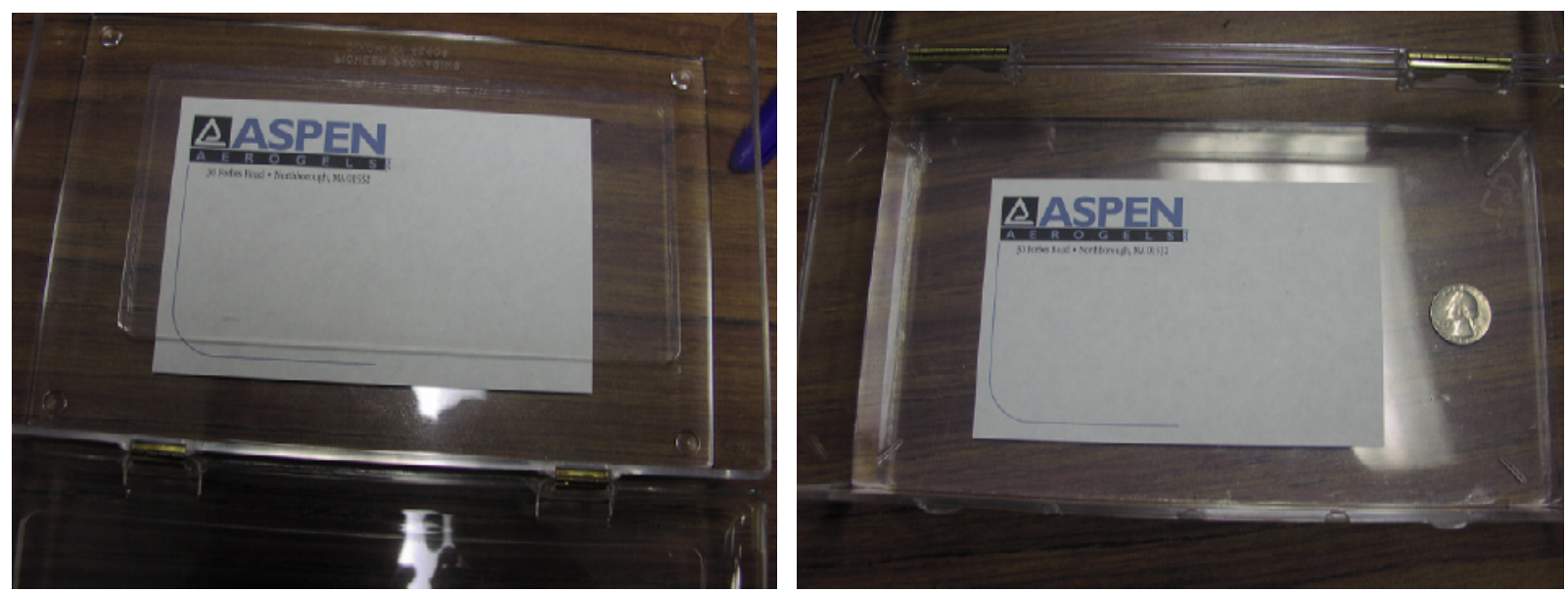

Figure 39. Large pieces of crack free Ormosil aerogel monolith with size of $10 \times 20 \times 1.1$ cm (left) and with size of $15.5 \times 26 \times 1 \mathrm{~cm}$ (right).

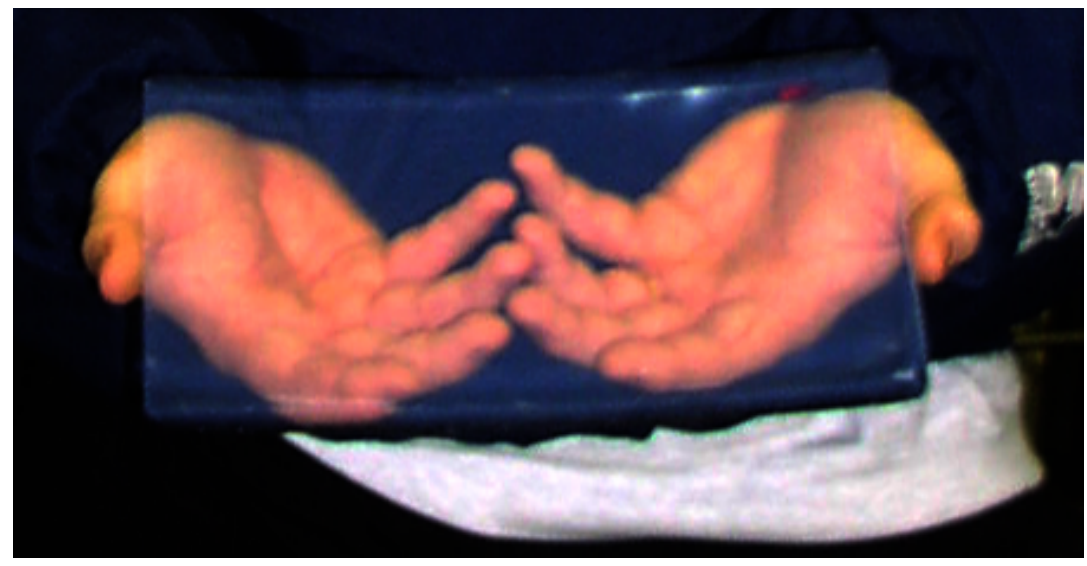

Figure 40. Panel of Ormosil POE/SiO 2 aerogel under flexural stresses.

\subsubsection{Aerogel size scale-up to 1'x1' panels in 120L autoclave}

A new closed mold (as shown in Figure 36, Figure 37, and Figure 38) having high quality surface smoothness (Teflon-coated) and a small opening on the topside to pour the solution into the mold was used to fabricate gels with perfectly flat and clean surfaces. The sol was prepared and poured into the mold and gelled (in situ). After the sol gelled, the system (mold + gel) was aged in ethanol/ammonia bath for a couple of hours at $55^{\circ} \mathrm{C}$ to allow the gel to shrink a little bit 
and allow removal of the side plates. The plates were replaced by perforated stainless steel plates (Figure 36). Perforated plates held the gel uniformly without exerting any pressure on the gel.

The mold design shown in Figure 36, Figure 37, and Figure 38 allowed us to cast and age the sol in either horizontal or vertical orientations. The advantage of horizontal casting is that this procedure was easy to operate and the samples were easy to de-mold. After removing the top plate of the mold, a stainless steel perforated plate was attached to the mold. After the mold was flipped over, the bottom plate was readily removed and replaced by the second perforated plate. This "gel+mold" remained intact during the hydrophobic agent treatment, aging, and rinsing steps. After aging, it was placed directly into the extractor for supercritical extraction. After many trials and intensive studies on the extraction process in the $120 \mathrm{~L}$ extractor, both Mn 2000 and Mn 4000 modified silica aerogel monoliths were successfully obtained as 1x1 ft panels, as shown in Figure 41, Figure 42, and Figure 43. After many attempts, we were able to make crack-free, transparent panels by adjusting and optimizing the drying procedures.

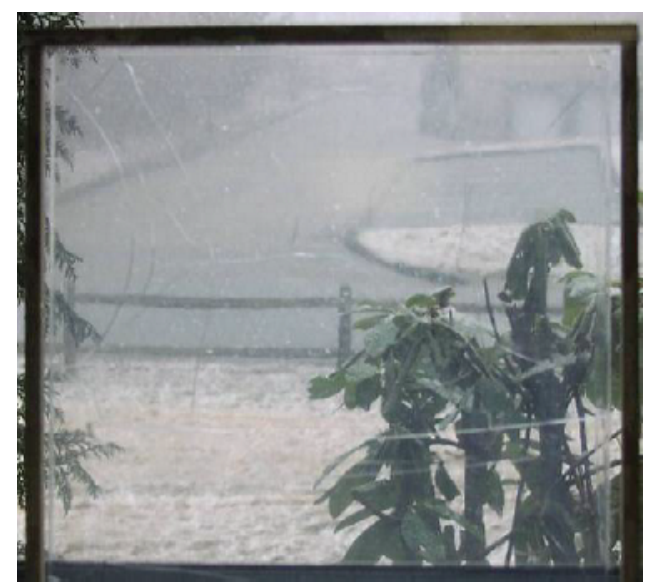

a

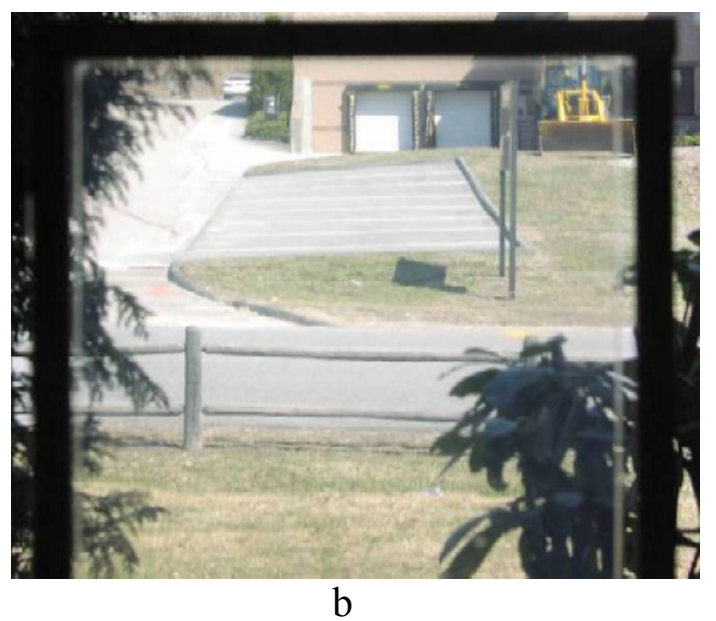

b

Figure 41. Transparent aerogel panels made during the last quarter: a) one of the first attempts which contained cracks and b) the most recent attempt is crack free.

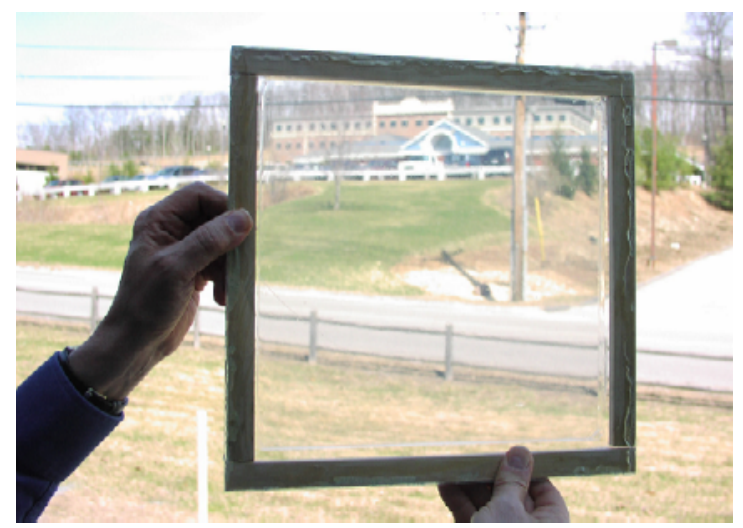

Figure 42. Hydrophobic and transparent POE/silica aerogel panel (1x1 ft) made using Mn 4000 . 

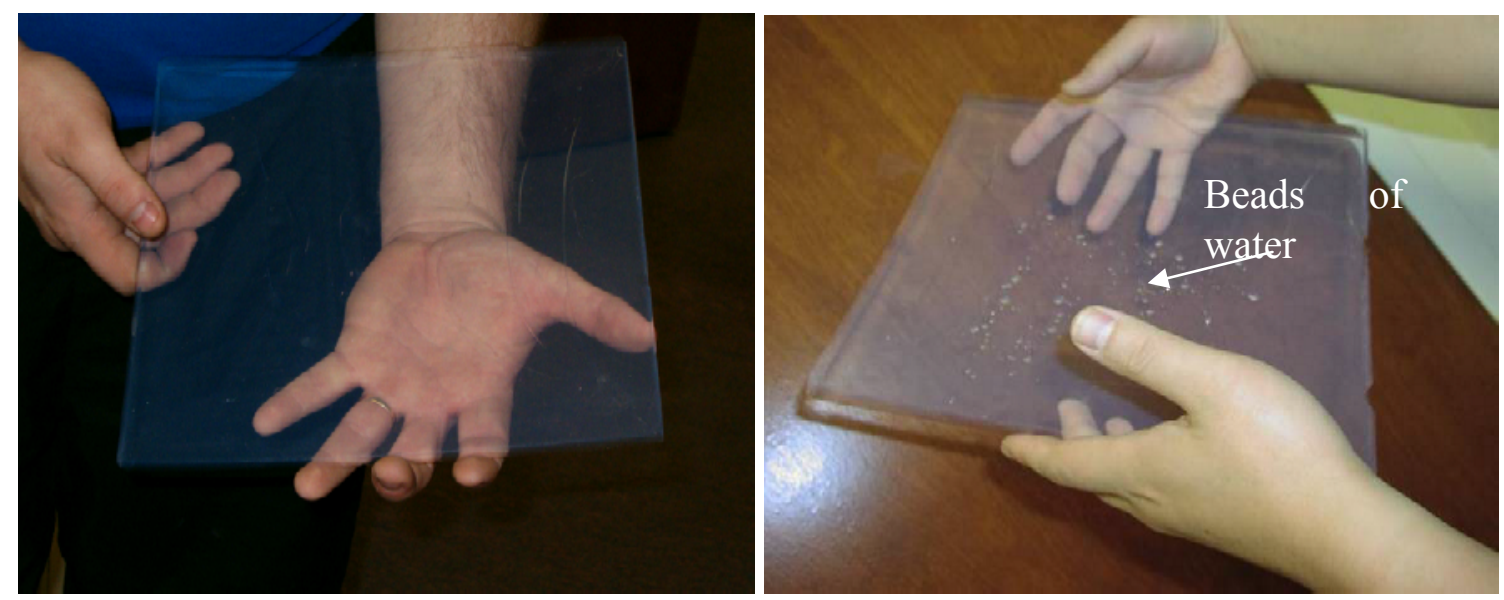

Figure 43. Hydrophobic and transparent POE/silica aerogel panels (1x1 ft) made using Mn 2000.

\subsubsection{Large panel preparation in the $1000 \mathrm{~L}$ autoclave}

We focused on optimizing the process for making 2'x 2' aerogel panels, using the 1000-liter autoclave. Four to five molds containing gels can fit into the 1000-liter autoclave in a vertical position, which would potentially allow us to dry a maximum of 4-5 panels (stacked one above another) at a time. However, we dried only one at a time for this study, since the autoclave is 11 feet deep and inserting and removing panels near the bottom is currently difficult.

In our first attempts to make $2 \mathrm{ft} \times 2 \mathrm{ft}$ panels, the gels were made, aged, and dried in a vertical orientation. We believe that there would be disadvantages with the vertical orientation since the stresses within the gel would likely not be evenly distributed. In our smaller scale experiments, the advantage of horizontal casting was that this procedure for making, aging, and de-molding the gels was straight forward.

After the precursors gelled, the top plate was removed and a stainless steel perforated plate was attached to the mold. The mold was flipped over and the bottom plate was removed and replaced by a second perforated plate. This "gel+mold" remained as it is during the hydrophobic agent treatment, aging, and rinsing steps. After rinsing, it was placed directly into the $1000 \mathrm{~L}$ autoclave for supercritical extraction of the solvent.

Due to the diameter of the 1000L autoclave, the 2'x2' panels were placed into the $1000 \mathrm{~L}$ autoclave in a vertical orientation for our first attempts at drying the large panels. The panels were dried in the top half of the autoclave.

During the first attempt to dry the gels, the autoclave developed a leak and supercritical conditions could not be attained. The next attempts went better, but the aerogel panels were cracked and the odor of solvent was apparent. Since the aerogels still contained some solvent, the solvent was not completely extracted during drying, and the panel probably cracked during depressurization. 


\section{Conclusions}

Overall, Aspen successfully prepared transparent, resilient, hydrophobic silica aerogels by using ethyl silicate and TMOS with a fast supercritical drying method. The aerogels showed a good thermal performance rating of R-10 per inch and either approach can be used for production of clear glass double-glazing windows (R-6 with 0.5 inch thick insulation layer). Durable hydrophobicity of the transparent aerogels was obtained by chemical treatment with a hydrophobic agent during the aging period. The Ormosils prepared using TMOS and triethoxysilane terminated POE had good transparency and improved mechanical properties that allowed us to prepared 1'x1' transparent panels. TMOS will be a better silica precursor for window applications due to a high product transparency that is less sensitive to density, has smaller shrinkage, and has better mechanical resiliency. However, because of its high toxicity, developing a safe, low-cost processing method for producing TMOS for direct production of aerogels and Ormosils will be critical for producing transparent aerogels.

\section{References}

1. National Fenestration Rating Council web site http://www.nfrc.org/press/morefacts.htm.

2. M.G. Hutchins, O Aschehoug, and J. Ballinger (Eds) 1997, International Energy Agency Solar Heating and Cooling Programme Task 18, Advanced Glazing Materials, Technical Reports of Subtask A and Subtask B.

3. S.S. Kistler, Nature, 127, 741 (1931)

4. S.S. Kistler, J. Phys. Chem., 34, 52 (1932).

5. G. Brinker and G. Scherer, "Sol-Gel Science: The Physics and Chemistry of Sol-Gel Processing," Academic Press, Inc., 1990

6. S.J. Kramer, F. Rubio-Alonzo, J.D. Mackenzie, Mat. Res. Soc. Symp. Proc. 435, 295 (1996).

7. J.D. Mackenzie, Y.J. Chung, and Y. Hu, Y., J Non-Cryst. Solids, 147\&148, 271 (1992).

8. Y. Yu and J.D. Mackenzie, Rubber like elasticity of organically modified silicates," J. Mater. Sci., 27, 4415, 1992

9. Y. Hu and J.D. Mackenzie, Mat. Res. Soc. Symp. Proc. 271, 681 (1992).

10. T. Iwamoto, K. Morita, J.D. and Makenzie, J Non-Cryst. Solids, 159, 65 (1993).

11. U.S. Patent 4,610,863, "Process for forming transparent aerogel insulating arrays," P.H. Param H. Tewari and Arlon.J. Hunt.

12. U.S. Patent 6,670,402, Rapid aerogel production process," K. Lee, R. Begag, Z. Altiparmikov

13. PCAS, Personal communication

14. DOE contract DE-FG02-98ER82534 "Aerogels for Cherenkov Detectors."

15. B.M. Novak, D. Auerbach and C. Verrier, Chem. Mater., 6, 282-286 (1994)

16. H. Shumidt, G. Philipp, J Non-Cryst. Solids, 63, 283(1984).

17. H. Shumidt, "New Type of Non Crystalline Solid Between Inorganic and Organic Material," J Non-Cryst. Solids, 73, 681(1985).

18. J. Fricke, T. Tilloson, Thin Solid Films, 1997, 297, 212-223.

19. www.aerogel.com

20. N. Husing and U. Schubert, Angew. Chem., Int. Ed. 1998, 37, 22-45 and the reference within.

21. O. Foussaier, M. Menetrier, J-J. Videau, and E. Duguet, Mat. Lett., 42, 305 (2000)

22. F. Schwertfeger, W. Glaubitt, U. Schubert, J. Non-Cryst. Solid, 1992, 145, 85.

23. D. A. Loy, G. M. Jamison, B. M. Baugher, E. M. Russick, R. A. Assink, S. Prabakar, K. J. Shea, J. Non-Cryst. Solid, 1995, 186, 44 
24. D. Carlos, Y. Messaddeq, H. F. Brito, R. A. Ferreira, V. de Zea Bermudez, and S. J. L. Ribeiro, Adv. Mater., 12(8), 594, 2000. 